Florida International University FIU Digital Commons

\title{
The Effect of Mobile Technology as an Active Student Response System on the Acquisition of U.S. History Content of Secondary Students with Specific Learning Disabilities
}

Ruba Monem

Florida International University, rmone001@fiu.edu

DOI: $10.25148 /$ etd.FI15032129

Follow this and additional works at: https://digitalcommons.fiu.edu/etd

Part of the Education Commons

\section{Recommended Citation}

Monem, Ruba, "The Effect of Mobile Technology as an Active Student Response System on the Acquisition of U.S. History Content of Secondary Students with Specific Learning Disabilities" (2015). FIU Electronic Theses and Dissertations. 1904.

https://digitalcommons.fiu.edu/etd/1904 


\section{FLORIDA INTERNATIONAL UNIVERSITY \\ Miami, Florida}

THE EFFECT OF MOBILE TECHNOLOGY AS AN ACTIVE STUDENT RESPONSE SYSTEM ON THE ACQUISITION OF U.S. HISTORY CONTENT OF SECONDARY STUDENTS WITH SPECIFIC LEARNING DISABILITIES

A dissertation submitted in partial fulfillment of the requirements for the degree of DOCTOR OF EDUCATION

in

EXCEPTIONAL STUDENT EDUCATION

by

Ruba Monem

2015 
To: Dean Delia C. Garcia

College of Education

This dissertation, written by Ruba Monem, and entitled, The Effect of Mobile

Technology as an Active Student Response System on The Acquisition of U.S. History Content of Secondary Students with Specific Learning Disabilities, having been approved in respect to style and intellectual content, is referred to you for judgment.

We have read this dissertation and recommend that it be approved.

Linda Blanton

Patricia Barbetta

Joan Wynne

Kyle D. Bennett, Major Professor

Date of Defense: March 16, 2015

The dissertation of Ruba Monem is approved.

Dean Delia C. Garcia

College of Education

Dean Lakshmi N. Reddi

University Graduate School

Florida International University, 2015 
(C) Copyright 2015 by Ruba Monem

All rights reserved. 


\section{DEDICATION}

I dedicate this work to my son Zachary. Thank you for being my biggest supporter. You are the best thing that has ever happened to me. 


\section{ACKNOWLEDGMENTS}

I would like to thank my Major Professor Dr. Kyle Bennett. There are no words to adequately express my gratitude for his endless hours of patience, support, and guidance. I have benefitted greatly from his wisdom, mentorship, and expertise in single subject research. I must also extend my gratitude to the members of my committee Dr. Patricia Barbetta, Dr. Linda Blanton, and Dr. Joan Wynne for their assistance and feedback throughout my doctoral studies.

I would like to extend a special thank you to Dr. Linda Blanton, Dr. Elizabeth Cramer, and Dr. Diana Valle-Riestra for creating the Project EDUCATE grant. The financial assistance provided by the grant made the completion of this project possible.

Many thanks to my fellow EDUCATE cohort member Vanessa Gil for her friendship, humor, and support throughout our doctoral studies.

I am eternally grateful to my friends, Betul, Nancy, Kahmran, Frances, and Juan for their unconditional support and encouragement. I am also grateful to my brothers who inspired me to pursue a career in education. And finally, I would like to thank my colleagues for their boundless energy and camaraderie throughout the years. 


\begin{abstract}
OF THE DISSERTATION
THE EFFECT OF MOBILE TECHNOLOGY AS AN ACTIVE STUDENT

RESPONSE SYSTEM ON THE ACQUISITION OF U.S. HISTORY CONTENT

OF SECONDARY STUDENTS WITH SPECIFIC LEARNING DISABILITIES
\end{abstract}

by

Ruba Monem

Florida International University, 2015

Miami, Florida

Professor Kyle D. Bennett, Major Professor

Students with specific learning disabilities (SLD) typically learn less history content than their peers without disabilities and show fewer learning gains. Even when they are provided with the same instructional strategies, many students with SLD struggle to grasp complex historical concepts and content area vocabulary. Many strategies involving technology have been used in the past to enhance learning for students with SLD in history classrooms. However, very few studies have explored the effectiveness of emerging mobile technology in K-12 history classrooms.

This study investigated the effects of mobile devices (iPads) as an active student response (ASR) system on the acquisition of U.S. history content of middle school students with SLD. An alternating treatments single subject design was used to compare the effects of two interventions. There were two conditions and a series of pretest probes in this study. The conditions were: (a) direct instruction and studying from handwritten notes using the interactive notebook strategy and (b) direct instruction and studying using the Quizlet App on the iPad. There were three dependent variables in this study: (a) 
percent correct on tests, (b) rate of correct responses per minute, and (c) rate of errors per minute.

A comparative analysis suggested that both interventions (studying from interactive notes and studying using Quizlet on the iPad) had varying degrees of effectiveness in increasing the learning gains of students with SLD. In most cases, both interventions were equally effective. During both interventions, all of the participants increased their percentage correct and increased their rate of correct responses. Most of the participants decreased their rate of errors.

The results of this study suggest that teachers of students with SLD should consider a post lesson review in the form of mobile devices as an ASR system or studying from handwritten notes paired with existing evidence-based practices to facilitate students' knowledge in U.S. history. Future research should focus on the use of other interactive applications on various mobile operating platforms, on other social studies subjects, and should explore various testing formats such as oral question-answer and multiple choice. 


\section{TABLE OF CONTENTS}

CHAPTER

PAGE

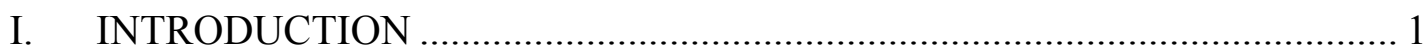

Instructional Strategies for History ...................................................... 7

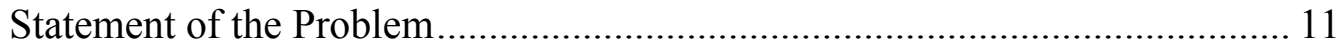

Theoretical Framework ............................................................................. 12

Purpose of the Study ............................................................................ 15

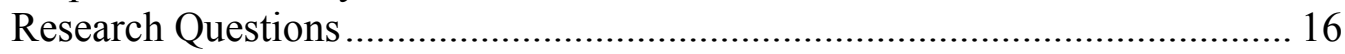

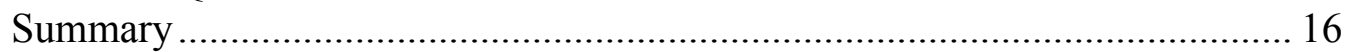

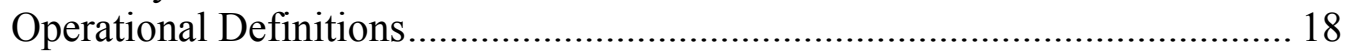

II. LITERATURE REVIEW ................................................................... 21

Learning Characteristics of Students with Specific Learning Disabilities ....... 21

Active Student Responding...................................................................... 25

Learning Theories Supporting Instructional Technology .............................. 32

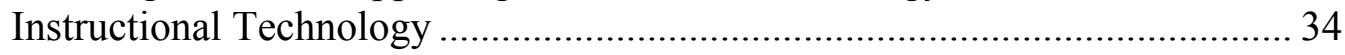

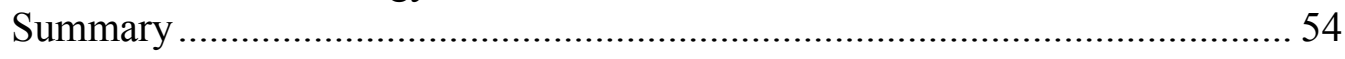

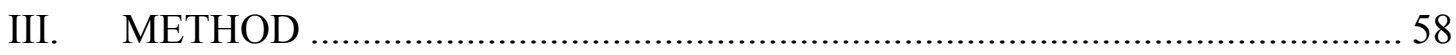

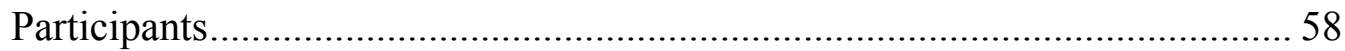

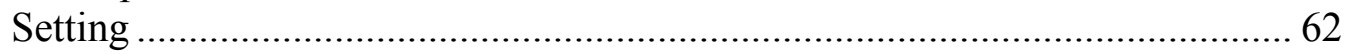

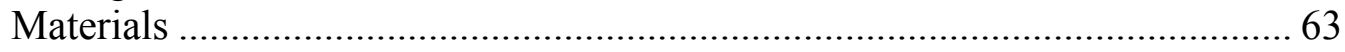

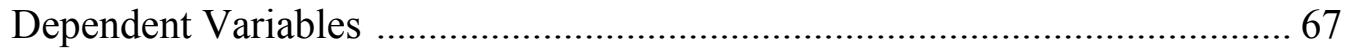

Interobserver Agreement and Procedural Fidelity ....................................... 68

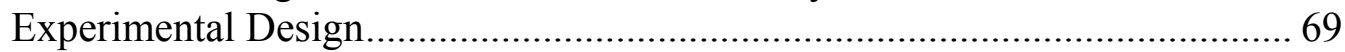

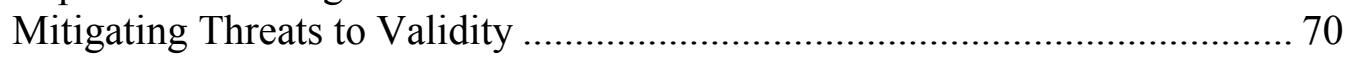

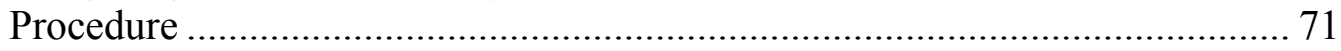

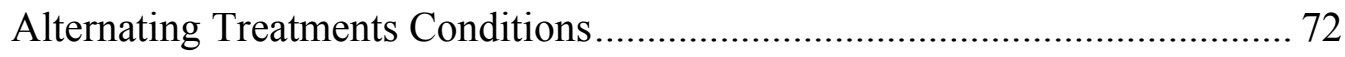

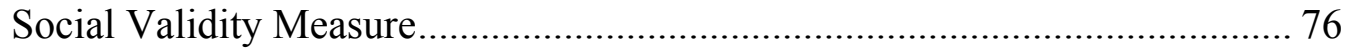

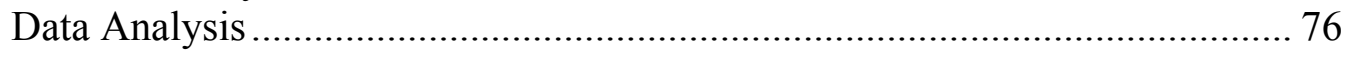

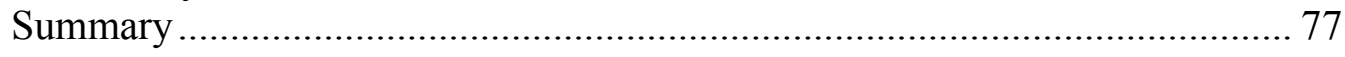

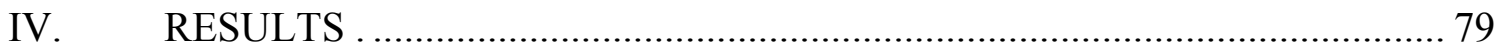

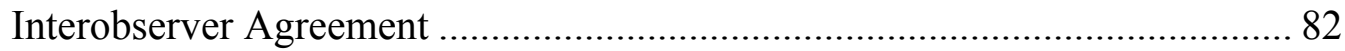

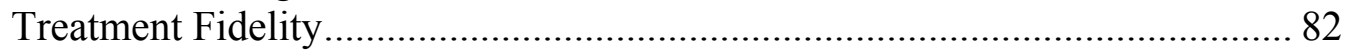

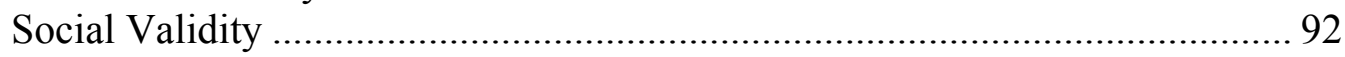

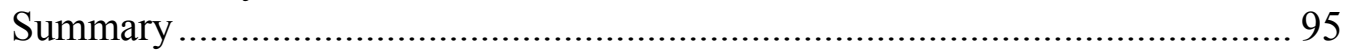

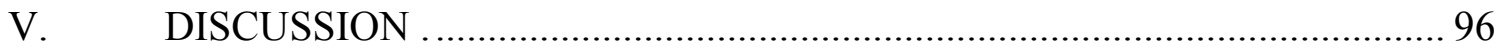

Percentage of Correct Responses ............................................................ 97

Matching Versus Fill-in-the-Blank ........................................................ 105

Rate of Correct Responses and Errors per Minute..................................... 106

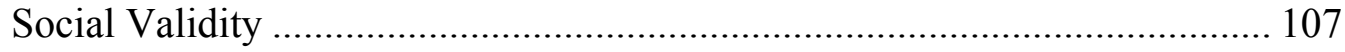




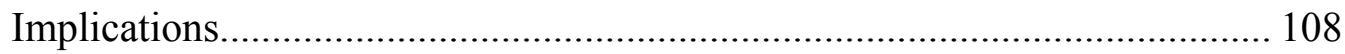

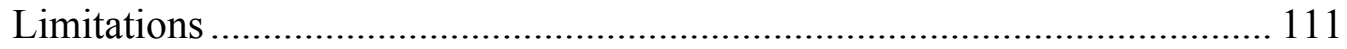

Suggestions for Future Research ............................................................. 113

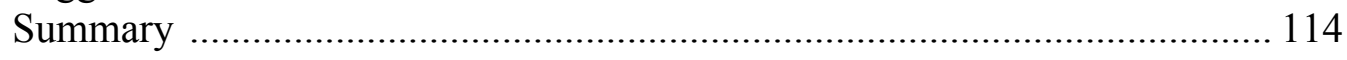

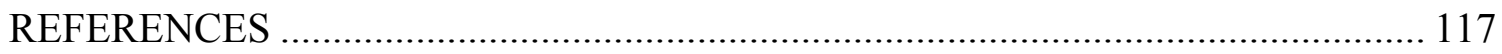

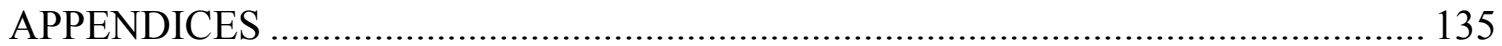

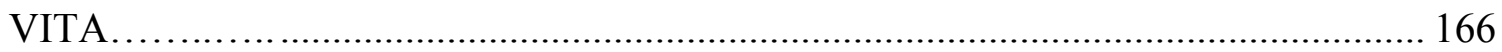




\section{CHAPTER I \\ INTRODUCTION}

Carl Becker (1932), former President of the American Historians Association (AHA), defined history as, "The memory of things said and done" (p. 221). According to Becker, every person is his or her own historian and every person's day-to-day life is affected by history. It was Becker's belief that the study of history is directly connected to improving human intelligence and quality of life. It was also Becker's belief that historical facts are meaningless unless individuals attach memory and meaning to them. Individuals who understand history can use their knowledge to inform and enhance their futures (Becker, 1932; Branson, 1998; Levin, 2007). Individuals who have knowledge of history tend to have more respect for human rights, rule of law, and greater tolerance for political and social differences (Kohut, Morin, \& Keeter, 2007; Ochoa-Becker, 2007; Wesley, 1944). Those who have a strong foundation of historical knowledge tend to be more politically involved in the democratic process, begin voting at a younger age, and vote on a more consistent basis (Kohut et al., 2007). Moreover, individuals who have a strong background in history are more likely to perform civic duties and responsibilities such as sitting on juries, performing public service, and paying taxes (Branson, 1998; Kohut et al., 2007).

The Bradley Commission on History in the Schools (1988) has asserted that historical knowledge is crucial for all citizens living in a democracy. Additionally, The National Center for History in the Schools (NCHS, 1996) has maintained that historical knowledge is the prerequisite for political aptitude. The National Council for Social Studies (NCSS, 2001), echoed these sentiments, which affirms that the goal of social 
studies is to arm students with the tools and skills necessary to become effective citizens. The NCSS posits that these tools and skills include: (a) knowledge of history that has shaped the world, (b) the ability to seek information from multiple sources and perspectives in order to form opinions, and (c) the ability to become effective problem solvers in local communities and in the world. The central theme in the statements presented by these organizations is that history education is essential to cultivating productive citizens.

Students who are history-literate become adults who are history-literate (Levine, 2007), and they can be better prepared for changes they face in the future (Bradley Commission, 1988). In essence, history is the foundation of effective citizenship and effective citizens possess an understanding of how history affects their lives in the present and how it may affect their lives in the future (Bradley Commission, 1988; Branson, 1998; Levin, 2007; NCHS, 1996; NCSS, 2001). Learning from the past allows individuals to: (a) challenge information or policies by thinking critically about the evidence presented to them, (b) preserve civil rights and the democratic process, (c) develop awareness of local and global current events, and (d) develop interest for cultures outside of their own (Kohut et al., 2007; Ochoa-Becker, 2007; NCSS, 2001; Vinovskis, 1999).

Secondary students with and without disabilities have traditionally scored poorly on exams assessing historical knowledge (Boyle, 2012; Patton, Polloway, \& Cronin, 1987; Paxton, 2003). Overall, on the 2001 administration of the National Assessment of Educational Progress (NAEP) for U.S. History, $84 \%$ of eighth grade students and $89 \%$ of $12^{\text {th }}$ grade students demonstrated below proficient levels of knowledge in United States 
History. In 2001, $75 \%$ of eighth grade students with disabilities (SWD), including those with 504 plans, scored below Basic on the NAEP for U.S. History. Twenty-five percent scored at or above Basic and 3\% scored at or above Proficient. Eighth grade students without disabilities also scored poorly - 34\% scored below Basic, $66 \%$ scored at or above Basic, and $17 \%$ scored at or above Proficient. The deficit in U.S. History knowledge was even greater for $12^{\text {th }}$ grade SWD. In $2001,88 \%$ percent of $12^{\text {th }}$ grade SWD (including those with 504 plans) scored below Basic.

The latest administration of the NAEP for U.S. History yielded similar results to the 2001 administration. According to data released by the United States Department of Education in 2010, $95 \%$ percent of eighth grade SWD and $96 \%$ of $12^{\text {th }}$ grade SWD (including those with 504 plans) scored below proficiency. The percentage of eighth grade SWD who scored below basic levels of knowledge of U.S. History was greater in 2010 than in 2001. Overall, concerning the 2010 administration of the NAEP for U.S. History, $83 \%$ of eighth grade students and $88 \%$ of $12^{\text {th }}$ grade students demonstrated below proficient levels of knowledge in United States History (NCES, 2010).

As secondary students advance from grade to grade, history standards and assessments become more rigid and more embedded in literacy and critical thinking. For example, in 2003, The National Assessment Governing Board (NAGB) made revisions to the specifications of the NAEP for U.S. History. The revisions called for specifications on the NAEP for U.S. History to assess historical themes across two cognitive domains: (a) historical knowledge and perspective and (b) historical analysis and interpretation. The eighth grade NAEP allocates $35 \%$ of the exam to the historical knowledge and perspective domain and $65 \%$ of the exam to the historical analysis and interpretation 
domain. For the $12^{\text {th }}$ grade exam, the distribution of assessment time shifts across the two domains to $30 \%$ and $70 \%$ respectively, with the bulk of the exam focused on historical analysis and interpretation.

Along these lines, the Common Core State Standards (CCSS) also require students to engage in assessment activities that require high levels of literacy and critical thinking in history. In 2010, the National Governor's Association (NGA) initiated the implementation of the CCSS, a nationwide set of learning standards that were designed to be consistent across the United States and its territories. The CCSS for history fall under the umbrella of English Language Arts standards. The four strands for history focus on literacy and include: (a) key ideas and details, (b) craft and structure, (c) integration of knowledge and ideas, and (d) range of and level of text complexity. The CCSS are intended to facilitate academic achievement and learning gains for students as they progress through K-12 education and ensure they are college ready (NGA, 2010).

Many states, including Florida, are currently in the process of fully implementing the common core literacy standards in history for Grades 6-12. In the state of Florida, the 2013-2014 school year may be the last year that the Florida Comprehensive Assessment Test (FCAT) assesses the Next Generation Sunshine State Standards (NGSSS). By the 2014-2015 school year, the state of Florida plans to align all of its student assessments with the CCSS for all content areas. Irrespective of curriculum and assessments chosen by various states, the complexity and depth of historical knowledge and analysis will continue to increase as students progress through secondary education.

The state of Florida has also placed greater emphasis on the subject of social studies. Beginning Spring of 2014, students in Grades 7 and 11 were required to take end 
of course (EOC) exams assessing their social studies knowledge. Seventh grade students were required to take an EOC exam for civics and $11^{\text {th }}$ grade students were required to take an EOC exam for U.S. history. Students' scores on their EOC exams accounted for $30 \%$ of their class grades for their respective social studies courses.

As members of a democratic society, students in the United States with specific learning disabilities (SLD) are held to the same civic and educational standards as their peers without disabilities and are expected to participate in the democratic process that shapes society. It is the democratic process that guarantees all students, regardless of abilities, have the opportunities to receive a free and appropriate public education (Curtis, 1991; Ferretti, MacArthur, \& Okolo, 2001). Yet, historically, students with SLD have received less history instruction than their peers without disabilities (Ferretti et al., 2001; Hughes \& Parker-Katz, 2013; Scruggs, Mastropieri, \& Okolo, 2008; Patton, Polloway, \& Cronin, 1987; Schenning, Knight, \& Spooner, 2013). Further complicating the issue is that o social studies often times receives less attention and priority in education than mathematics, science, or reading (Scruggs et al., 2008). Even when provided with the same history instruction as their peers without disabilities, students with SLD learn less content than their peers without disabilities and show fewer learning gains (Ferretti et al., 2001; Hughes \& Parker-Katz, 2013).

Students with SLD in secondary U.S. history classrooms often struggle with the content being taught and become passive, disengaged learners (Lerner, 2003). These students may struggle with learning history because they: (a) lack conceptual/critical thinking skills (Okolo, 2005), (b) read below their grade level (Gersten, Baker, SmithJohnson, Dimino, \& Peterson, 2006; Mastropieri, Scruggs, \& Graetz, 2003), (c) do not 
have adequate background knowledge (Okolo, 2005), (d) cannot keep up with the pace of instruction, and/or (e) have learning styles that are not compatible with classroom instructional methods (Bouck, Okolo, Englert, \& Heutsche, 2008; Ferretti et al., 2001; Mastropieri \& Scruggs, 2010).

To learn, understand, and communicate about history, students must be able to think critically about the past (NCSS, 2008). This requirement is especially demanding for students with SLD, who typically have poor comprehension, difficulties with higher order cognitive tasks, and deficits in their written and verbal abilities (Faggella-Luby \& Deshler, 2008; Gersten, Fuchs, Williams, \& Baker, 2001; Schumaker \& Deshler, 2003). Historical literacy requires a specific set of skills necessary to read, interpret, and communicate about historical evidence (Hughes \& Parker-Katz, 2013; Nokes, 2011). Students are challenged with the task of individually constructing meaning, forming judgments, and creating texts based on historical artifacts (Draper, Broomhead, Jensen, Nokes, \& Siebert, 2010; Gagnon, 1989; Shanahan \& Shanahan, 2008). Traditionally, expository textbooks have been the primary instructional method for delivering history content (Bain, 2006). In order to interpret and construct meaning from expository historical texts, students must understand the origin of the text and its intended audience (Nokes, 2011). This is especially challenging for students with SLD because they have difficulty understanding perspectives and have deficits in verbal learning and memory (Bouck et al., 2008, Mastropieri \& Scruggs, 2010). Expository texts also are often filled with dense information and vocabulary that challenges students (Beck, McKeown, \& Gromoll, 1989; Kinder \& Bursuck, 1992). Moreover, history textbooks are often written at a reading level that is beyond students' reading comprehension levels (Hawkins, 1997). 
This can be frustrating for students with SLD who typically read below their grade level (Gersten et al., 2006).

History content is taught in a linear, chronological manner and requires students to think chronologically, meaning that students must be able to distinguish whether events have happened in the past, are happening presently, or will happen in the future (Bain, 2005; Johnson, 2010; NCHS, 1996). This may be challenging for students with SLD because they often struggle with complex expository structures such as cause and effect relationships, sequence of events, and problem-solution relationships (Gersten et al., 2001). Also, a spiral, thematic curriculum is often used to teach history content, wherein key concepts are introduced in lower grades and are revisited and expanded upon in later grades (Bruner, 1960; Cantu \& Warren, 2003; Johnson, 2010; NCSS, 1992). Lack of mastery and/or lack of exposure to concepts, content, and academic vocabulary may impede students' access to learning new content information (Snow, Lawrence, \& White, 2009; Townsend, Filippini, Collins, \& Biancarosa, 2012). Students who did not master content in lower grades will likely struggle mastering new content in later grades (Okolo, 2005).

\section{Instructional Strategies for History}

Although expository texts are frequently used for learning and understanding history, specific strategies must be used to engage and provide equal access to learning for students with SLD (De La Paz, 2012). Several technology based and non-technology based instructional strategies have been used to increase and sustain the interest of students with and without SLD in history classrooms. These strategies include but are not limited to alternative textbooks (Paxton, 2002), graphic organizers (Bulgren, Deshler, \& 
Lenz, 2007), computerized study guides (Boon, Burke, Fore, \& Spencer, 2006; Higgins, Boone, \& Lovitt, 1996), multimedia-enhanced projects (Ferretti \& Okolo, 1997), the use of mnemonic devices (Mastropieri, Scruggs, \& Whedon, 1997), and active student responding (Jerome \& Barbetta, 2005). For the remainder of this chapter, social studies instructional strategies involving technology will be the primary focus.

The National Council for Social Studies (1996/2006) has strongly encouraged the use of meaningful technology to enrich history content instruction. Furthermore, Nokes (2008) proposed that secondary social studies classrooms should integrate modern learning theories and the new age of information with history instruction. Instructional strategies involving technology have been particularly helpful in facilitating learning gains in history for students with and without SLD (Berson, 1996; Boon, Burke, Fore, \& Spencer, 2006).

Instructional technology strategies such as computerized study guides, multimedia projects, games and simulations, interactive whiteboards (IWBs), and computer-assisted instruction (CAI) via desktop computers have been used with a degree of success in facilitating social studies knowledge for students with and without SLD. In a study conducted by Higgins and Boone (1992), secondary students with and without SLD made positive learning gains when computerized study guides were used to support social studies content. In a later study conducted by Higgins, Boone, and Lovitt (1996), students with SLD and students identified as remedial readers scored higher on posttest measures after participating in classroom lectures coupled with computerized study guides. The results of a study by Boon, Burke, Fore, and Spencer (2006) suggest that declarative social studies knowledge increased when computerized study guides were integrated into 
social studies instruction for middle school students. The findings of the study by Boon et al. (2006) are consistent with those of Higgins and Boone and of Higgins, Boone, and Lovitt, and together these studies contribute to the notion that technology assists students with SLD in acquiring history content.

In a study conducted by Heafner and Friedman (2008), $11^{\text {th }}$ grade history students who created multimedia, multi-page Wikis demonstrated greater knowledge and retention of historical content than $11^{\text {th }}$ grade history students at the same school who did not create Wikis. The results of a study conducted by Hernandez-Ramos and De La Paz (2009) also supported the use of multimedia projects to enhance knowledge of American History. Eighth grade students who participated in the study used software to create digital multimedia projects based on primary and secondary historical sources. According to the data, students who used the multimedia software program made greater learning gains than students who did not use the program.

Games and simulations have also been used to enhance learning in social studies classrooms. In a study conducted by Okolo et al. (2011), 51 eighth grade history students with and without SLD demonstrated improvement in knowledge of historical facts after they participated in a web-based program that simulated the museum experience. Interactive whiteboards (IWBs) are another type of instructional technology that has been used to enhance social studies instruction. The reported advantages to using interactive whiteboards included the ability to share interactive media with multiple students and students' ability to be physically involved with instruction (Higgins et al., 2005; Smith, Higgins, Wall, \& Miller, 2005). Although many teachers and students reported being more engaged when IWBs were used, there is still much debate about the degree of 
individual learning and/or incidental learning gains made by students when using this technology because the focus is on group instruction and group responding (Allsopp et al., 2012; Smith et al., 2005). Indeed, Allsopp et al. (2012) cited IWBs limited capacity to individualize instruction and lack of individualized student responding as limitations to the effective use of IWBs. This lack of individualized responding may limit the success students with SLD experience when being instructed using this technology.

The use of technology-based instruction emphasizing individualized active student response (ASR) to facilitate learning socials studies content is emerging, but limited. Jerome and Barbetta (2005) studied the effects of two ASR conditions during CAI on desktop computers. Fifth grade students with SLD were presented with social studies facts using computer-based software. ASR conditions required students to click on responses to complete fill-in-the-blank statements or to click on a symbol to hear and orally repeat facts. The data indicated that students were able to learn and maintain social studies facts under both ASR conditions during computer-assisted instruction. The results of that study support the premise that the use of technology paired with ASR might enhance learning in social studies.

In recent years, mobile devices, such as tablets, have become increasingly popular in K-12 settings. School districts have placed a high priority on wireless technology and investing in tablets for students (Software Information Industry Association [SIIA], 2013). During the 2013 school year, districts were projected to invest in 7 million wireless devices for their students (up from 3.5 million devices in 2012) with most of these devices being iPads (Futuresource, 2013). Programs such as, Bring Your Own Device (BYOD), continue to gain popularity. According to the results of a 2013 survey 
conducted by SIIA, $46 \%$ of U.S. K-12 districts allowed students to bring their own wireless devices to school. Of K-12 districts that did not currently participate in BYOD, $87 \%$ predict they will implement a BYOD program in the next five years (SIIA, 2013).

Notwithstanding this surge of mobile technology in today's classrooms, research on the effectiveness of mobile technology, specifically tablets such as the iPad, as learning tools to increase learning gains has only recently emerged (Chou, Block, \& Jesness, 2012; Murray \& Olcese, 2011; Neely, Rispoli, Camargo, Davis, \& Boles, 2013; Passey, 2013) with much of the initial focus on improving student performance in math and science. The literature in the field of social studies using iPad integration is extremely limited (Berson, Berson, \& Manfra, 2012), as most of the research on the effectiveness of using iPads or tablet devices has been in the content areas of math and science (Neely et al., 2013; Passey, 2013). Therefore, research on the effectiveness of using an iPad, or other tablet device, is needed in subjects outside of math and science.

\section{Statement of the Problem}

Students with SLD in secondary U.S. history classrooms make fewer learning gains than their peers without disabilities. On standardized tests assessing knowledge of U.S. history, students with SLD consistently score lower than students without learning disabilities (NAEP, 2001, 2006, 2010). However, all students need to understand history content in order to become productive adults.

Many barriers exist in today's history classrooms, including limited background knowledge (Nokes, 2011), difficult-to-read textbooks, lack of differentiated instruction, lack of universal design for learning (UDL), and high cognitive demands (Scruggs, Mastropieri, \& Marshak, 2012). Mobile technology may be a promising tool to overcome 
the aforementioned barriers in history classrooms, and there has been an increased push for the integration of mobile technology in content area classrooms. To date, however, much of the research on mobile devices focuses on learning gains made in science and math when students interacted with multi-modal math and science applications (Passey, 2013; Risconscente, 2012). Preliminary studies suggest that the use of mobile technology, such as tablets, may enhance student engagement in social studies by promoting on-task behaviors during content area instruction (Berson, Berson, \& Manfra, 2012; Passey, 2013; Pilgrim, Bledsoe, \& Reily, 2012). For instance, according to Passey (2013), working with mobile devices (e.g., iPads) motivated students to work independently in social studies, collect and present research, and access virtual materials via the Internet. Additionally, secondary students demonstrated positive feelings towards learning with and using iPads to create presentations and digital books. Notwithstanding the reports on high levels of engagement and user satisfaction, there is little research to support the notion that the use of mobile technology improves the academic learning gains of students with SLD in history (Berson, Berson, \& Manfra; Passey, 2013).

\section{Theoretical Framework}

Skinner's (1958) theory of educational behaviorism and Mayer's $(2001,2005)$ Cognitive Theory of Multimedia Learning (CTML) are two, among many approaches focused on active engagement, that are currently used in today's K-12 classrooms (Conderman, Bresnahan, \& Hedin, 2011; Haydon et al., 2010; Haydon, Marsicano, \& Scott, 2013; Plass, Heidig, Hayward, Homer, \& Um, 2014). When used concurrently, these approaches may provide learners with a heightened level of engagement by combining digital text and visuals with active learning and corrective feedback. 
Educational behaviorism is rooted in Skinner's (1958) understanding of the learner's role in the learning process. Skinner believed that students acquire knowledge by: (a) active engagement, (b) repeated practice, and (c) supportive and corrective feedback. The practice of implementing behavioral approaches to teaching in applied settings, such as classrooms, is often referred to as direct and explicit instruction (Archer \& Hughes, 2011; Goeke, 2009; Hall, 2002). Direct and explicit instruction methodologies have had positive effects for students in general and special education classrooms (Archer \& Hughes, 2011; Gersten et al., 2009a, 2009b). The characteristics of direct and explicit instruction include: (a) active student participation, (b) integrating small units of learning into meaningful wholes, and (c) frequent teacher monitoring with supportive and corrective feedback (Goeke, 2009).

ASR is an example of a direct and explicit instructional approach (Kinder \& Carnine, 1991). ASR is defined as "an observable student response made to an instructional antecedent" (Barbetta, Heron, \& Heward, 1993, p. 111). An instructional antecedent is the presentation of a learning unit. An observable student response to an antecedent may be verbal, written, or physical. Examples of ASR include, but are not limited to, the use of dry erase response boards, classroom electronic clicker systems, and yes/no response cards. ASR is important in today's classrooms because it: (a) increases students' time on-task, (b) builds content area fluency, and (c) reinforces desired behaviors (Axtell, McCallum, Bell, \& Poncy, 2009; Cullen, Keesey, Alber-Morgan, \& Wheaton, 2013).

There have been several studies in which ASR was shown to be a successful instructional strategy for students with SLD and other disabilities. For example, Jerome 
and Barbetta (2005) found that students with SLD made academic gains in social studies when they used a computer-based ASR system. In that study, students maintained the highest number of facts (93.2\%) during a repeated ASR condition. In another study using a computer-based ASR system, Cullen, Keesey, Alber-Morgan, and Wheaton (2013) measured literacy gains of students with SLD and other disabilities. Cullen et al. (2013) found that students maintained $80 \%$ of the sight words they learned and acquired 15-20 new words after using the ASR strategy.

Behaviorism in educational technology can be traced back to Skinner's (1958) use of the teaching machine. The teaching machine required students to respond to a series of questions. When students responded correctly, the machine moved on to the next item. If students responded incorrectly, they were prompted to continue answering the question until they achieved the correct response. Innovations in instructional technology have made it possible to expand early teaching machines into multimedia, interactive tools. These innovations, combined with Skinner's beliefs concerning the learning process, are complementary to Mayer's CTML which proposes that individuals learn best when content is presented in small units of information delivered in a dual format of visuals and text. Mayer's theory is based on three basic principles: (a) dual coding, (b) limited capacity, and (c) active participation. Dual coding refers to learners possessing two separate channels (visual/pictorial and auditory/verbal) to process information. Limited capacity describes learners' ability to process small units of information in working memory at a given time. The last principle, active participation, posits that learners must be active in the cognitive learning process in order to gain knowledge (Mayer, 2001, 2005). 


\section{Purpose of the Study}

The purpose of this study was to determine the effectiveness of using mobile devices, particularly tablets, on the acquisition of U.S. history content by secondary students with SLD. Specifically, this study was an extension of the research conducted by Jerome and Barbetta (2005). In that study, Jerome and Barbetta reported that ASR during computer-assisted instruction enhanced learning in social studies demonstrating that students with SLD can learn and retain more social studies facts when they participated in Clicking-ASR (clicking with a mouse) and Repeating-ASR (oral repeating) conditions on desktop computers. Considering that more schools are implementing programs that encourage students to use their personally owned mobile devices to supplement content being taught in their classrooms, it seems prudent to investigate the utility of such devices on content areas other than math and science.

This study examined the effectiveness of employing mobile devices, specifically tablets, as an active student response system on the acquisition of U.S. history content by secondary students with SLD. Students used a mobile tablet application called Quizlet to supplement U.S. history content taught in the classroom. Quizlet (2013) is a program that allows students to interact with content using various modalities. For example, students can review content by listening to audio and/or reading text of terms and definitions. Students can also match terms to definitions and type responses to descriptions of terms they hear or visuals they see. For students with SLD, such technology can serve as "equalizer" in learning opportunities (Wyer, 2001, p.1) and provide more meaningful access to the general curriculum (Bouck, 2010; Smith \& Okolo, 2010). Through the implementation of effective technology, content area material can be made more flexible 
and accessible in a variety of formats for students with varying levels of academic abilities in K-12 classrooms. These enhancements are consistent with the provisions of UDL and make learning more equitable (Hitchcock, Meyer, Rose, \& Jackson, 2002; Smith \& Okolo, 2010). Aside from flexibility, such technology-based content can be now made available on demand via mobile devices and wireless capabilities. For teachers of students with SLD in inclusive classrooms, technology may be a viable tool to accommodate the needs of learners who require more individualized practice (Akpan, Beard, McGahey, 2014).

\section{Research Questions}

This study investigated the effectiveness of mobile technology as an active student response system on the acquisition of U.S. history content of secondary students with SLD. Using the Quizlet mobile application, the following research questions were examined:

1. What is the effect of mobile technology when used as an end of session, independent review ASR system, on students' acquisition of U.S. history content?

2. What is the effect of mobile technology when used as an end of session, independent review ASR system, on the rate (correct and incorrect responses) at which students acquire U.S. history content?

3. Is there a difference in the performance of students with SLD when answering questions in a matching format versus a fill-the-blank-format?

\section{Summary}

Branson (1998) asserted that students who do not gain an understanding of history will become adults who do not understand the purpose of American government and its 
function. The skills students learn during history instruction provide them with the instruments they need to analyze and form connections, think critically, and communicate and write effectively. All of these skills are crucial to succeeding personally and professionally (Becker, 1932; Graham, 2008). Historical literacy sets the foundation for a lifetime of civic engagement and participation (Becker, 1932; Branson, 1998).

Students with and without learning disabilities continue to struggle with making learning gains in history. As secondary students progress through the history curriculum, concepts become more complex and course requirements become more rigid. Success on high stakes tests, such as Florida's EOC exams for seventh grade civics and $11^{\text {th }}$ grade U.S. history carries serious implications for social studies students. Students who do not meet the criteria for mastery face the possibility of failing their social studies courses based on their performance on EOC exams. For students with SLD, this is especially concerning because they typically make fewer learning gains than their peers without disabilities and are required to participate in the same state and national assessments as their peers without disabilities.

There are many barriers to learning in secondary social studies classrooms, including difficult-to-comprehend textbooks and heavy teacher reliance on the lecture method of instruction. Many strategies involving various types of instructional technology have been utilized in the past with a degree of success. Some examples include computerized study guides, multimedia based projects, and ASR during CAI via desktop applications.

Mobile technology devices, such as tablets, have emerged as promising instructional tools. Existing literature suggests that tablets may engage K-12 learners and 
make technology more accessible for students (Passey, 2013). Literature in the field of instructional technology also supports the use of tablets to promote literacy and learning gains in academic areas (Hutchinson, Beschorner, \& Schmidt-Crawford, 2012).

However, much of the literature on the effectiveness of tablets is focused on learning gains in science and math. This study was undertaken because there is little research in the field of social studies to adequately determine the effectiveness of using tablets in secondary U.S. history classrooms.

\section{Operational Definitions}

Active Student Response (ASR)

Active student response (ASR) is defined as "an observable student response made to an instructional antecedent" (Barbetta, Heron, \& Heward, 1993, p. 111). An instructional antecedent is the presentation of a learning unit. An observable student response to an antecedent may be verbal, written, or physical. Examples of ASR include oral reading, use of dry erase response boards, classroom electronic clicker systems, yes/no and true/false response cards, and thumbs up/down physical gestures, to name a few.

Carryover Effects

Carryover effects refers to a participant's performance in one condition impacting his or her performance in a later condition (Wolery, Gast, \& Hammonds, 2010).

\section{Emerging Technology}

The term emerging technology refers to a class of innovative tools that show high potential to transform and expand the way individuals interact with information (Halaweh, 2013). 


\section{Historical Literacy}

In elementary and secondary education, the term historical literacy is broadly defined as students' ability to individually construct meaning, form judgments, and create texts based on historical artifacts (Draper, Broomhead, Jensen, Nokes, \& Siebert, 2010; Gagnon, 1989; Shanahan \& Shanahan, 2008).

\section{Mobile Technology}

Mobile technology refers to a wide range of wireless, handheld devices that are equipped with operating system (OS) software and hardware compatibility that allow users to communicate and store data over service networks. Mobile technology devices include, but are not limited to, mobile phones, tablets, and portable digital assistants (Jarvenpaa \& Lang, 2005).

Sequence Effects

Sequence effects refers to a participant's experience in one condition affecting his or her performance in subsequent conditions due to the ordering of the conditions (Wolery et al., 2010).

\section{Social Studies}

The National Council for Social Studies (NCSS, 1992) defines social studies as the combined, coordinated study of humanities and social sciences to foster civic engagement and competence. Disciplines within social studies include anthropology, archaeology, economics, geography, history, law, philosophy, political science, psychology, religion, and sociology. 
Specific Learning Disability (SLD)

Specific learning disability (SLD) refers to a disorder in one or more of the basic psychological processes involved in perceiving and/or understanding written or verbal language that may manifest itself in a deficient in one or more of the following areas: listening, thinking, speaking, reading, writing, spelling, or performing mathematical calculations (IDEA, 2004). 


\section{CHAPTER II}

\section{LITERATURE REVIEW}

Students in the 21 st century are learning history content in a fast-paced, dynamic, multi-tasking digitalized environment (Kidd \& Keengwe, 2010). The juxtaposition of learning about the past using the tools of the future is a reality that must be dealt with immediately. This task may be particularly daunting for students with specific learning disabilities (SLD) who must balance the demands of comprehending history content and keeping up with emerging technologies. In order for students with SLD to meet $21^{\text {st }}$ century historical literacy demands, they must be exposed to instructional technology that is relevant to their lives and provides them with an active mode of learning and responding (Dede, 2005; Javeri, 2007; NCSS, 2008). Therefore, the purpose of this literature review is to discuss: (a) the characteristics of students with SLD, (b) the benefits of active student responding (ASR), (c) educational theories underpinning successful instructional technology methods, (d) effective instructional technologies, and (e) the potential of emerging mobile technology to facilitate historical literacy for students with SLD.

\section{Learning Characteristics of Students with Specific Learning Disabilities}

SLD is considered a high incidence disability, with as much as $5 \%$ of students enrolled in K-12 public schools with this eligibility (NCES, 2012). Further, of all K-12 students receiving special education services, $63 \%$ are identified as having SLD (NCES, 2012). Students with SLD demonstrate difficulties adjusting academically and socially (Matson \& Fodstad, 2010). Only 10\% of students with SLD enroll in a college or university within two years of graduating from high school (Wagner, Newman, Cameto, 
Garza, \& Levine, 2005). According to Wagner et al. (2003), nearly 50\% of students with SLD perform more than three grade levels below their enrolled grade and earn lower academic grades than their peers without disabilities. These students typically display negative attention seeking behaviors to avoid learning tasks and demonstrate an inability to maintain friendships (Matson \& Fodstad, 2010). They also have difficulty attending to a task for an extended period of time (Matson \& Fodstad, 2010). In the long-term, students with SLD experience higher drop-out rates, issues with interpersonal-social relationships, poor job skills, and job instability (Cortiella, 2009; Matson \& Fodstad, 2010).

SLD is characterized by a deficit in one or more of the psychological domains involved in perceiving and understanding written or verbal communication (IDEA, 2004; Matson \& Fodstad, 2010). Students with SLD exhibit processing deficits and delays in the areas of: (a) expressive/receptive language, (b) phonological processing, and (c) working memory (Flanagan, Ortiz, Alfonso, \& Dynda, 2006; Swanson, 2011). These deficits typically manifest themselves in low academic achievement in the areas of reading and mathematics (Fletcher, Lyons, Fuchs, \& Barnes, 2007; Swanson, 2009).

Difficulty in reading is the most common way a SLD may manifest itself (Matson \& Fodstad, 2010). Successful readers engage in active processing of text wherein readers decode words with a degree of accuracy and apply meaning to the words (National Reading Panel, 2013). Reading, in and of itself, is an especially demanding task for students with SLD because they typically display deficits in working memory and lack essential reading skills such as comprehension, decoding, phonological awareness, fluency, and drawing inferences (Mercer, Campbell, Miller, Mercer, \& Lane, 2000). In 
order to decode words accurately and apply meaning, students must have phonological awareness, fluency, and vocabulary skills. The active processing component of reading poses a challenge for students with SLD who usually have weaknesses in their working memory. These weaknesses may result in difficulties accessing and recalling information, which is a necessary process in matching letters and sounds (phonological awareness).

Lack of reading fluency - the rate and accuracy of text being read - also affects the comprehension of students with SLD. According to Kuhn and Stahl (2003) students who struggle with fluency spend much of their time trying to decode words, leaving fewer cognitive resources to focus on comprehension of the text they are reading. Parmar, Deluca, and Janzak (1994) found that students with SLD read content area text (i.e. science) at half the fluency rate of their peers without learning disabilities. Difficulty in reading becomes more pronounced and difficult to remediate as students move up in grade level and literacy demands shift towards comprehension of more expository texts, especially in the content areas (Berkeley, 2007; Matson \& Fodstad, 2010). Moreover, traditional history books present a tremendous barrier to historical literacy for students with SLD because they are often written at a reading level above that of students with SLD (Okolo et al., 2011). As such, reading of content material can be overwhelming for students with SLD because they tend to devote much of their active memory to decoding text, in turn, devoting less time to comprehending the text.

Historical literacy requires students to actively engage in critical thinking so that they can construct meaning, make connections, and communicate what they have learned (Hughes \& Parker-Katz, 2013; NCSS, 2008; Nokes, 2011). Middle school students with 
SLD typically lack the cognitive tools, prior knowledge/experience, and reading skills that are critical for success in secondary history classrooms (Okolo et al., 2007). For these students, comprehension and memory of history content is influenced by the causeeffect relationships they are able to understand and deem as logical (Dimino, 2007; Espin, Cevasco, van den Broek, Baker, \& Gersten, 2007). If students with learning disabilities deem the history content as illogical, they must retrieve background knowledge to bridge what they know with what they do not know (Dimino, 2007; Espin et al., 2007). For students with learning disabilities, this task is exceedingly difficult because they often do not possess the background knowledge or retrieval skills to make such connections (Dimino, 2007; Okolo, 2005).

In addition to struggling with complex cause-effect relationships, students identified as SLD also encounter challenges when they attempt to: (a) comprehend content vocabulary, (b) differentiate main topics from supporting details, (c) actively manipulate and manage information (Bulgren et al., 2007), (d) compare and contrast events (Dimino, 2007), (e) balance and sort through large amounts of information in their memory, and (f) communicate what they have learned on exams or tests (Deshler et al., 2001; Dimino, 2007; Espin et al., 2007). Students with SLD tend to focus on irrelevant details and fixate on information that does not directly influence the outcome of a particular historic event (Bulgren et al., 2007). The dense nature of content and vocabulary in history textbooks, coupled with lack of background knowledge, leads students with SLD to disengage and lose interest in the subject of history (Okolo et al., 2007). 
Learning history content is predicated on reading, understanding, and remembering details from different types of informational texts. Various learning strategies have been found to be helpful for students with SLD. Taylor, Smiley, and Richards (2009) recommend using a systematic review of materials to help students with SLD because it helps them maintain information. Friend and Bursuck (2012) recommend implementing a post lesson review because it may help students with learning disabilities rehearse information and clarify confusing information from the lesson. Along these lines, Boyle (2012) suggests that students with learning disabilities benefit from the implementation of a post lesson review because it allows them to study key concepts and new vocabulary. When studying from notes, Boyle suggests that students with learning disabilities review their notes as soon as possible after the end of a lesson. Further, regarding notes and students with learning disabilities, Taylor et al. (2009) suggest that a structured note taking system is beneficial for students with learning disabilities.

\section{Active Student Responding}

Support for the use of ASR with students identified as having SLD and other disabilities in K-12 classroom settings can be traced back to several studies that linked the rate of opportunities to respond with positive academic and behavioral outcomes. Early studies by Becker, Madsen, and Arnold (1967), Carnine (1976), Becker and Gersten (1982), and West and Sloane (1983) underpin the foundation of ASR by suggesting the students' active role in learning paired with multiple opportunities to respond and receive feedback leads to: (a) decreased disruptive behaviors, (b) more efficient use of instructional time, and (c) an increased rate of correct responses. 
For students identified as SLD and other disabilities, ASR is associated with many positive outcomes including increased content area achievement, increased on-task behavior, and timely performance feedback for the teacher and the student (Barbetta \& Heward, 1993; Carnine, 1976; Greenwood, Delquadri, \& Hall, 1984; Haydon et al., 2010; Heward, 2003; Jerome \& Barbetta, 2005). ASR is most effective when it is designed to: (a) provide immediate feedback to the student, (b) provide feedback that is contingent upon the student's response, and (c) provide corrective feedback that will direct/guide the student to the accurate response or answer (Barbetta, Heron, \& Heward, 2003; Jerome \& Barbetta, 2005). Immediate feedback and error correction are critical for students with reading deficits, such as students with learning disabilities (Rankhorn, England, Collins, Lockavitch, \& Algozzine, 1998). Research suggests that the longer students are actively engaged in direct learning activities, the more likely they are to acquire and maintain learned content (Berliner, 1980, 1990; Greenwood et al., 1984).

Low performing students, such as students with SLD, often do not receive the same number of opportunities to respond as average to high performing students (Haydon et al., 2010). This is especially true during teacher lead discussions that require students to volunteer their responses to questions posed by the teacher (Haydon et al., 2010). ASR is an effective instructional method that provides students with SLD and other disabilities multiple, repeated opportunities to respond and receive feedback (Barbetta et al., 2003; Haydon et al.). The more opportunities students have to respond, the more likely they are to stay on task and remain engaged in the lesson (Carnine, 1976; Sutherland, Alder, \& Gunter, 2003). 
Several studies have focused on the use of ASR during corrective feedback to facilitate learning for students with disabilities. Barbetta, Heron, and Heward (1993) used an alternating treatments design to measure the effectiveness of ASR and noresponse (NR) conditions on the acquisition, maintenance, and generalization of sight words by elementary aged students with developmental disabilities. Under the ASR condition, students' errors were corrected by the teacher, who then orally modeled the word. The students then responded by repeating the word. In the NR condition, the teacher orally corrected the students' errors and the students attended to their errors by looking at a word card of the incorrect word rather than orally repeating the word. According to the data from same-day tests, next-day tests, and maintenance tests after two weeks, students who participated in the ASR condition read more words accurately. For example, during the maintenance tests, as a group, the participants provided 3,369 correct responses during the ASR condition versus 2,306 responses during the NR condition.

In a similar study, Barbetta and Heward (1993) used an alternating treatments design to compare the effects of ASR and NR conditions on students' ability to learn geography facts (i.e., state capitals). The participants were three elementary aged students with SLD. Under the ASR condition, when student made an error on the state capital, the teacher orally stated the capital and the student repeated it. Under the NR condition, the teacher orally stated the capital and then the student attended to (i.e., looked at) a geography card with the capital and state typed on it. Data from same-day, next-day, and one-week maintenance tests indicated that students learned more state capitals under ASR conditions than NR conditions. On same-day tests, scores for the ASR condition 
were higher than the NR condition for 32 out of 48 tests. On next-day tests, scores for the ASR condition were higher than the NR condition for 37 out of 48 tests. Lastly, results for the one-week maintenance tests indicated that participants learned 15 more facts during the ASR condition than the NR condition.

Barbetta, Heward, and Bradley (1993), focused on the theme of corrective feedback and compared the effects of two error correction procedures, whole-word error correction and phonetic-prompt error correction, on students' acquisition and maintenance of sight words. The researchers used an alternating treatments design. The participants were five elementary aged students with developmental disabilities. Under the whole word error correction condition, the teacher modeled the whole word for the student. Under the phonetic-prompt error correction condition, the teacher assisted the student with prompts based on the number of syllables in the word. Both conditions required students to read sight words printed on a card that was held up by the teacher. Students learned and maintained sight words under both error correction conditions. However, the results indicated that students read a higher percentage of words correctly under the whole-word error correction condition.

In a related study, Barbetta, Heward, Bradley, and Miller (1994) extended on previous research by Barbetta, Heward, and Bradley (1993) and Barbetta, Heron, and Heward (1993). Barbetta et al. (1994) compared the effects of immediate error correction and delayed error correction on science content area sight word acquisition and maintenance by elementary school students with developmental disabilities. During immediate error correction, the teacher corrected the student's word error and the student repeated the correct word. During delayed error correction, the teacher told the student he 
or she made a word error and told the student that he or she would try the word again later during the session. The results gathered from same-day tests, next-day tests, and 1-2 week maintenance tests indicated that immediate error correction was more effective than delayed error correction. These findings are consistent with the principles of ASR and support the idea that students who receive immediate feedback are likely to remain actively engaged and continue to work towards the correct response. Moreover, this series of studies by Barbetta and colleagues supports the use of ASR with students with disabilities by suggesting that they perform better when they are: (a) actively engaged, (b) frequently re-directed, (c) frequently prompted for a correct response, and (d) provided with a complete model of missed words or vocabulary. These findings also provide a link between active support and student achievement when it comes to acquiring and maintaining content area sight words. These aforementioned studies are relevant to this current study in that one of the conditions in this study (Quizlet on the iPad) utilized direct and immediate feedback and these features have been found to be beneficial to students with SLD and other disabilities.

The body of research on ASR and content area academic skills was expanded by the research of Jerome and Barbetta (2005). Jerome and Barbetta paired the ASR strategy with instructional technology. To achieve this, the researchers studied the effects of two ASR conditions during computer-assisted instruction (CAI) on desktop computers. Fifth grade students with SLD were presented with social studies facts using a computer-based hypermedia software program. ASR conditions required students to click on responses (clicking ASR) to complete fill-in-the-blank statements or to click on a symbol to hear and orally repeat facts (repeating ASR). The data from same-day, next-day, and one and 
two week maintenance tests indicated that students were able to learn and maintain social studies facts under both ASR conditions during CAI. However the repeating ASR condition produced better results. On same-day tests, repeating ASR produced higher scores on $72 \%$ of tests (there were 124 same-day tests) and clicking ASR produced a higher score on $21 \%$ of same-day tests. Overall, on maintenance tests, students maintained the highest number of facts $(93.2 \%)$ during the repeating ASR condition. The results of the study support the premise that the use of technology paired with ASR might enhance learning in social studies.

In a more recent ASR study, Cullen, Keesey, Alber-Morgan, and Wheaton (2013) used a multiple probe design to examine the effects of CAI on the sight word recognition of four students receiving special education services. The four participants were in fourth grade. Two of the participants had SLD, one was identified as other health impaired (OHI), and one was identified as having an intellectual disability (ID). The intervention consisted of having students use a computer program called Kurzweil 3000. The program required students to provide active input using typed responses, verbal responses, and clicking to answer multiple choice items. During the maintenance phase, the participants showed high rates of correct responding (between $84 \%-100 \%$ ) on sight word recognition. The four participants maintained $80 \%$ of the sight words they learned during the study. Each student acquired between 15-20 new words, enhancing their reading fluency (Cullen et al., 2013).

In another study focused on ASR and content area skills, Axtell, McCallum, Bell, and Poncy (2009) found that middle school students' division-fact fluency increased when they used an ASR strategy called detect, repair, practice (DRP) to complete math 
worksheets. The researchers used a pretest-posttest design. The participants were 23 middle school students identified as at-risk for failing their grade level. The participants were in Grades 6-8 and were enrolled in a summer school program. During the intervention, students were given 2 minutes to complete a math worksheet consisting of 48 problems. After 2 minutes, the teacher presented the correct answers on a board. The teacher then guided students through the DRP strategy. First, the teacher prompted students to circle (detect) the last five problems they answered incorrectly. The students were then instructed to orally repeat the problem and the correct answer to themselves five times (e.g., the student would repeat " 24 divided by 8 equals 3 " five times). To repair the incorrect responses, students covered the problems on their worksheets using one of their hands and copied the problem into a blank box on the same worksheet. Again, students repeated the correct responses to themselves five times (practice). Lastly, each student removed his or her hand covering the problem and compared the results. Teachers circulated the room to ensure that students followed the steps in the DRP strategy. The ASR strategy was shown to be effective in increasing math fluency. According to pretest-posttest data, students raised their mean scores from 27.56 to 52.13. The results of this study were consistent with the findings of Cullen et al. (2009) because they support the premise that ASR leads to academic learning gains and increased fluency in content area skills.

The studies by Barbetta et al. (1993), Jerome and Barbetta (2005), and Cullen et al. (2013) provide support for the use of ASR for students with SLD. Although these studies are focused on elementary aged students, and the studies by Jerome and Barbetta's and Cullen et al. are based on the desktop computers, they provide a 
springboard for future research on the use of technology based ASR merged with content area instruction. Along with the studies by Jerome and Barbetta and Cullen et al., the study by Axtell et al., (2009) also provides support for the use of ASR by demonstrating that the strategy helped learners develop content area fluency in math. Notwithstanding these findings, there is a need for studies focused on ASR strategies for secondary students in the content area of history paired with the use of emerging technology such as mobile devices.

\section{Learning Theories Supporting Instructional Technology}

The foundation of interactive instructional technology is based, in part, on educational principles derived from behavioral and cognitive learning theories (Gillani, 2010). The most effective instructional technologies create a platform where learners can actively engage and interact with content in a way consistent with Skinner's (1954) understanding of the learning process and Mayer's (2001) position regarding cognitive input and output during the learning process. Interactive technologies that provide a method of active student responding (ASR) and corrective feedback are consistent with Skinner's (1954) behaviorist learning theory. Based on his theory, Skinner (1958) advocated the use of teaching machines, mechanical devices that provided immediate feedback and praise for correct responses. It was Skinner's belief that learning should be

divided into small, sequential steps and that instruction requires learner participation and feedback.

Keeping in line with Skinner's theory, successful interactive technologies present learners with a series of related tasks and are designed to prompt the correct response from learners (Heffernan, Heffernan, Decoteau, \& Militello, 2012; Tennyson \& Schott, 
1997). If the learner does not provide the correct response, he or she is made aware of his or her error and provided with corrective feedback in a manner that guides the learner towards the correct answer. When the correct answer is achieved, the learner is rewarded. Learning occurs when students experience reinforcement for a response associated to a stimulus. With instructional technology, this closely relates to the principles underlying drill-and-practice programs, mobile response systems, and touch-based technology (Keskin \& Metcalf, 2011; Smith \& Ragan, 2005). Burton, Moore, and Magliaro (2004) assert that the best of behaviorally-based learning technologies support learners by allowing information to move from working memory to long-term memory. This is important for learners of all ages and abilities because it allows them to acquire new information and expand their background knowledge. Learners' depth of background knowledge is a vital component to academic success and is an indicator of how well students learn new content in the future (Bloom, 1976; Nagy, Anderson, \& Herman, 1987; Schiefele \& Krapp, 1996).

Effective interactive instructional technologies also incorporate Mayer's Cognitive Theory of Multimedia Learning (CTML), which proposes that learners possess two information processing systems, verbal and visual (Mayer, 2001, 2005). The two systems work in tandem to construct meaning. The verbal system takes in auditory narration and the visual system takes in animations. CTML is based on three central assumptions: (a) dual channel assumption, (b) limited capacity assumption, and (c) active processing assumption (Mayer, 2001, 2005). From these assumptions, Mayer extrapolates three cognitive processes that a learner engages in during exposure to multimedia environments: (a) selecting, (b) organizing, and (c) integrating. During the selecting 
process, the learner applies a text base to incoming visual information to yield an image base. During the organizing process, the learner associates verbal and visual bases to construct cause-and-effect relationships. In the last cognitive process, integrating, the learner connects the verbal and visual representations (Mayer, 2001, 2005). Essentially, students learn better from visuals and text than from visuals alone or text alone. This theory is also aligned with Skinner's (1958) belief that audio-visual aids should be used to supplement instruction because they may help sustain the learner's interest and clarify confusing topics.

In this present study, one of the interventions (Quizlet on the iPad) was a multimedia application that helped participants review U.S. history content. Using Quizlet on the iPad, participants were able to see and hear the information presented to them. Furthermore, when participants provided an incorrect response, the Quizlet application provided immediate corrective feedback and guided participants towards the correct response.

\section{Instructional Technology}

Instructional technology refers to a broad spectrum of tools that are designed, produced, and implemented to facilitate learning (AECT, 2004). Traditional classroom technologies include desktop computers, laptops, printers, and software. A newer generation of technology includes mobile devices (e.g., iPhones, iPads, DSis, Androids, tablets) and Web 2.0. Web 2.0 refers to the second generation of Internet-based applications that allow users to participate in highly interactive $2 \mathrm{D}$ and $3 \mathrm{D}$ virtual activities (O'Reilly, 2005). Mobile devices provide a gateway to Web 2.0 and have 
ensured that Internet content is always on regardless of time, location, or space. This type of access has redefined ubiquitous learning.

With the push for achievement in the content areas and focus on Common Core Standards, researchers and educators may overlook national and state goals concerning achievement in technology. One of the goals of The Enhancing Education through Technology Act of 2001, Sec. 2402, is, “To assist every student in crossing the digital divide by ensuring that every student is technologically literate by the time the student finishes the eighth grade, regardless of the student's race, ethnicity, gender, family income, geographic location, or disability."

\section{Technology for Whole Group Instruction}

Beginning in the 1970s, overhead projectors provided educators with an effective means to share information with multiple students (Dallman-Jones, 1994). With the use of overhead projectors, educators no longer had to turn their backs to their students. Educators could maintain eye contact with their students while sharing visuals and writing on transparencies (Dallman-Jones). As new technologies made their way into the educational sphere, overhead projectors began to lose their popularity. By the 1990s, educators found more innovative means to share information and engage students. Whereas overhead projectors limited educators to transparencies, newer technologies such as multimedia data projectors and interactive white boards (IWBs) allowed teachers to share, manipulate, and customize sounds, videos, and 3D objects (Liang, Huang, \& Tsai, 2012).

IWBs, sometimes referred to as SMART Boards, or electronic boards, were developed by SMART Technologies and first appeared in the 1990s (SMART, 2010). 
IWBs require a connection to a computer and a data projector. IWBs are touchresponsive. The user can use his or her finger, a stylus, or an electronic pen to manipulate objects on a screen. In whole group classroom instruction, the IWBs serve as a large touch screen that can be shared by multiple users. IWBs allow teachers to share information with multiple students and reinforce important skills. Some drawbacks to using IWBs include exclusion of students who are shy learners and limited interaction for students who are not actively engaged in the lesson (i.e., students who are physically handling the technology and not focusing their attention on the lesson). Another drawback to IWBs is that they are teacher dominated and may lack individualized feedback for students (Allsopp et al., 2012).

Much of the research on student achievement and IWBs has focused on the content areas of math, science, and language arts/reading. Results of research on the use of IWBs and student learning gains are mixed. Lewin, Somekh, and Steadman (2008) found that students aged 7-11 made positive learning gains in the areas of science, math, and reading. Students who had longer exposure to learning with IWBs made more positive learning gains. Lewin et al. (2008) also found that learning gains were stronger for students who were average or above average performing students. Along these lines, a study by Mechling, Gast, and Krupa (2007) also yielded positive results. Mechling et al. (2007) used an alternating treatments design to compare the effects of Smart Board instruction and flashcard instruction on the sight word acquisition of three adult learners with moderate intellectual disabilities. Although participants made positive learning gains under both conditions, data indicated that participants read a greater percentage of targeted vocabulary words under the SMART Board condition. 
In contrast to the findings of Lewin et al. (2008) and Mechling et al. (2007), the results of a 2-year study conducted by Higgins, Beauchamp, and Miller (2007) showed no significant learning gains between students in schools with IWBs and students in schools without IWBs. The study investigated the achievement of students in fifth and sixth grade in the areas of math, science, and language arts. The researchers also noted that there were no learning gains made by the lowest achieving students, and this is particularly important considering the overall performance typical of students with SLD. Higgins et al. (2007) suggested that there is still much to be discovered about how teachers' professional skills impact their use of IWBs and how that use may or may not maximize the effectiveness of IWBs.

It should be noted that the use of IWBs (or any technology) alone cannot impact student achievement, effective instruction is the foundation to learner achievement (Glover, Miller, Averis, \& Door, 2007; Higgins, Beauchamp, \& Miller 2007). IWBs (and other technology) are merely tools for teachers to transmit content, and although IWBs are lauded for their interactivity, they fall short in fostering learning for students with SLD who benefit from corrective feedback and multiple opportunities to respond (Allsopp et al., 2012). Furthermore, IWBs may inhibit students with SLD because their potential incorrect responses are offered in a whole group, public forum.

\section{Multimedia Instructional Technology}

Several studies have examined the use of multimedia instructional technology and found results that support the aforementioned principles developed by Skinner and the theories posited by Mayer (e.g., Ferretti, MacArthur, \& Okolo, 2001; Hernandez-Ramos \& De La Paz, 2009; Kingsley \& Boone, 2006). Mayer (1997) found that the effects of 
synchronous multimedia presentation were strongest for learners with low prior knowledge and high spatial ability. Students who were presented with synchronous dual modality multimedia explanations (i.e., verbal and visual) generated more problemsolving solutions than students who were presented with single mode (i.e., verbal) explanations. Additionally, multimedia activities helped learners feel an increased sense of control, resulting in less frustration, higher motivation to learn, and increased perseverance (Mayer, 1997, 2001; Mayer \& Moreno, 2002).

Chambers, Cheung, Madden, Slavin, and Gifford, (2006) observed that multimedia embedded reading instruction was a contributing factor in the reading achievement of elementary-aged beginning readers. The reading program used by the students incorporated embedded video instruction. The study consisted of a randomized trial of 394 elementary students in 10 high-poverty schools. In the study, the control group was not provided with multimedia instruction. Teachers used picture cards to demonstrate letter shapes that corresponded with students' books. The experimental group used a multimedia embedded program that included live action skits and puppet skits to teach students phonemic awareness and letter-blending skills. Data were collected for one year. According to the results of posttest measures using the Woodcock Reading Mastery Test-Revised, students in the experimental group made significant learning achievement in reading. Specifically, the results demonstrated significant gains in the students' word attack skills. Students in the experimental group raised their mean scores for word identification skills from 381.74 to 425.30 .

Further support for multimedia instruction was provided by Biggs, Homan, Dedrick, Minick, and Rasinski (2008). Biggs et al. (2008) conducted a study to 
investigate the effects of interactive, multimedia singing software on the reading achievement of struggling middle school readers. The study consisted of 24 students in an experimental group and 24 students in a control group. Students who were part of the experimental group used multimedia reading software for 30 minutes three times a week. Students in the control group received non-multimedia based instruction. Students in the experimental group made more significant gains in comprehension and reading achievement than students in the control group. Students in both groups were seventh and eighth graders who read at a fourth grade level at the start of the study. At the end of nine weeks, the reading level of the experimental group increased to mid-fifth grade level. Students in the control group did not make significant gains.

The findings of these studies (Biggs et al., 2008; Chambers et al., 2006) demonstrated that when students attend to the two modes of learning (i.e., visual and verbal) in Mayer's CTML, and engage in the learning process described by Skinner (e.g., immediate feedback), they have the potential to experience greater learning gains. The use of multimedia learning may also enhance students' acquisition of skills and content area knowledge by actively engaging them in mental processing as they try to learn concepts presented to them via images and text. Moreover, these studies suggest that when instructional technology is embedded with multimedia components, it has the potential to jumpstart learning by helping students form connections between sounds, letters, and words.

\section{Individualized Technology}

There is a vast body of literature supporting the use of individualized learning technologies (Darling-Hammond, 2001; Ford, 2001; Junglas et al., 2007; Plumert, 
Kearney, \& Cremer, 2004; Skinner, 1958; Smith; 2004; Tamim et al., 2011). The unifying theme in students' effective use of individualized technologies seems to be that the tools are multimedia based and interactive in nature. For students with SLD, individualized technologies may hold an advantage over group technologies because they offer students with SLD a platform for private feedback and eliminate the stigma associated with negative public feedback (Scheeler, Macluckie, \& Albright, 2010). Multimedia and interactive technologies also support students with and without SLD by increasing accessibility and affording them opportunities that would be otherwise inaccessible (Campigotto, McEwen, \& Demmans Epp, 2013; Van Scoter \& Boss, 2002). Interactive technologies, in particular, allow users to play and replay audio/visual tutorials, turn subtitles on or off, and control volume settings. Their multi-sensory cues and levels of user control far exceed the criteria for effective design that Universal Design for Learning (UDL) and differentiated instruction stipulate (Higher Education Opportunity Act, 2008; Tomlinson \& McTighe, 2006).

\section{Individualized Technologies in Social Studies}

As early as 1984, social studies students have participated in technology-based learning activities, such as playing the simulation-style game Oregon Trail (Rose \& Fernlund, 1997). Since then, technology has evolved and become more engaging and interactive. Individualized technology instruction in social studies usually consists of software programs such as word processors, drill-and-practice programs, simulations, tutorials, and Internet-based activities (NCSS, 2006; Rose \& Ferlund, 1997).

To examine the connection between multimedia software and academic achievement in social studies, Kingsley and Boone (2006) explored the effects of an 
Internet-based program called Ignite on middle school students' achievement in American History. The study consisted of an experimental group comprised of 93 students and a control group of 91 students. Each student in the experimental group used an individualized, Internet-based multimedia history program called Ignite in conjunction with textbook and lecture based activities. The control group received textbook and lecture based instruction only. Posttest scores indicated that both groups made learning gains. However, students in the control group increased their mean test scores by $6 \%$ while students in the experimental group increased their mean scores by $12 \%$. Data revealed that the difference in mean scores between the two groups was statistically significant. The increase in mean scores of the experimental group was double that of the control group. When comparing the results of multimedia instruction and non-multimedia instruction, the data suggest that students' learning gains improve if multimedia instruction is integrated into history classroom practices.

Similar to Kingsley and Boone (2006), Fry and Gosky (2007) found positive results when technology was used to supplement social studies content. Fry and Gosky explored the effects of online social studies textbooks on the reading comprehension of 129 middle school students, including English Language Learners (ELLs). The researchers used a quantitative counterbalance design to compare reading test scores from three conditions: (a) a hard copy textbook, (b) an online textbook with a pop-up dictionary function for every word, and (c) an online textbook with no dictionary function. The result of statistical analysis indicated that the online textbook with the popup dictionary yielded the most positive results. The pop-up dictionary textbook was shown to have a significant effect on students' reading comprehension scores on pretest 
and posttest measures. The researchers reported a greater estimated effect size (3.13) for the online textbook with a pop-up dictionary versus the hardcopy textbook. The estimated effect size for the online textbook with no dictionary function was 1.90 .

Positive results linking social studies instruction and technology were also found by Heafner and Friedman (2008) who conducted a study with two $11^{\text {th }}$ grade history classes in the same school. The researchers used a quasi-experimental design. One class served as the control group; the second class served as the experimental group (the researchers did not provide the exact number of participants in either group). Both groups were taught the same historical content (i.e., WWII). Students in the experimental group were assigned the task of creating multi-page Wikis to demonstrate their knowledge of the historical content they learned during classroom instruction. The control group did not create Wikis. According to data gathered by the researchers, students who were involved in creating the Wikis demonstrated the following: (a) greater rate of assignment completion, (b) increased attendance (the researchers noted there were fewer absences during the WWII unit than prior or post units of study), and (c) greater long-term retention of historical information (students were interviewed eight months after the conclusion of the study). Additionally, the results of a posttest showed that students in the experimental group achieved a higher mean score higher (66.0) than students in the control group (44.0).

In a study that targeted eighth graders studying $19^{\text {th }}$ century American History, Hernandez-Ramos and De La Paz (2009) conducted a quasi-experimental study using a pretest-posttest design involving 170 eighth grade American History students in two different middle schools. In one middle school, 100 students served as the intervention 
group. In the second middle school, 70 students served as the comparison group (the researchers noted there was no use of a control group). Students in the intervention group used a multimedia software program to create digital presentations (mini-documentaries). Students in the comparison group engaged in traditional student-teacher question and answer style discussions that relied on recitation of the content being taught. The students in the comparison group also engaged in classroom simulations and did not use the software program. Students in both groups received instruction on primary and secondary historical sources. Students were given a 50-question multiple choice pretest and posttest. According to data from pretests and posttests, students in both groups demonstrated learning gains. However, learning gains were greater for students in the intervention group who used the multimedia software program. Students in the intervention group raised their scores from a mean of 9.6 to 41.8. Students in the comparison group who did not use the multimedia software raised their scores from 11.0 to 27.4.

These studies suggest that students engaged in individualized multimedia learning during content area instruction may achieve learning gains in social studies. The results of these studies indicated that multimedia tools may help students: (a) sustain their interest in social studies, (b) improve their reading comprehension skills, and (c) retain information. These studies also provide support for the link between Mayer's CTML and Skinner's learning theory by illustrating that mental processing of text and visuals and active engagement are powerful aids in helping learners build background knowledge. Furthermore, these findings hold promise for students with SLD who are characterized by their lack of background knowledge, weak comprehension skills, and deficits in mental processing. 


\section{Individualized Technology in Social Studies for Students with SLD}

Several studies have shown that the use of individualized technology in social studies classrooms benefitted students with SLD. Some of these technologies include hypermedia tools and web-based multimedia activities. Higgins and Boone (1990) investigated the effects of hypermedia study guides on students' achievement in history. There were 40 participants consisting of secondary students with SLD, remedial students, and general education students. Participants were randomly assigned to three conditions: (a) lecture, (b) lecture with study guide, and (c) computerized study guide only. The conditions were implemented as a supplement to students' history textbooks. The results of daily quizzes, pretest and posttest measures, and retention tests indicated no significant improvement in students' performance during any of the three conditions. Although, remedial students and general education students outperformed students with SLD on retention tests under all three conditions, students with SLD steadily increased their mean scores under the lecture and computerized study guided condition from the pretest $(34 \%)$, posttest (47\%) and retention test (62\%).

In 1992, Higgins and Boone repeated their investigation, and this time the researchers found different results. In the second study, Higgins and Boone used similar hypermedia study guides to measure the effectiveness of computerized study guides with 49 secondary students with and without SLD. Again, participants were assigned to three random conditions: (a) lecture, (b) lecture with study guide, and (c) computerized study guide only. As in their previous study, the researchers wanted to evaluate which condition was the most successful as a supplement to students' history textbooks. Students made the most learning gains under the computerized study guides only 
condition. The results of daily quizzes, pretest and posttest measures, and retention tests showed that participants increased their mean scores from $41 \%$ to $52 \%$. For students with SLD, the results suggest that computerized study guides are an effective supplement to traditional textbooks and may help them better comprehend social studies content. Computerized study guides may also be a bridge to overcome the dense, vocabularyladen nature of social studies textbooks.

To gain deeper knowledge of the finding from Higgins and Boone (1992), Higgins, Boone, and Lovitt (1996), conducted a study with 25 participants. The participants were 13 students with SLD and 12 students identified as remedial readers. Similar to the studies of Higgins and Boone (1990) and Higgins and Boone (1992), Higgins et al. (1996) used hypermedia study guides as an intervention to measure the effect of computerized study guides on students' acquisition of history content. Higgins et al. (1996) utilized the same three conditions as Higgins and Boone (1992). All of the participants scored higher on posttest measures during the classroom lecture coupled with the computerized study guide condition. It is worth noting that the results of retention quizzes indicated that students who used the hypermedia guides displayed better retention of history content than students who did not use the hypermedia guides. Specifically, students with SLD who participated in the lecture and computerized study guide condition scored better on retention tests (mean score of $81 \%$ ) than students with SLD who participated in the lecture only condition (mean score 49\%). These results support the integration of multimedia learning for students with SLD and suggest that teacher lectures paired with technology supplements are more likely to lead to learning gains in social studies than lectures alone or technology-based instruction alone. 
In a more recent study, Blankenship, Ayers, and Langone (2005) explored the effect of computerized concept mapping on students' reading comprehension of world history content. Blankenship et al. (2005) used a multiple probe across behaviors design. The intervention was replicated across three participants who were high school students identified as having emotional behavior disorder (EBD). The target behavior was students' use and design of cognitive maps using the Inspiration software. During the intervention condition, students read from the textbook and mapped for 20 minutes. All three participants demonstrated learning gains with the assistance of the mapping intervention. By the end of the study, all the participants scored $75 \%$ or above on their chapter tests. Prior to the intervention, all of the participants scored below $15 \%$ on their quizzes. The researchers also noted that the use of the computerized cognitive map kept students engaged and working independently for 20 minutes, a difficult task for students with EBD. These findings lend support for Mayer's (1997) CTML by illustrating that when students engage in multimedia learning using visual and verbal representations, they are more likely to persevere through learning tasks and feel an increased sense of control over their tasks.

Cognitive organizers were also the focus of a study by Boon, Burke, Fore, and Spencer (2006). Boon et al. (2006) compared the effects of computer-based cognitive organizers and printed textbook methods of teaching world history content to 20 secondary students with SLD. The researchers utilized a pretest-posttest treatment control group design. Students in the control group received instruction using a traditional textbook. Students in the experimental group used computer-based cognitive organizers generated using Inspiration 6 software coupled with the traditional textbook. Analysis of 
the results indicated a statistically significant main effect for pretest and posttest measures. Students in the experimental group made greater learning gains than students in the control group. Students in the experimental group had a pretest mean score of 11.60 and students in the control group had a mean score of 13.08. On the posttest, students in the control group achieved a mean score of 26.84 and students in the experimental score achieved a mean score of 52.52. A replication study by Boon, Burke, Fore, and Hagan-Burke (2006) yielded similar results to aforementioned Boon et al. 2006 study and provided further support for the use of computerized cognitive organizers for students with SLD.

In another study that examined the use of technology in social studies, Ferretti, MacArthur, and Okolo (2001) used a pretest-posttest design to investigate the effect of a specific curriculum model, Strategy-Supported Project-Based Learning (SSPBL), on fifth grade students understanding of historical content. The SSPBL model included a technology component that required students to create multimedia projects to demonstrate what they learned after a particular unit of study. The participants were 59 students without disabilities and 28 students with SLD in a U.S. history class. Pretest and posttest results indicated that students made greater learning gains after they created multimedia projects. For students with disabilities, understanding of historical content increased from a mean score of 2.8 to 9.4 out of 16 . Students without learning disabilities made even greater gains raising their mean score from 5.0 to 14.0 out of 16 . These results support the premise that multimedia learning assists students with SLD by helping them with the cognitive demands of learning content area skills. These results also 
suggest that multimodal activities enhance learning for students with SLD and increase their understanding of history content.

In a more recent study conducted by Okolo et al. (2011), 51 eighth grade history students (with and without disabilities) demonstrated improvement in knowledge of historical facts after participation in the web-based Virtual History Museum (VHM). The students were in three different classes. There were 14 students with SLD, 21 students without disabilities, and 16 students enrolled in an honors course. Each class spent 270 minutes (six class periods) in a computer lab where each student worked independently on a computer on the VHM site. The multimedia site allowed students to access information in text or audio form or both. The results from pretest and posttest measures indicated that all three classes made learning gains. Students with disabilities tests scores increased from a mean of 2.79 to 3.93 out of 6.00 .

The pattern of these results supports the overarching theme that technology based interventions are viable tools for students with SLD. Furthermore, these tools enhance background knowledge for students with SLD and help them retain social studies content. These studies also demonstrate the type of approach educators should take to successfully integrate strategies for students with SLD, technology, and content area instruction. Most importantly, these studies illustrate that students are more likely to learn from technology paired with teacher instruction than technology use on its own.

\section{Emerging Technology}

The term emerging technology refers to a class of innovative tools that show high potential to transform and expand the way individuals interact with information (Halaweh, 2013). In the field of education, emerging technologies are reshaping the 
teaching and learning methods practiced in today's classrooms (Halaweh, 2013). The unique aspects of emerging interactive technologies allow learners to practice achieving their goals, fail, and continue to try until they achieve their desired outcomes. Furthermore, emerging technologies may help prepare learners to transfer their newly acquired skills to real life situations (Smith, 2004). Emerging technologies have the potential to combine the essential elements of 21 st century skills and underlying theories for effective instruction. Mobile devices may merge the best strategies with the best learning theories and instructional practices.

According to surveys conducted by the Pew Research Center (2013a, 2013b), there is a rising trend in the number of teenagers who own wireless devices such as tablets and smart phones. The number of teenagers who own smart phones increased from $23 \%$ in 2011 to $37 \%$ in 2013 , and $23 \%$ of teens surveyed own wireless tablets (Pew Research Center, 2013a; 2013b). Of parents with minor children who were surveyed, $50 \%$ owned a tablet computer, an increase of $26 \%$ from parents surveyed in 2012 (Pew Research Center, 2013b).

Wireless devices developed and manufactured by Apple continue to increase in popularity as the demand for mobile technology grows. The iPod Touch with video and the iPhone were introduced by Apple in 2005 and 2007, respectively (Apple, 2014). These mobile devices made access to videos, music, movies, games, Apps, and the Internet available to the masses. Users were no longer tethered to desktop computers or bulky laptops. In 2010, Apple introduced the iPad. The iPad presented users with a larger screen and many additional Apps. The iPod Touch, iPhone, and iPad have provided a gateway for interactive applications. This type of access has redefined 
ubiquitous learning. Learners do not need desktop computers or laptops to access interactive applications or retrieve information. Mobile devices have ensured that Internet content is always on regardless of time, location, or space.

In special education, much of the research on mobile devices has been focused on their ability to enhance communication skills for students with developmental disabilities and autism spectrum disorder (Edyburn, 2013). However, there is a developing line of research involving the use of iPads to facilitate the instruction of math and reading among students with varying levels of academic abilities in various educational settings. The results of these studies are promising because they suggest that multimedia Apps offer educators new ways to supplement difficult to learn concepts. For example, in a controlled experimental study conducted by Risconsente (2012), 122 fifth-graders used the math app Motion Math for 20 minutes a day for five days, for a total of one hour and 40 minutes of game play. According to the data, knowledge of fractions increased an average of $15 \%$. Many students reported liking fractions more after using Motion Math. Students also stated they thought the game was fun and would recommend it to their friends to help them learn fractions (Risconscente, 2012).

Haydon et al. (2012) also explored the effectiveness of iPads in math. The researchers conducted a study using an alternating treatments design to compare the effects of using worksheets and iPads on the math skills of three high school students with emotional disturbance. During the worksheet condition, students were instructed to complete all the problems on the worksheet and were not provided with corrective feedback. During the iPad condition, students used a math application that provided immediate feedback for correct responses. The application also provided corrective 
feedback for incorrect responses and guided students toward the correct response. The three participants demonstrated greater learning gains under the iPad condition. The number of correct responses per minute was greater for all three participants during the iPad condition. As a group, the percentage of problems answered correctly per minute under the worksheet condition was .66 and the percentage of problems answered correctly per minute under the iPad condition was 3.24. Researchers also found that students answered twice as many problems correctly under the iPad condition than the worksheet condition.

In another study focused on math, Jowett, Moore, and Anderson (2012) explored the impact of an iPad based intervention package on the numeracy skills of a 5 year-old child with autism spectrum disorder (ASD). The researchers used a multiple baseline across tasks design. The intervention package consisted of iPad-based video modelling, gradual fading of prompts, reinforcement, and in vivo prompts. The intervention was shown to be effective. The participant acquired numeracy skills including the ability to write and identify numbers 1-7.

The viability of iPads as learning tools to enhance math content was also highlighted in a study by Neely, Rispoli, Camarga, Davis, and Boles (2013). Neely et al. (2013) used an ABAB reversal design to compare the effects of traditional math instruction and iPad math applications on students' academic engagement. The participants were two males aged seven and three with ASD. To accommodate participants' ages and abilities, researchers used a different math App with each participant. During the first condition, math instruction was delivered using traditional pencil and paper materials or flashcards. During the second condition, instruction was 
provided using the iPad. Academic engagement was defined as having the participants look at the assignment, respond to questions verbally or in writing, and engage in a demand-related discussion with the teacher. Both participants demonstrated increased academic engagement during the iPad conditions. However, the researchers did not include a variable to measure math skills. As such, it cannot be determined if there was an increase in participants' math skills. The researchers noted there was a reduction of challenging behaviors exhibited by both participants during the iPad condition. After the implementation of the iPad condition, one participant decreased his challenging behavior from an average of $87.0 \%$ of the intervals to an average of $6.2 \%$. The second participant reduced his challenging behavior from an average of $62.0 \%$ of the intervals to an average of $15.3 \%$.

Positive results for integrating iPads into classroom instruction were also found in the content area of reading. According to observations by Harmon (2011), at-risk students in an urban high school who had access to iPads were more likely to pass reading and writing standardized tests, had more motivation to learn, and wrote longer essays on the iPad than they did on paper. In the study, students were given access to iPads prior to taking the Ohio Graduation Test (OGT). According to the data, $6 \%$ of students who had access to an iPad had a greater chance of passing the OGT's reading section than students who did not have access to an iPad. Harmon (2011) noted that 79\% of students in that school district passed the reading test. Of those students who passed, $85 \%$ had access to iPads during the previous school year. Additionally, $8 \%$ of students who had access to an iPad had a greater chance of passing the writing section of the OGT than students without 
access to an iPad (Harmon, 2011). Of the $84 \%$ of students who passed the writing test, $92 \%$ had access to iPads during the previous school year.

Although research has shown that the use of iPads can facilitate learning in certain content areas, such as math and reading with students in general education and self-contained settings, empirical, peer-reviewed research focused on iPads and history instruction is lacking. To that end, an action research project focused on iPads and American History content was presented at Wake Forest University in 2011. Importantly, this action research project did not go through the peer review process. The action researchers, Garcia and Friedman (2011) explored the effect of an iPad App (Explore 911) on the learning outcomes of high school students. The action researchers used a quasi-experimental design with a pretest and posttest measure consisting of a graphic organizer. Of the 74 participants, 49 used iPads and 25 used paper-based materials. All students were asked to complete written graphic organizers, work cooperatively in groups of 2-3, and watch news clips from September 11, 2001. According to results of the action research project, students who used the iPad earned better grades on their graphic organizers ( $M=9.2$ out of 10 points) and wrote more detailed descriptions of what they learned. The students who did not use the iPads scored a mean of 6.6 out of 10 points on their graphic organizers. A limitation of this action research project was that there were too many variables and it is not clear whether learning gains were attributed to the use of the iPad or to the cooperative learning group condition. Although this was an action research project, its limitations and implications may help guide future research on effective practices for using iPads in history classrooms. 
There are only a handful of studies highlighting the use of iPads during content area instruction with students with disabilities. However, the results are promising and illustrate that iPads may hold the potential to be a powerful means of promoting content area knowledge. These studies also suggest that the use of iPads can: (a) increase academic engagement, (b) motivate students to persevere through difficult tasks, and (c) deliver immediate feedback. Above all, these studies provide support for the use of emerging technologies and add to the body of literature on iPad use to facilitate content area skills. However, the aforementioned empirical studies did not include students with SLD learning any social studies content. Empirical, peer-reviewed studies are extremely limited and difficult to find. This lack of literature underscores the importance of extending research focused on history and mobile devices such iPads.

\section{Summary}

The purpose of this literature review was to discuss the academic potential of emerging technologies, such as iPads, to enhance content area knowledge in the subject of history for students with SLD. Students with SLD are characterized by deficits in the psychological domains involved in understanding verbal and written language (IDEA, 2004). The most common form of SLD is difficulty in reading (Matson \& Fodstad, 2010). Students with SLD typically read below grade level and earn academic grades lower than their peers without disabilities (Fletcher et al., 2007).

Students with SLD often struggle to meet the demands and expectations of their grade level history classroom. Academic success in history classrooms requires students to: (a) connect previously learned content with new content, (b) analyze cause-effect 
relationships, and (c) engage in critical thinking to construct meaning from complex concepts and vocabulary (Nokes, 2011). These tasks are difficult for students with SLD because they often lack background knowledge, have deficits in working memory, and experience difficulty with reading fluency and comprehension (Okolo, 2005; Faggella \& Deshler, 2008). Active student responding (ASR) has been a successful method to facilitate content area learning for students with SLD and other disabilities (Barbetta et al., 1993; Jerome \& Barbetta, 2005). ASR paired with technology has also been effective in increasing content area skills (Jerome \& Barbetta, 2005). Empirical research focused on ASR suggests the strategy supports student learning by: (a) providing repeated opportunities to respond, (b) actively engaging students in learning tasks, and (c) providing corrective feedback (Barbetta et al., 1993, Haydon et al., 2010). An additional strategy that benefits students with learning disabilities is the use of post lesson reviews to rehearse information and study new concepts and vocabulary (Boyle, 2012; Friend \& Bursuck, 2012).

Current research in the field of education supports the use of individualized technology for students with SLD in content area classrooms to: (a) facilitate the acquisition of academic skills (Cullen et al., 2013; Okolo et al., 2011), (b) provide multiple opportunities for practice and learning (Haydon et al., 2013), (c) increase ontask behavior and academic engagement (Haydon et al.), and (d) prepare students for work in the 21st century (Izzo, Yurick, Nagaraja, \& Novak, 2010). The characteristics of effective individualized instructional technologies are consistent with Mayer's (2001) Cognitive Theory of Multimedia Learning (CTML) and Skinner's (1958) assertions regarding the learning process. Effective individualized technologies support learning by: 
(a) providing students with non-judgmental environments to learn and practice in, (b) catering to visual and verbal modes of learning, and (c) supplementing difficult to learn concepts with graphics and simplified text.

The use of individualized technologies in social studies dates back to 1984 when simulation games were used to teach students about United States expansion and migration (NCSS, 2006; Rose \& Ferlund, 1997). Since then, more interactive, engaging technologies have emerged. Some of these technologies include 2D environments, such as Wikis, and 3D virtual environments such as iCivics. Examples of successful instructional technologies used in history classrooms include: (a) multimedia websites (Ferretti et al., 2001; Heafner \& Friedman, 2008), (b) hypermedia study guides (Higgins \& Boone, 1990, 1992), (c) computerized graphic organizers (Blankenship et al., 2005; Boon et al., 2006), and (d) virtual learning environments (Okolo et al., 2011).

Mobile technology is ubiquitous and makes information accessible to the masses. Within the next five years, $87 \%$ of school districts predict they will implement a Bring Your Own Device (BYOD) program (SIIA, 2013). The emergence of new technologies demands that researchers identify effective uses of technology and ways to incorporate them into content area classroom instruction. The mobile technology surge will not benefit learners if it is used to layer what students do not know rather than enhance what they do know. Emerging technology, such as the iPad, has the capacity to enhance the learning of students with disabilities by providing more meaningful access to the general curriculum (Bouck, 2010; Edyburn, 2013; Smith \& Okolo, 2010).

In order to take full advantage of mobile devices, researchers and educators must find their most effective uses. Therefore, the purpose of this study was to determine the 
effectiveness of using mobile devices on the acquisition of social studies content by secondary students with SLD. Specifically, this study focused on examining the effects of using iPads as an ASR system on the acquisition of U.S. history content by middle school students with SLD. Using the Quizlet mobile application, the following variables were examined: (a) the number of correct responses on U.S. history tests, (b) the rate of correct responses, and (c) the rate of incorrect responses. 


\section{CHAPTER III}

\section{METHOD}

This study investigated the effectiveness of mobile technology as an active student response (ASR) system on the acquisition of U.S. history content of students with specific learning disabilities (SLD). More specifically, this study investigated the effect

of an iPad application (Quizlet) as an end of session independent review ASR system on middle school students' acquisition of U.S. history facts. This chapter provides information on the study's participants, setting, dependent and independent variables, materials, measures, experimental design, and procedures.

\section{Participants}

The seven participants ( 1 girl and 6 boys) were students in Grade 8 who were enrolled in a large suburban middle school in the southeast region of the United States. The seven participants were identified as having SLD. Each participant demonstrated past difficulty with social studies content and had comprehension of content area material listed as a weakness on his or her Individualized Education Plan (IEP). The participants received U.S. history instruction in a self-contained classroom. Typically, these participants were with other students in inclusion classrooms. However, as an artifact of scheduling for the 2014-2015 school year, they were grouped together. The researcher was also their U.S. history teacher. Participants were required to have basic technology skills to operate an iPad. An iPad Technology Skills Assessment was used to assess each participant's ability to use Quizlet on the iPad (see Appendix D). A demographic description of each participant is presented in Table 1 followed by a more detailed description of each participant in the narrative. 
Table 1

Participant Demographic Information

\begin{tabular}{|c|c|c|c|c|c|c|c|}
\hline Participant & Gender & Age & Grade & $\begin{array}{c}\text { Primary } \\
\text { Exceptionality }\end{array}$ & $\begin{array}{c}\text { Intelligence } \\
\text { Score }\end{array}$ & $\begin{array}{c}\text { 2013- } \\
2014 \\
\text { FCAT } \\
\text { Reading } \\
\text { Level }\end{array}$ & $\begin{array}{c}\text { Florida } \\
\text { Civics } \\
\text { End of } \\
\text { Course } \\
\text { Exam } \\
t \text {-score } \\
\text { E*** }\end{array}$ \\
\hline 1 & $\bar{F}$ & 14 & 8 & SLD & $94 *$ & 2 & 44 \\
\hline 2 & M & 15 & 8 & SLD & $78 * *$ & 1 & 30 \\
\hline 3 & M & 14 & 8 & SLD & 88 & 1 & 36 \\
\hline 4 & M & 14 & 8 & SLD & $80 *$ & 1 & 20 \\
\hline 5 & M & 13 & 8 & SLD & $91 * *$ & 2 & 46 \\
\hline 6 & $\mathrm{M}$ & 13 & 8 & SLD & $70 * *$ & 1 & 25 \\
\hline 7 & $\mathrm{M}$ & 15 & 8 & SLD & $77 * *$ & 1 & 20 \\
\hline
\end{tabular}

\section{Participant 1}

Participant 1 was a 14-year-old Hispanic female who met eligibility requirements for SLD. Her General Conceptual Ability (GCA) score on the Differential Ability Scales II (DAS-II) was 94. On the Florida Civics End of Course Exam, she scored in the middle third when compared to other students in the state. From Grades 3-7, she maintained a level 2 in reading on the Florida Comprehensive Assessment Test (FCAT). She was enrolled in remedial reading courses during sixth, seventh, and eighth grade. She was retained in kindergarten due to inadequate learning gains. 


\section{Participant 2}

Participant 2 was a 15-year-old Hispanic male with SLD. He was retained in kindergarten due to lack of academic progress in acquiring basic math and reading skills. He was also retained in third grade due to inadequate learning gains and failure to pass the FCAT. On the Florida Civics End of Course Exam, he scored in the lowest third when compared to other students in the state. On the Wechsler Intelligence Scale for Children Fourth Edition (WISC-IV), he obtained a Full Scale Intelligence Quotient (IQ) score of 78. He failed civics in seventh grade and attended summer school to make up the credits. From Grades 3-7, he scored a level 1 in reading on the FCAT. He was enrolled in remedial reading courses during Grades 6-8.

\section{Participant 3}

Participant 3 was a 14-year-old Hispanic male who was identified as having SLD as his primary exceptionality and ASD as his secondary exceptionality. He was retained in third grade due to inadequate learning gains and failure to pass the FCAT. On the WISC-IV, he obtained a Full Scale IQ score of 88 . He received speech therapy for communication skills once per week as part of the support services delineated in his IEP. On the Florida Civics End of Course Exam, he scored in the lowest third when compared to other students in the state. He failed civics in seventh grade. He was enrolled in remedial courses during sixth, seventh, and eighth grade. His FCAT reading scores for Grades 3-7 were a level 1.

\section{Participant 4}

Participant 4 was a 14-year-old Hispanic male who was identified as having SLD. On the DAS-II, he obtained a GCA score of 80 . He received speech therapy for 
communication skills once per week as delineated in his IEP. On the Florida Civics End of Course Exam, he scored in the lowest third when compared to other students in the state. He was retained in first grade due to inadequate learning gains. From Grades 3-7, he scored a level 1 on the FCAT reading test. He was enrolled in remedial reading courses during sixth, seventh, and eighth grade.

\section{Participant 5}

Participant 5 was a 13-year-old Hispanic male who was identified as having SLD as his primary exceptionality and Emotional Behavior Disorders (EBD) as his secondary exceptionality. On the WISC-IV, he obtained a Full Scale IQ score of 91. On the Florida Civics End of Course Exam, he scored in the middle third when compared to other students in the state. From Grades 3-7, his FCAT reading level was a level 2. He was enrolled in remedial reading courses during Grades 6-8. He was not retained in elementary or middle school.

\section{Participant 6}

Participant 6 was a 13-year-old Hispanic male who was identified as having SLD. On the WISC-IV, he obtained a Full Scale IQ score of 70. He received pull-out speech therapy once per week for communication skills as delineated in his IEP. He scored a level 1 in reading on the FCAT from grades 3-7. He was enrolled in remedial reading courses during Grades 6-8. On the Florida Civics End of Course Exam, he scored in the lowest third when compared to other students in the state. He failed civics in seventh grade and repeated the course during the first semester of his eighth grade year. He was not retained in elementary or middle school. 


\section{Participant 7}

Participant 7 was a 15-year-old Hispanic male who was identified as having SLD. On the WISC-IV, he obtained a Full Scale IQ score of 77. He was retained in first grade due to lack of adequate academic progress. He was also retained in third grade due to inadequate learning gains and failure to pass the FCAT. On the Florida Civics End of Course Exam, he scored in the lowest third when compared to other students in the state. He scored a level 1 in reading on the FCAT from grades 3-7. He was enrolled in remedial reading courses during Grades 6-8.

\section{Setting}

The setting for this study was a large suburban middle school located in the southeast region of the United States. The school served students in Grades 6 through 8. The school was a low-income Title I school where $84 \%$ of students received free or reduced-lunch. The school's racial/ethnic breakdown was as follows: 93\% Hispanic, 3\% Black, 3\% White, and 1\% Asian. Thirteen percent of enrolled students were identified as students with disabilities. Twenty percent of students were identified as English Language Learners (ELLs).

The school was considered a high performing academic school. On an achievement scale of 1 to 5, 61\% of students achieved a passing score of 3 or above on the reading portion of the 2013 Florida Comprehensive Assessment Test 2.0 (FCAT 2.0; MDCPS, 2013). However, only $31 \%$ of students with disabilities scored a 3 or above on the reading portion of the FCAT 2.0 (MDCPS, 2013).

The study took place in a U.S. history classroom that was approximately 400 square feet with two large windows and one entrance/exit door. There were eight 
students in the classroom during each session but only seven of those students met the eligibility requirement for this study. Those seven eligible students participated in one study session per day, two to three times per week. The study lasted 8 weeks.

\section{Materials}

The following materials were used in this study:

\section{IRB Approval Form}

Approval to conduct the study was obtained from the university prior to the start of the study (see Appendix A).

\section{Parental Consent Forms}

The parents of each participant were provided with a consent form (see Appendix B). The form was written in a jargon-free manner. The form provided pertinent information such as the expectations of the parent and his or her child, the purpose of the study, procedures for the study, the length of the study, and potential benefits and risks of participating in the study. The form stated that participants would not be penalized for not participating in the study and that they could quit the study at any time without penalty.

The form was provided in English and Spanish. The local participating school district and Florida International University (FIU) approved the form that included contact information for the researcher and the university.

\section{Participant Assent Forms}

Each participant was given a Participant Assent Form after his or her parent had signed the Parental Consent Form. The assent form was written at a level the students could understand and provided information regarding the length of the study, procedures for the study, the purpose of the study, the expectations of the participant during the 
study, and potential benefits and risks of participating in the study (see Appendix C). The form stated that participants would not be penalized for not participating in the study and they could quit the study at any time without penalty. The form used was approved by the local participating school district and FIU and included contact information for the researcher and the university.

\section{Technology Skills Assessment and Checklist Form}

A technology skills assessment created by the researcher was used to determine participants' ability to operate an iPad (see Appendix D). The form included a list of eight basic skills necessary to successfully use an iPad for the purposes of this study. Each participant had to be able to: (a) attach headphones, (b) adjust the stand, (c) use the wake mode, (d) change orientation from landscape to portrait, (e) use one finger to scroll, (f) adjust volume settings, (g) single tap to access applications, and (h) power off the iPad screen.

\section{iPad Mobile Devices and Quizlet Application}

Four iPads were used in the study. The iPads were preloaded with the Quizlet Application (App). The iPads were set to Guided Access. Guided Access is an accessibility feature that allows educators to block students from using or accessing Apps other than the App that is currently open on the device. The researcher enabled the Guided Access feature via a four-digit passcode before the iPads were distributed to the participants.

Quizlet (2013) is an interactive App that integrates text, sound, and graphics that allows learners to study material using three different modes: cards, learn, and match. In the cards mode, students study terms by shuffling/randomizing terms and listening to 
audio recordings of the term and its definition. In the learn mode, students are presented with a definition or a graphic and prompted to type in the correct response. If they do not know an answer, they can tap the "Don't Know" button and the correct answer will appear. In the learn mode, students can also track their correct and incorrect responses and retest themselves on terms they did not answer correctly. Lastly, in the match mode, students are timed and must match terms with their correct definitions.

The researcher created the Quizlet learning sets that corresponded with each lesson. Microsoft Word to measure the Flesch-Kincaid level of each Quizlet set to ensure that the readability level was consistent with the readability level of participants' eighth grade U.S. history textbook. Flesch-Kincaid level refers to the readability or grade level at which text is written (Kincaid, Fishburne, Rogers, \& Chissom, 1975).

\section{Interobserver Agreement (IOA) and Treatment Fidelity Forms}

An IOA form was completed by the researcher and an additional observer (see Appendix E). The forms were used to compare participant data collected from the same session.

A treatment fidelity form detailing the components during each condition was used to ensure proper implementation of the treatments (see Appendix F). The form was used by an additional observer to assess the procedural integrity of the intervention conditions and pretest probes (Gresham, Gansle, \& Noell, 1993).

\section{Data Collection Forms}

Data collection forms were used to document the percentage of correct responses provided by each participant (see Appendix G) and the rate of correct and incorrect responses by each participant (see Appendix H). 


\section{U.S. History Pretest and Tests}

Permanent products were collected from each participant from each session in the form of paper-and-pencil hard copy pretests (see Appendix I for an example) and tests (see Appendix K for an example). The researcher created all pretests and tests. Each pretest consisted of 15 vocabulary-matching items and 15 fill-in-the-blank statements. Test content material was aligned with Florida's Next Generation Sunshine State Standards (NGSSS) for Social Studies (see Appendix J) and derived from the school district's established Social Sciences curriculum and adopted social studies textbooks published by McGraw Hill.

The 30-question pretest for each unit was used to develop individual U.S. history tests for each participant. The researcher selected 20 questions that the participant answered incorrectly and used those questions to create two post session tests for the participant. Each test corresponded to a particular unit and lesson. Each test consisted of five vocabulary-matching items and five fill-in-the-blank items (see Appendix K for an example). There were a total of 13 tests.

The decision to use specific content units (i.e., Exploration and Colonization) divided into lessons was based on standards established by the National Council of Social Studies (NCSS) and the NGSSS. Both sets of standards stipulate that social studies content should be taught chronologically and thematically. Further, social studies content should be presented to students in units with a unified them or big idea (Cantu \& Warren, 2003; Florida Department of Education, 2008; NCSS, 1992; Nokes, 2008). Additionally, the decision to use vocabulary-matching items and fill-in-the-blank items on tests was 
based on the need to keep the test style consistent with the type of items the participants experienced using the Quizlet App's match and learn modes.

\section{Dependent Variables}

There were three dependent variables measured at the end of each session: (a) percentage of correct responses on a U.S. history test, (b) the rate of correct responses, and (c) the rate of incorrect responses. Greer (2002) notes that rate correct and rate incorrect are independent measures of behavior, and therefore, should be measured concurrently to examine behavioral fluency.

Each variable was measured using the procedures for direct measurement of a permanent product (Gast, 2010). The product used to measure behaviors is consistent with the criteria for permanent product recording because (a) each occurrence will produce the same target behavior (i.e., responses on a written test, and (b) the permanent

product can only be produced by the target behavior; that is, responses on a written test (Cooper, Heron, \& Heward, 2007).

\section{Percentage of Correct Responses}

Percentage of correct responses refers to the number of times a participant provided the correct written answer to a test or pretest item per total number of opportunities to obtain a correct answer, multiplied by 100 (Gast, 2010). To measure percent correct, the following formula was used: number correct divided by the total number of test or pretest items multiplied by 100 . There were 10 items on each test and 30 items per pretest. The percentage of correct responses is an appropriate measure to use when (a) a permanent product is generated and (b) the number of opportunities to respond across permanent products is unequal (Gast, 2010). 


\section{Rate of Correct Responses}

Rate of correct responses refers to the number of correct answers given per total minutes to complete the test or pretest. Rate of correct responses is a measure of progress. Each participant's test and pretest was marked with a start and finish time. Participants were given 15 minutes to complete each test and 45 minutes to complete each pretest.

\section{Rate of Incorrect Responses}

Rate of incorrect responses refers to the number of wrong answers given per total minutes to complete a test. Each participant's test was marked with a start and finish time.

\section{Interobserver Agreement and Procedural Fidelity}

Two independent observers recorded data that were used to determine IOA. One independent observer was the researcher. The second independent observer was the dissertation committee chairperson. During an IOA training session, the researcher and the independent observer developed a collective understanding of what constituted an occurrence or nonoccurrence of the target behavior (Cooper et al., 2007; Richards, Taylor, Ramasamy, \& Richards, 1999).

Permanent product recording is recommended when measuring academic outcomes in that it allows the researcher and independent observer to objectively evaluate behaviors (Gast, 2010). Copies of each participant's tests were provided to the independent observer. To ensure accuracy of scoring responses, an answer key was given to the independent observer. A plus sign $(+)$ was used to denote correct responses. 
A minus sign (-) was used to denote incorrect responses. Unanswered items were scored with a minus sign (-).

The researcher and the independent observer compared responses. A plus sign (+) was used to denote agreement. A minus sign (-) was used to denote disagreement. IOA data were scored by both observers for $34.89 \%$ of sessions for Conditions A and B across participants. IOA data for the pretest probes were scored by both observers for $43.75 \%$ of sessions across participants. IOA was calculated using Kazdin's (1982) pointby-point agreement formula: total number of agreements divided by disagreements plus agreements multiplied by 100 .

\section{Procedural Fidelity}

Procedural fidelity data were recorded for $50 \%$ of the sessions by a second independent observer, who was a social studies teacher employed at the school. The independent observer was trained on the use of the Treatment Fidelity Form prior to the start of the study. That observer completed a checklist that delineated the procedures of the study across all conditions (see Appendix F). A plus sign (+) was scored when a planned researcher behavior was observed and a minus (-) sign was scored when a researcher behavior should have occurred but did not. Fidelity was calculated by dividing the number of observed researcher behaviors by the number of planned behaviors and then multiplied by 100 (Gast, 2010).

\section{Experimental Design}

An alternating treatments design (ATD) was used in this study. An ATD requires the rapid alternation of two or more distinct conditions (independent variables) and observing their effects on the target behaviors, or dependent variables (Cooper et al., 
2007; Richards et al., 1999). An ATD was used because it is a practical design for: (a) comparing the effectiveness of two or more instructional interventions and (b) treatment phases can be implemented immediately (Cooper, et al., 2007; Richards et al., 1999; Wolery, Gast, \& Hammonds, 2010).

\section{Mitigating Threats to Validity}

There are potential threats to validity when using an ATD: (a) sequence effects, (b) carryover effects, (c) multi-treatment interference, (c) history and maturation, and (d) additional potential confounding variables (Cooper et al., 2007; Richards et al., 1999). The term sequence effects refers to a participant's experience in one condition affecting his or her performance in subsequent conditions due to the ordering of the conditions (Wolery et al., 2010). To control sequence effects, interventions were counterbalanced across participants and sessions. Carryover effects refers to a participant's performance in one condition impacting his or her performance in a later condition (Wolery et al., 2010). To control carry over-effects, the order of the presentation of conditions were presented in a random order. If, however, the same condition was randomly selected two consecutive times, the third opportunity would default to the other condition. To mitigate multi-treatment interference, there was at least 24 hours between sessions. To measure threats due to maturation and history, participants were given a pretest before the start of each unit. The pretest consisted of content that had not been taught to the participants. To avoid any additional potential confounding variables regarding total duration of instruction, the total time of instruction was held constant across conditions as well as the total time of independent review under both conditions. Additionally, the academic skills 
taught were not likely to reverse. Therefore, different topics organized thematically and of equal complexity were used for every session (Wolery et al., 2010).

\section{Procedure}

\section{Participant Selection}

The researcher obtained permission from the local participating school district, FIU, and the school principal to conduct a study on the school site. Once permission was granted, the researcher selected a pool of seven potential participants based on the following criteria: (a) the participant was in Grade 8 and was identified as having SLD, (b) the participant had comprehension of content material listed as a weakness on his or her IEP, and (c) the participant demonstrated a history of difficulty with social studies content. The seven potential participants were chosen for the study. Once participants were recruited, the consent and assent process was implemented.

\section{Pre-study Technology Assessment}

Participants were given a technology skills assessment to ensure they had adequate skills to operate the iPad mobile device (see Appendix D). The skills assessment was conducted in a 1:1 session. If a participant was not proficient in using an $\mathrm{iPad}$, the researcher provided training on the basic operations of the device. Participants had to demonstrate $100 \%$ accuracy of skills prior to the start of the study.

\section{Quizlet Training}

The researcher trained each participant on the use of the Quizlet App during a 1:1 session. Training consisted of: (a) how to identify the volume symbol in Quizlet in order to enable/disable or start/stop the voice feature, (b) how to swipe through screens to advance terms in the cards mode, (c) how to use type in responses in the learn mode, and 
(d) how to tap responses in the match mode. Each participant then practiced using the App during a practice session. Participants demonstrated 100\% accuracy of skills using the App prior to the start of the study.

\section{Alternating Treatments Conditions}

There were two conditions and a series of pretest probes in this study. Condition A consisted of direct and explicit instruction and independent review of interactive notes and Condition B consisted of direct and explicit instruction and independent review using Quizlet on the iPad. Pretest probes consisted of 30-question tests.

The following is a description of content instruction for Conditions A and B. U.S. history content was delivered in the form of individual units. A single unit was delivered over the course of three classes. Each unit consisted of new content. Each unit was broken down into two lessons (Lesson A and Lesson B). During the first class, participants were given a pretest probe in the form of 30-question test. During the second class, participants were presented with Lesson A. Participants were then randomly assigned to Condition A (review with interactive notes) or Condition B (review with Quizlet on the iPad). Participants were randomly assigned to using interactive notes or Quizlet on the iPad intervention by drawing their ID numbers out a bag. If a given participant was randomly assigned to the same condition (i.e. interactive notes or Quizlet on the iPad) for two consecutive sessions, that participant would default to the other condition for the very next lesson. After the post lesson review, all of the participants were given a test for Lesson A. During the third class, participants were presented with Lesson B. Again, conditions were randomly assigned to Condition A or Condition B. 
After studying, all of the participants took a test for Lesson B. This continued throughout the study. In total, there were seven units.

For both intervention conditions (Condition A and Condition B), content instruction consisted of 30 minutes of direct and explicit instruction (Archer \& Hughes, 2011; Friend \& Bursuck, 2012; Goeke, 2009; Hall, 2002; Taylor, et al., 2009). Prior to the start of each lesson, the teacher activated prior knowledge by posing content-related questions to the participants. The teacher then explained the goal/objective of that day's lesson. Next, the teacher presented the new content for that day's lesson using PowerPoint slides. Lessons consisted of approximately 10 slides that contained text, visuals, maps, and diagrams appropriate to the goals of the lesson. Throughout lessons, the teacher checked participants' understanding by asking questions and requiring participants to respond. Verbal praise was given for correct responses and corrective feedback was given for incorrect responses.

Moreover, during the instructional phase of both conditions, the participants were instructed to write important information in their interactive notebooks if the information was repeated three times by the teacher (Brower \& Lobdell, 1999; Fisher, 2001; Young, 2003). The interactive notebook is a note-taking style that consists of a spiral notebook or composition notebook organized in a structured manner (Bower \& Lobdell, 1999; Mallozzi \& Heilbronner, 2013; Young, 2003). In an interactive notebook, the right page is used for input (i.e., teacher-driven materials such as discussion notes and graphic organizers). The left page of the interactive notebook is used for output (i.e., student drawings, cartoons, reflections, and questions). Headings, key ideas, terms, and new vocabulary are underlined or highlighted. A title page is created for every new unit and 
every page is dated (Brower \& Lobdell, 1999; Young, 2003). Each participant learned this note taking strategy during seventh grade (the previous year). Each participant was taught the strategy by the same teacher. The strategy was reviewed with each participant at the start of eighth grade by the same teacher (all the participants had the same social studies teacher for seventh and eighth grade).

\section{Condition A: Instruction and Independent Review Using Interactive Notes}

During Condition A, the participants received 30 minutes of content instruction consisting of direct and explicit instruction, student-written notes using the interactive notebook strategy, and PowerPoint slides as described above. After instruction, the participants were directed to independently review their handwritten notes for 15 minutes.

After reviewing their notes, the participants were given a 10 question test based on the content from that day's lesson. The participants were given 15 minutes to complete the test. Test questions were read to any participant upon request.

\section{Condition B: Instruction and Independent Review Using Quizlet}

During Condition B, the participants received 30 minutes of content instruction consisting of direct and explicit instruction, student-written notes using the interactive notebook strategy, and PowerPoint slides as describe above and identical to Condition A. After instruction, the participants reviewed the content by using Quizlet on the iPad for 15 minutes. The participants spent 5 minutes in the cards mode reviewing the terms, 5 minutes in the learn mode typing in responses, and 5 minutes in the match mode matching terms and definitions. The participants were timed in each mode. Once the time for a mode expired, participants were prompted to move to the next mode. The 
participants used the modes in order of cards, learn, and match on a consistent basis. The read aloud feature was also used on a consistent basis.

Quizlet (2013) is an interactive App that integrates text, sound, and graphics that allows learners to study material using three different modes: cards, learn, and match. In the cards mode, students study terms by shuffling/randomizing terms and listening to audio recordings of the term and its definition. In the learn mode, students are presented with a definition or a graphic and prompted to type in the correct response. If they do not know an answer, they can tap the "Don't Know" button and the correct answer will appear. In the learn mode, students can also track their correct and incorrect responses and retest themselves on terms they did not answer correctly. Lastly, in the match mode, students are timed and must match terms with their correct definitions.

After using Quizlet on the iPad, the participants took a 10-question test based on content from that day's session. The participants had 15 minutes to complete the test. Test questions were read to the participants upon request.

For Conditions A and B, tests were generated from a 30-question pretest. The researcher chose 20 questions (10 vocabulary-matching and 10 fill-in-the-blank statements) that the participant answered incorrectly and created two tests for the participants. Each of the two tests consisted of five vocabulary-matching items and five fill-in-the-blank statements. The items chosen for each test corresponded to the appropriate lesson. For example, Test \#4a had 10 items corresponding to Unit 4, Lesson A and Test \#4b had 10 items corresponding to Unit 4, Lesson B (see Appendix K). 


\section{Pretest Probes}

Participants took a 30-question pretest prior to the start of each unit (see Appendix I). The content on the pretest was unknown to students. Each pretest covered information from the two lessons that were going to be taught for that particular unit. The pretest consisted of 15 vocabulary-matching items and 15 fill-in-the-blank statements. The pretest was used to develop the individual tests for each participant.

Participants were given 45 minutes to complete each pretest. Pretests were marked with the participants' start and finish times. Test questions were read to participants upon request.

\section{Social Validity Measure}

Social validity refers to the social importance of the outcomes for key stakeholders (Wolf, 1978). Social validity measures enhance a study by demonstrating that interventions are meaningful to the accomplishment of a goal in the participant's life (Wolf, 1978). To measure social validity, participants were given a written questionnaire at the end of the study (see Appendix L). The questionnaire consisted of five open-ended questions about participants' experiences using Quizlet on the iPad to study U.S. history.

\section{Data Analysis}

Data points were collected for participants on a continuous basis and data were plotted on a line graph in order to allow the researcher to focus on individual patterns. Each participant's data were graphed separately. The researcher analyzed the level, trend, and variability of the data paths for each participant. This analysis was conducted using data across both interventions and a series of pretest probes. Additionally, the 
researcher analyzed any differences between the data paths; that is, the mean for each condition was analyzed. This, along with the visual analysis, aided the researcher in determining the vertical spread between the data paths to determine the differential effects that the independent variable had on the dependent variable (Cooper et al., 2007).

\section{Summary}

This study investigated the effect of mobile devices, specifically iPads, as active student response systems on the acquisition of U.S. history content of secondary students with SLD. The participants for this study were seven students in Grades 8 who were identified as having SLD. Comprehension of content area material (i.e. social studies content) was listed as a weakness on each participant's IEP. The participants were enrolled in a large suburban middle school in the Southeast region of the United States.

The dependent variables for this study were: (a) the percentage of questions answered correctly on a U.S. history test, (b) rate of correct responses, and (c) the rate of incorrect responses. This study used an alternating treatments design. There were two conditions and a series of pretest probes in this study. The two conditions were: (a) instruction and independent review of interactive notes, (b) instruction and independent review using the Quizlet App on an iPad.

Before the start of the study, parental consent and participant assent were obtained. Each participant was given a technology skills assessment to make sure he or she was able to properly operate an iPad. Each participant was trained on the basic operations of the iPad and the Quizlet App.

During Condition A, each participant received 30 minutes of content instruction consisting of a direct and explicit instruction, written notes using the interactive notebook 
strategy, and PowerPoint slides followed by 15 minutes of independent review using written notes. During Condition B, each participant received 30 minutes of instruction consisting of direct and explicit instruction, written notes using the interactive notebook strategy, and PowerPoint slides followed by 15 minutes of independent review using Quizlet on the iPad. Tests were given after each session for Conditions A and B. During the series of pretest probes, participants were given a 30-question test. 


\section{CHAPTER IV}

\section{RESULTS}

This chapter details the results of a study which used an alternating treatments design to explore the effects of mobile devices as an active student response system (ASR) on the acquisition of U.S. history content by students with SLD (a summary of participant demographics is presented in Table 1). There were two intervention conditions and a series of pretest probes used in this study. The two conditions were: (a) instruction and independent review using interactive notes and (b) instruction and independent review using Quizlet on the iPad. The dependent variables were percentage of correct responses, rate of correct responses per minute, and rate of errors per minute on U.S. history tests. Pretests probes consisted of 30 questions (15 matching and 15 fill-inthe-blank) and tests consisted of 10 questions (five matching and five fill-in-the-blank). Overall, participants demonstrated improvements in their test scores during both intervention conditions. These gains represent a substantial improvement considering that questions from the post session tests were compromised of those that participants answered incorrectly during the series of pretest probes. That is, participants' post session test scores were compared to zero correct responses. However, the graph presented in Figure 1 displays participants' percent correct responding on the series of pretest probes so that an analysis of potential confounding variables could be conducted (i.e. history, maturation, multiple treatment interference).

For several participants, there were differences between the two treatment conditions. For the remaining participants, differences in test scores between the two treatment conditions were negligible. Six participants indicated a preference for studying 
using the iPad and one participant indicated a preference for studying from handwritten

notes.

Figure 1.

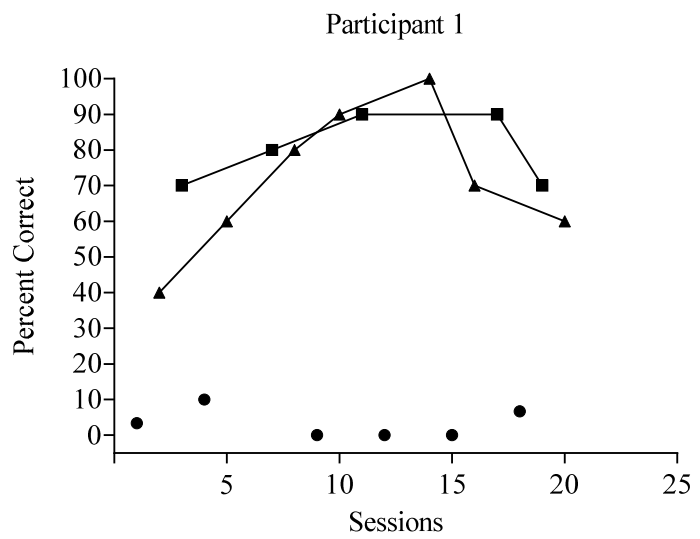

- Pretest Probe

$\rightarrow$ Interactive Notes

$\leftarrow$ Quizlet on the iPad

Participant 2

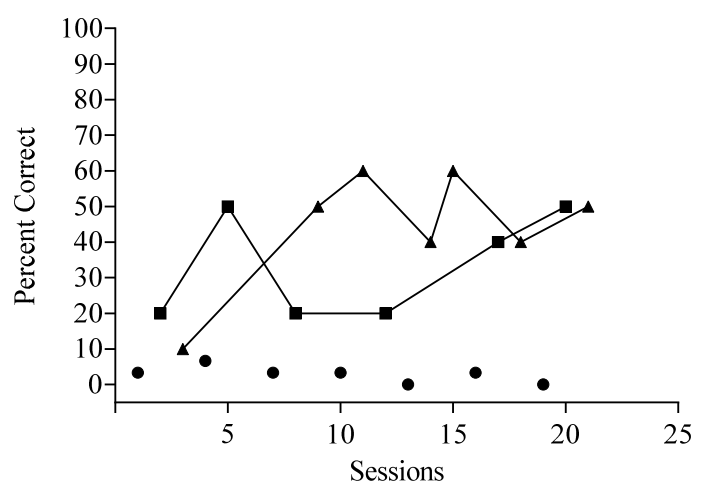

- Pretest Probe

- Interactive Notes

$\rightarrow$ Quizlet on the iPad

Participant 3

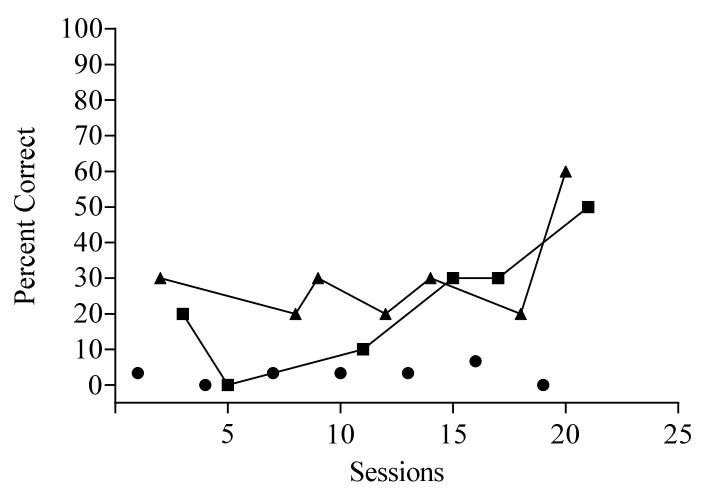

- Pretest Probe

$\rightarrow$ Interactive Notes

$\rightarrow$ Quizlet on the iPad 
Figure 1 cont.
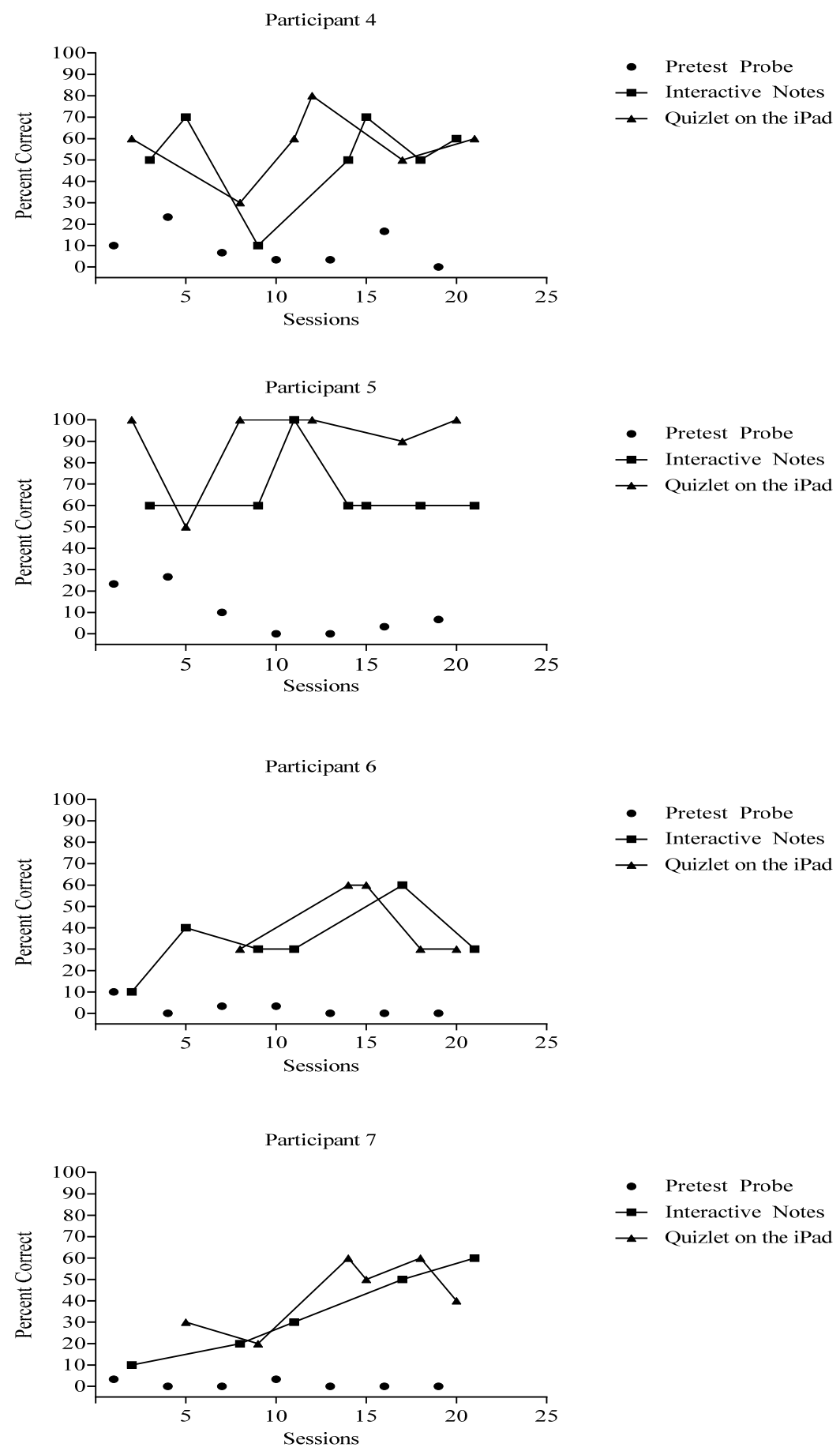

Figure 1. Percentage correct during two conditions (interactive notes and Quizlet on the iPad) and a series of pretest probes for Participants 1-7. Pretest probes consisted of 30-question tests and post session tests were 10 questions. 


\section{Interobserver Agreement}

The researcher and one independent observer collected IOA data. Data for the pretest probes were collected for $43.75 \%$ of sessions and equaled $99.05 \%$ (range 96.67 $100 \%$ ). For both intervention conditions, IOA data were collected for $34.89 \%$ of sessions and equaled 99.78\% (range 96.67-100\%).

\section{Treatment Fidelity}

The researcher and one independent observer collected treatment fidelity data for $50 \%$ of sessions. Seven sessions were pretest probes while 13 sessions were the interactive notes intervention (Condition A) and Quizlet on the iPad intervention (Condition B) conducted simultaneously. Treatment fidelity equaled $100 \%$ and was calculated by dividing the number of observed researcher behaviors by the number of planned behaviors and then multiplied by 100 .

\section{Participant 1}

Participant 1's scores improved during both treatment conditions (see Figure 1). During the series of pretest probes, her mean correct responding was $3.33 \%$ correct (range $0.00-10.00 \%$ ). These data were stable with little performance variability.

During the interactive notes intervention, the mean correct responding was $80 \%$ (range 70-90\%). Although these data were stable, there was a slight ascending trend in the data at the beginning of the intervention but the data path descended toward the end of the intervention. During the Quizlet on the iPad intervention, the mean score was $71.43 \%$ (range $40-100 \%$ ). There was a moderate ascending trend for the first five data points but the final data points descended, and other than those final data points, these data were stable. There was no overlap between both intervention data paths and the 
series of pretest probes. There was, however, overlap between both intervention data paths.

An analysis of the specific test question type (matching vs. fill-in-the-blank) was also conducted (see Table 2). Participant 1's results on the matching items were highest overall with the interactive notes condition ( $M=96 \%$, range $80-100 \%)$. During the Quizlet on the iPad condition, she scored a mean of $85.74 \%$ (40-100\%). For the fill-inthe-blank items, Participant 1's scores were highest with the interactive notes condition ( $M=64 \%$, range 40-100\%). Under the Quizlet on the iPad condition for fill-in-the blank items, the mean score was $57.14 \%$ (range $20-100 \%$ ).

An analysis of the rate of correct and error responses was conducted (see Table 3) and her mean rate of correct responses per minute during the series of pretest probes was 0.08 (range $0.00-0.22$ ). During the interactive notes intervention, the mean rate of correct responses was 1.30 per minute (range 0.47-2.25). Under the Quizlet on the iPad intervention, the mean of correct responses was 1.01 per minute (range $0.29-2.50$ ). Overall, Participant 1's rate of correct responses improved in both intervention conditions but was highest during the interactive notes intervention.

The mean rate for errors per minute during the series of pretest probes was 3.00 (range 1.61-6.00; see Table 3). During the interactive notes intervention, the mean rate of errors was 0.29 per minute (range 0.17-0.60). Using Quizlet on the iPad, the mean rate for errors was 0.30 per minute (range $0.00-0.50$ ). The rate of errors during both intervention conditions was comparable. 


\section{Participant 2}

Participant 2 demonstrated an improvement in test scores under both intervention conditions (see Figure 1). His mean score during the series of pretest probes was $2.86 \%$ (range $0.00-6.67 \%$ ). These data were low and stable with little performance variability.

During the interactive notes intervention, his mean score was $33.33 \%$ correct (range 20-50\%). The data were mostly stable with an ascending trend toward the end of the intervention. Under the Quizlet on the iPad condition, his mean score was $44.29 \%$ (range 10-60\%). There was an ascending trend during the beginning of the intervention with slight variability toward the end. There was no overlap between the series of pretest probes and both intervention conditions. There was an overlap of data paths between both intervention conditions, with the exception of the middle data points.

In regards to performance on specific test question type (matching vs. fill-in-theblank), Participant 2's performance was highest overall on matching items under the Quizlet on the iPad condition ( $M=60 \%$, range $20-100 \%$; see Table 2). Under the interactive notes condition, he scored a mean of $46.67 \%$ (range $20-80 \%$ ). For fill-in-theblank items, his scores overall were highest under the iPad condition ( $M=28.57$, range $0.00-80 \%$ ). For the notes intervention, his mean score was $20 \%$ (range $0.00-60 \%$ ).

Table 3 displays Participant 2's rate for correct responses and errors. The mean rate of correct responses per minute during the series of pretest probes was 0.19 (range 0.00-0.50). During the interactive notes intervention, the mean rate of correct responses was 0.61 (range 0.13-1.25). During the Quizlet on the iPad condition, the mean rate of correct responses was 0.88 (range 0.10-1.25). Participant 2's rate of correct responses was highest under the Quizlet on the iPad condition. 
During the series of pretest probes, Participant 2's mean score for errors per minute was 7.11 (range 1.71 to 14.50 ; see Table 3). Under the interactive notes intervention, his mean rate for errors per minute was 1.24 (range 0.53-2.00). Using Quizlet on the iPad, his mean rate for errors per minute was 0.99 (range 0.80 to 1.50 ). Overall, he produced fewer errors per minute under the Quizlet on the iPad condition.

\section{Participant 3}

Participant 3's performance scores during both conditions and series of pretest probes are presented in Figure 1. His performance data during the series of pretest probes were low and demonstrated a stable trend $(M=2.86 \%$, range $0.00-6.67 \%)$.

Under the interactive notes intervention, the mean correct responding was $23.33 \%$ (range $0.00-50 \%$ ), indicating a low performance level. These data were relatively stable with a slight ascending trend. During the Quizlet on the iPad intervention, his mean score correct was 30\% (range 20-60\%). These data were stable with a slight ascending trend, but the performance level was low-to-moderate. Towards the final sessions, there was a greater spread between the intervention data paths and the series of pretest probes. There was overlap between both intervention data paths throughout the study.

An analysis of the specific test question type (matching vs. fill-in-the-blank) is presented in Table 2. Participant 4's scores for matching items was highest under the Quizlet on the iPad condition ( $M=54.29 \%$, range $20-100 \%)$. During the interactive notes condition, his mean score for matching items was $43.33 \%$ (range $0.00-100 \%$ ). For fill-inthe-blank items, Participant 4's scores were relatively low under both conditions with a mean of $3.33 \%$ (range $0.00-20.00 \%$ ) for the interactive notes condition and $5.71 \%$ (range $0.00-40.00 \%)$ for the Quizlet on the iPad condition. 
An analysis of the rate correct and errors per minute was also conducted (see Table 3). During the series of pretest probes, the rate of correct responses per minute was 0.03 (range 0.00-0.09). The mean rate for correct responses per minute under the interactive notes condition was 0.28 (range $0.00-0.50$ ). For the Quizlet on the iPad condition, mean rate of correct responses per minute was 0.43 (range 0.30-0.67). In general, Participant 4's rate of correct responses was higher using Quizlet on the iPad.

During the series of pretest probes, the mean rate of errors per minute was 1.08 (range of 0.91-1.36; see Table 3). For the interactive notes condition, the mean rate of errors per minute was 0.98 (range $0.50-1.50$ ). Using Quizlet on the iPad, the mean rate of errors per minute was 1.23 (range 0.29-2.67). Fewer errors per minute were made during the interactive notes condition.

\section{Participant 4}

During the series of pretest probes, Participant 4's scores were low and stable with a mean of $9.05 \%$ (range $0.00-23.33 \%$; see Figure 1). Participant 4 's scores indicate that he made gains during both intervention conditions. Participants 4's mean score under the interactive notes intervention was $51.43 \%$ correct (range $10-70 \%$ ). These data were variable with no trend. During the Quizlet on the iPad intervention, his mean score was $56.67 \%$ (range $30-80 \%$ ). Again, these data were variable with no trend. There was minimal overlap between the interactive notes condition and the series of pretest probes. However, there was considerable overlap between the intervention data paths. Overall, his performance during both interventions produced relatively similar results.

In comparing the results of Participant 4's performance on specific test question type (matching vs. fill-in-the-blank), his performance was highest for matching items 
under the Quizlet on the iPad condition with a mean score of 80\% (range 20-100\%; see Table 2). For matching items under the interactive notes condition, his mean score was $74.23 \%$ (range 20-100\%). Participant 4 scored highest on fill-in-the-blank items under the Quizlet on the iPad condition ( $M=33.33 \%$, range $0.00-60 \%)$. His mean score for fillin-blank items during the interactive notes conditions was $28.57 \%$ (range $0.00-60 \%$ ).

An analysis of the rate correct and error responses was also conducted (see Table 3). Participant 4's mean rate for correct responses per minute during the series of pretest probes was 0.12 (range $0.00-0.38$ ). Under the interactive notes condition, his mean rate for correct responses per minute was 0.88 (range of 0.20 to 1.75). During the Quizlet on the iPad condition, the mean rate of correct responses per minute was 1.50 (range $0.55-$ 4.00). Overall, his highest rate of correct responses was during the Quizlet on the iPad condition.

For the series of pretest probes, Participant 4's mean rate of errors per minute was 1.64 (range $0.61-3.75$; see Table 3 ). Under the interactive notes condition, his mean rate for errors per minute was 0.81 (range 0.38-1.80). During the Quizlet on the iPad intervention, the mean rate for errors per minute was 1.07 (range $0.36-2.33$ ). The rate of errors per minute was lower during the interactive notes condition.

\section{Participant 5}

Participant 5's made learning gains during both treatment conditions. His data for percentage correct during the two conditions and the series of pretest probes is presented in Figure 1. During the series of pretest probes, his mean correct score was $10.00 \%$ (range $0.00-26.67 \%$ ). These data were stable with little performance variability. 
During the interactive notes intervention, the mean correct responding was $65.71 \%$ (range $60-100 \%$ ). These data were mostly stable with no trend with the exception of the third data point which accelerated drastically but returned to its prior level by the fourth data point. During the Quizlet on the iPad intervention, the mean score was $90.00 \%$ (range $50-100 \%$ ). These data were stable with a slight ascending trend except for the second data point which decelerated but returned to an ascending trend by the third data point. Both interventions were effective. There was no overlap between the intervention data paths and the series of pretest probes. Moreover, there was minimal overlap between the two interventions indicating that Quizlet on the iPad was superior to the interactive notes intervention.

An analysis of the specific test question type (matching vs. fill-in-the-blank) was also conducted (see Table 2). Participant 5's results on the matching items were highest overall with the Quizlet on the iPad condition ( $M=96.67 \%$, range $80-100 \%)$. During the interactive notes condition, he scored a mean of $85.71 \%(20-100 \%)$. For the fill-in-theblank items, Participant 5's scores were highest during the Quizlet on the iPad condition ( $M=83.33 \%$, range $20-100 \%)$. Under the interactive notes condition for fill-in-the blank items, the mean score was $45.71 \%$ (range $20-100 \%$ ).

Moreover, an analysis of the rate of correct and error responses was conducted (see Table 3). The mean rate of correct responses per minute during the series of pretest probes was 0.30 (range $0.00-0.80$ ). During the interactive notes intervention, the mean rate of correct responses was 1.67 per minute (range $0.60-3.33$ ). Under the Quizlet on the iPad intervention, the mean of correct responses was 3.66 per minute (range 0.63-5.00). 
Overall, Participant 5's rate of correct responses was highest during the Quizlet on the iPad intervention.

The mean rate for errors per minute during the series of pretest probes was 3.75 (range 1.53-6.25; see Table 3). During the interactive notes intervention, the mean rate of errors was 0.79 per minute (range $0.00-1.33$ ). Using Quizlet on the iPad, the mean rate for errors was 0.16 per minute (range $0.00-0.63$ ). There were fewer errors per minute under the Quizlet on the iPad condition.

\section{Participant 6}

During the series of pretest probes, Participant 6's scores were low and stable with a mean of $2.38 \%$ (range $0.00-10.00 \%$; see Figure 1 ). His scores indicate that he made learning gains under both intervention conditions (studying using interactive notes and studying using Quizlet on the iPad).

Participants 6's mean score under the interactive notes intervention was $33.33 \%$ correct (range 10-60\%). The data points for his overall percentage correct varied over the course of the study and did not show a trend. During the Quizlet on the iPad intervention, his mean score was $42 \%$ correct (range 30-60\%). Using Quizlet on the iPad, the data for percentage correct were variable and showed a descending trend. There was a low-to-moderate spread between the pretest probes data path and the intervention data paths. There was, however, considerable overlap between the intervention data paths indicting that both interventions are possibly equal.

In comparing the results of Participant 6's performance on specific test question type (matching vs. fill-in-the-blank), his performance was highest for matching items under the Quizlet on the iPad condition with a mean score of 68\% (range 40-100\%; see 
Table 2). For matching items under the interactive notes condition, his mean score was $40 \%$ (range $0.00-60 \%$ ). Participant 6 scored highest on fill-in-the-blank items under the interactive notes condition $(M=26.67 \%$, range $0.00-60 \%)$. His mean score for fill-inblank items during the Quizlet on the iPad condition was 16\% (range 0.00-20.00\%).

An analysis of the rate correct and errors per minute was also conducted (see Table 3). During the series of pretest probes, Participant 6's rate of correct responses per minute was 0.09 (range $0.00-0.25$ ). The mean rate for correct responses per minute under the interactive notes condition was 0.59 (range 0.11-1.00). For the Quizlet on the iPad condition, the mean rate of correct responses per minute was 0.92 (range 0.60-1.50). For Participant 6, his greatest rate of correct responses per minute was under the Quizlet on the iPad condition.

During the series of pretest probes, Participant 6's mean score for errors per minute was 6.59 (range 1.80-10.00; see Table 3). Under the interactive notes intervention, his mean rate for errors per minute was 1.14 (range 0.67-1.75). Using Quizlet on the iPad, his mean rate for errors per minute was 1.45 (range 0.40-2.33). Overall, he produced fewer errors per minute under the interactive notes condition.

\section{Participant 7}

Participant 7 demonstrated learning gains under both intervention conditions. Figure 1 provides data for percentage correct during the two conditions. His mean score on the series of pretest probes was $0.95 \%$ (range $0.00-3.33 \%$ ). His data were low and stable with little performance variability.

During the interactive notes intervention, his mean percent correct score was $34 \%$ (range 10-60\%). These data were stable with a moderate ascending trend. Under the 
Quizlet on the iPad condition, his mean score was 43.33\% (range 20-60\%). These data were stable with an ascending trend during the beginning of the intervention. The last data point showed a deceleration in the data path. In the beginning of the study, there was little spread in the data paths for both interventions. Towards the end of the study, however, there was a moderate spread among the two data paths. Notwithstanding this difference, there was overlap between both intervention data paths throughout the study. However, there was no overlap between the intervention data paths and the series of pretest probes.

In regards to performance on specific test question type (matching vs. fill-in-theblank), Participant 7's performance was highest overall on matching items under the Quizlet on the iPad condition ( $M=60 \%$, range $40-100 \%$; see Table 2). Under the interactive notes condition, he scored a mean of $52 \%$ with a range of $0.00-100 \%$. For fill-in-the-blank items, his scores overall were highest under the Quizlet on the iPad condition $(M=26.67$, range $0.00-60 \%)$. For the interactive notes intervention, his mean score was $16 \%$ (range $0.00-20.00 \%$ ).

Table 3 displays Participant 7's rate for correct responses and errors. The mean rate of correct responses per minute during the series of pretest probes was 0.03 (range $0.00-0.17)$. During the interactive notes intervention, the mean rate of correct responses was 0.44 (range $0.07-1.00$ ). During the Quizlet on the iPad condition, the mean rate of correct responses was 0.51 (range $0.29-0.67$ ). His highest rate of correct responses was under the Quizlet on the iPad condition.

During the series of pretest probes, Participant 7's mean score for errors per minute was 7.59 with a range of 1.50 to 15.00 (see Table 3 ). Under the interactive notes 
intervention, his mean rate for errors per minute was 0.67 (range 0.60-0.73). Using Quizlet on the iPad, his mean rate for errors per minute was 0.70 (range of $0.40-1.14$ ). Overall, he produced fewer errors per minute under the Quizlet iPad condition.

\section{Social Validity}

A social validity questionnaire was administered to participants at the end of the study. All seven participants reported that they felt using Quizlet on the iPad helped them learn U.S. history content. Moreover, six participants reported they preferred learning U.S. history with Quizlet, direct instruction, and note-taking versus direct instruction and note-taking only. One participant indicated a preference for learning U.S. history via direct instruction and note-taking only. When participants were asked if they would use Quizlet on an iPad to study U.S. history in the future, five participants said yes, one participant said maybe, and one participant said no. 
Table 2

Percentage Correct Matching and Fill-in

\begin{tabular}{|c|c|c|c|c|c|c|}
\hline \multirow[t]{2}{*}{ Participant } & \multicolumn{2}{|c|}{ Pretest Probes } & \multicolumn{2}{|c|}{ Interactive Notes } & \multicolumn{2}{|c|}{ Quizlet on the iPad } \\
\hline & Matching \% & Fill-in \% & Matching \% & Fill-in \% & Matching \% & Fill-in \% \\
\hline \multirow[t]{2}{*}{1} & 5.56 & 1.11 & 96.00 & 64.00 & 85.74 & 57.14 \\
\hline & $(0.00-13.33)$ & $(0.00-6.67)$ & $(80.00-100.00)$ & $(40.00-100.00)$ & $(40.00-100.00)$ & $(20.00-100.00)$ \\
\hline \multirow[t]{2}{*}{2} & 5.72 & 0.00 & 46.67 & 20.00 & 60.00 & 28.57 \\
\hline & $(0.00-13.33)$ & $(0.00)$ & $(20.00-80.00)$ & $(0.00-60.00)$ & $(20.00-100.00)$ & $(0.00-80.00)$ \\
\hline \multirow[t]{2}{*}{3} & 4.67 & 0.95 & 43.33 & 3.33 & 54.29 & 5.71 \\
\hline & $(0.00-13.33)$ & $(0.00-6.67)$ & $(0.00-100.00)$ & $(0.00-20.00)$ & $(20.00-100.00)$ & $(0.00-20.00)$ \\
\hline \multirow[t]{2}{*}{4} & 15.24 & 2.86 & 74.23 & 28.57 & 80.00 & 33.33 \\
\hline & $(0.00-40.00)$ & $(0.00-6.67)$ & $(20.00-100.00)$ & $(0.00-60.00)$ & $(20.00-100.00)$ & $(0.00-60.00)$ \\
\hline \multirow[t]{2}{*}{5} & 20.00 & 0.00 & 85.71 & 45.71 & 96.67 & 83.33 \\
\hline & $(0.00-53.33)$ & $(0.00)$ & $(20.00-100.00)$ & $(20.00-100.00)$ & $(80.00-100.00)$ & $(20.00-100.00)$ \\
\hline \multirow[t]{2}{*}{6} & 3.81 & 0.95 & 40.00 & 26.67 & 68.00 & 16.00 \\
\hline & $(0.00-20.00)$ & $(0.00-6.67)$ & $(0.00-60.00)$ & $(0.00-60.00)$ & $(40.00-100.00)$ & $(0.00-20.00)$ \\
\hline \multirow[t]{2}{*}{7} & 1.91 & 0.00 & 52.00 & 16.00 & 60.00 & 26.67 \\
\hline & $(0.00-6.67)$ & $(0.00)$ & $(0.00-100.00)$ & $(0.00-20.00)$ & $(40.00-100.00)$ & $(0.00-60.00)$ \\
\hline
\end{tabular}

Note. The top number represents the individual mean for percent correct and the bottom numbers represent the range of scores. 
Table 3

Rate Correct Per Minute and Errors Per Minute

\begin{tabular}{lcccccc}
\hline Participant & \multicolumn{2}{c}{ Pretest Probes } & \multicolumn{2}{c}{ Interactive Notes } & \multicolumn{2}{c}{ Quizlet on the iPad } \\
& Correct & Errors & Correct & Errors & Correct & Errors \\
\hline 1 & 0.08 & 3.00 & 1.30 & 0.29 & 1.01 & 0.30 \\
2 & $(0.00-0.22)$ & $(1.61-6.00)$ & $(0.47-2.25)$ & $(0.17-0.60)$ & $(0.29-2.50)$ & $(0.00-0.50)$ \\
& 0.19 & 7.11 & 0.61 & 1.24 & 0.88 & 0.99 \\
3 & $(0.00-0.50)$ & $(1.71-14.50)$ & $(0.13-1.25)$ & $(0.53-2.00)$ & $(0.10-1.25)$ & $(0.80-1.50)$ \\
& 0.03 & 1.08 & 0.28 & 0.98 & 0.43 & 1.23 \\
4 & $(0.00-0.09)$ & $(0.91-1.36)$ & $(0.00-0.50)$ & $(0.50-1.50)$ & $(0.30-0.67)$ & $(0.29-2.67)$ \\
& 0.12 & 1.64 & 0.88 & 0.81 & 1.50 & 1.07 \\
5 & $(0.04-0.38)$ & $(0.61-3.75)$ & $(0.20-1.75)$ & $(0.38-1.80)$ & $(0.55-4.00)$ & $(0.36-2.33)$ \\
& 0.30 & 3.75 & 1.67 & 0.79 & 3.66 & 0.16 \\
6 & $(0.00-0.89)$ & $(1.53-7.25)$ & $(0.60-3.33)$ & $(0.00-1.33)$ & $(0.63-5.00)$ & $(0.00-0.63)$ \\
& 0.09 & 6.59 & 0.59 & 1.14 & 0.92 & 1.45 \\
7 & $(0.00-0.25)$ & $(1.80-10.00)$ & $(0.11-1.00)$ & $(0.67-1.75)$ & $(0.60-1.50)$ & $(0.40-2.33)$ \\
& 0.03 & 7.59 & 0.44 & 0.67 & 0.51 & 0.70 \\
& $(0.00-0.17)$ & $(1.50-15.00)$ & $(0.07-1.00)$ & $(0.60-0.73)$ & $(0.29-0.67)$ & $(0.40-1.14)$ \\
\hline
\end{tabular}

Note. The top number represents the individual mean for rate correct and rate of errors per minute.

The bottom numbers represent the range of scores. 


\section{Summary}

This study was conducted to examine the effects of using mobile devices (iPads) as an ASR system on the acquisition of U.S. history content by students with SLD. More specifically, this study examined the effects of Quizlet on the iPad as ASR system.

Because this was a comparison study, the results of using Quizlet on the iPad as an end of session review were compared to the results of studying from interactive notes as an end of session review. This study measured percentage correct, rate of correct responses per minute, and rate of errors per minute for both interventions. This study also analyzed the percentage correct on specific question types (matching and fill-in-the-blank) for both interventions.

The results of this study indicated that all participants made learning gains during both treatment conditions (interactive notes and Quizlet on the iPad). An analysis of specific question type indicated that all participants performed better on matching items than on fill-in-the-blank items during both conditions (studying from interactive notes and studying using Quizlet on the iPad). 


\section{CHAPTER V}

\section{DISCUSSION}

This chapter presents a discussion of the results of this study. This study examined the effects of using mobile devices (i.e. iPads) as an active student response (ASR) system on the acquisition of U.S. history content by secondary students with SLD. The following research questions were posed:

1. What is the effect of mobile technology when used as an end of session, independent review ASR system, on students' acquisition of U.S. history content?

2. What is the effect of mobile technology when used as an end of session, independent review ASR system, on the rate at which students acquire U.S. history content?

3. Is there a difference in the performance of students with SLD when answering questions in a matching format versus a fill-in-the-blank-format?

Data were collected on the following variables: (a) percentage of correct responses on tests, (b) rate of correct responses per minute, and (c) rate of errors per minute. An analysis of specific question type (fill-in-the-blank and matching) was also conducted. An alternating treatments design with two conditions and a series of pretest probes was used in this study. The two conditions were: (a) studying using interactive notes and (b) studying using Quizlet on the iPad. All of the participants had varying degrees of learning gains during both interventions. Additionally, all of the participants demonstrated an increase in correct responses per minute and a decrease in errors per minute during both intervention conditions. Even with these gains, only two of the seven participants consistently had test scores that would be considered a passing grade. 


\section{Percentage of Correct Responses}

In answering the research question, "What is the effect of mobile technology when used as an end of session, independent review ASR system, on students' acquisition of U.S. history content?", the results of the study suggest that pairing Quizlet on the iPad with direct and explicit instruction had varying degrees of effectiveness when used as an end of session, independent review ASR system. During the Quizlet on the iPad intervention, all seven participants showed gains over their pretest scores. For some participants, these gains were more considerable than others. For example, Participant 1's mean score of $71.43 \%$ and Participant 5's mean score was 90\%. Participant 4 made moderate gains $(M=56.67 \%)$ while the remaining five participants made modest gains (see Figure 1). These results are compared to zero, therefore all of the participants made substantial gains.

A visual examination of the data showed that there was no overlap of data points between the pretest probes and the Quizlet on the iPad condition for any of the participants. The effects of the Quizlet on the iPad intervention were immediate for all of the participants. The effect for Participant 1 was clear and resulted in an ascending trend for her first five data points. Participant 2 demonstrated results leading to an ascending trend for his first three data points during the early part of the study, although, his percentages correct were very low for his initial data points. The ascending trends for the aforementioned participants may suggest that they were becoming more efficient in producing correct responses. Towards the end of the study, several participants (Participants 3, 5, and 6) demonstrated increases in their scores using the iPad for their last data point. This may suggest that the intervention may have been more effective if 
they had additional (future) sessions under the iPad condition. This may have been because the participants became used to operating the iPad and/or navigating through the Quizlet App. Becoming more efficient with Quizlet on the iPad may have allowed them to spend more time studying thereby possibly increasing their test scores.

ASR was one of the overarching themes of this study. ASR is associated with positive learning outcomes for students with SLD (Barbetta \& Heward, 1993; Carnine, 1976; Greenwood, Delquadri, \& Hall, 1984; Haydon et al., 2010; Heward, 2003; Jerome $\&$ Barbetta, 2005). This study provides further support for the use of ASR, particularly with social studies instruction. Moreover, the results of this study support the findings of Jerome and Barbetta (2005) in that pairing ASR with technology enhances social studies achievement for students with learning disabilities. In the Jerome and Barbetta study, participants used a desktop clicking ASR system to learn social studies facts. The desktop software program allowed participants to click on responses and listen to audio of social studies facts. These properties are similar to the features of the Quizlet App on the iPad used in this present study in that participants were able to listen to social studies facts and tap on responses. In both studies, the ability for participants to repeat information and receive feedback for their responses may have helped them build and acquire social studies knowledge. These results also support the premise that active engagement in learning enhances achievement in core content areas (Cullen, et al., 2013; Jerome \& Barbetta, 2005).

The results of this study lend support to the theoretical framework of Mayer (2001, 2005) in that the implementation of multimedia, interactive instructional technology, that is designed to provide corrective feedback, may engage learners and 
facilitate learning. In regards to multimedia learning, these results support the notion that applications that involve visual and audio components may assist students with learning disabilities by helping them with the cognitive demands of learning content area skills (Mayer 2001, 2005). The interactive, multimedia functions of the Quizlet App on the iPad may have helped sustain students' interest and facilitated their understanding of concepts (Mayer, 2005). Furthermore, these results also lend further support for the findings of Ferretti, MacArthur, and Okolo (2001), and Okolo, Englert, Bouck, Heutsche, and Wang (2011) in that multimodal activities enhanced learning for students with learning disabilities and increased their understanding of history content.

The results of this study link back to the theoretical framework of Skinner (1958) that was previously discussed in Chapter 1, as well. Skinner posited that students acquire knowledge through active engagement, repeated opportunities to practice, and receiving positive and corrective feedback. These principles are consistent with the ASR system utilized in this study. The Quizlet App on the iPad allowed students to repeatedly practice, respond, and receive supportive and corrective feedback. The results of this study also support the results of the studies by Barbetta, Heron, and Heward (1993) and Barbetta and Heward (1993). In those studies, students with disabilities who were exposed to supportive, corrective, and immediate feedback were more likely to: (a) remain actively engaged, (b) continue working towards a correct response, and (c) make learning gaining. The strategy of providing immediate corrective feedback was embedded in the learn and match modes of the Quizlet App. In the learn mode, participants typed in their responses and if their response was incorrect or misspelled, the application would provide participants with the correct response and re-prompt them for 
the correct response. In the match mode, if participants matched the wrong term and definition, their selections immediately turned red in color alerting participants that their selections were incorrect. If participants selected the correct matching set, their selections turned blue in color and immediately alerted them that their response was correct.

The findings of this study also suggest that using mobile devices, such as iPads, may increase achievement in core content areas among students with SLD. These results support the findings of Harmon (2011), Haydon et al. (2012), Neely et al. (2013), and Risconsente (2012). In those studies, participants demonstrated an increase in learning gains in the content areas of math and reading. Prior to this study, there was no research focused on the use of iPads in U.S. history classrooms specifically, and thus, extends the aforementioned literature on the effects of such technology on student learning. Moreover, previous social studies research focused on desktop computers and multimedia web-based programs while the current research examined the utility of mobile devices.

The second intervention in this study required participants to study from their hand written notes using the interactive notebook strategy. An examination of the results showed that all seven participants demonstrated learning gains over their pretest scores. The results for percentage correct are displayed in Figure 1. These gains were substantial for some participants such as Participant 1 who achieved a mean score $80 \%$. Participants 4 and 5 made moderate gains by achieving mean scores of $51.43 \%$ and $67.71 \%$ respectively.

A visual analysis of the data showed that there was an immediate effect of the intervention for 6 out of 7 participants. The data paths for Participants 1 and 7 resulted in an ascending trend for their first three data points. However, for Participants 3, 4, and 6, 
there was an overlap of data points between the pretest probes and the interactive notes condition. However, this overlap was minimal and nonexistent for most of the sessions and suggests a treatment effect. Participants 2 and 7 had ascending trends for their last three data points indicating that additional sessions with the interactive notes intervention may have resulted in further learning gains. While literature in the field of education does support implementing note taking strategies for students with SLD and other disabilities (Boyle, 2012; Taylor et al., 2009), there are very few empirical studies that have explored the effectiveness of interactive notebooks. To this author's knowledge, there is only one such study in the literature. Mallozzi and Heilbronner (2013) found that science instruction embedded with the interactive notebook strategy helped students achieve learning gains in science compared to students who did not receive content instruction embedded with the strategy. This current study is one of the first exploring the effects of interactive notebooks in the content area of social studies and it adds to the budding literature on this popular, yet, under-studied strategy.

The results of this present study indicated that both interventions, studying from interactive notes and studying from Quizlet on the iPad, were effective in improving learning gains in U.S. history for students with SLD. In some cases, Quizlet on the iPad was more effective (e.g., Participant 5). In one case, the interactive notes intervention seemed to be more effective (i.e. Participant 1). For the remaining participants, the difference between the two strategies was negligible.

Because this was a comparison study, it warrants a discussion regarding similarities and differences between the effects of the two interventions. Visual analysis of the data illustrates that there was considerable overlap for 5 of the 7 participants, 
lending to the argument that differences between the interventions in this study were negligible. Both interventions produced positive changes. However, there is not enough difference between the two treatments to suggest that one intervention was superior to the other. These results may suggest that the implementation of a post session review, whether it is on a mobile device or from a student's handwritten interactive notebook, might bring about learning gains. Because both interventions were effective, they could both be considered viable post lesson review options for students with SLD. In this study, 6 out 7 participants indicated a preference for using Quizlet on the iPad over studying from their interactive notes. Perhaps, because both were effective, students could choose the study method they prefer. If students were given an option, perhaps they would spend more time studying if they were using the iPad.

The results of this study indicated that both interventions had a degree of effectiveness on students' ability to make learning gains; however, these gains were not enough for most participants to achieve passing scores on their tests. Consequently, most would still fail their U.S. history class given this trajectory. For instance, Participants 2, 3, 6 and 7 produced gains in learning, but their scores remained low compared to standards of content mastery. Notwithstanding these students, two of the participants would pass their U.S. history classes with the mean scores they achieved during the study (Participant 1 and Participant 5). Two potential features of these students pertain to their previous intelligence test scores and achievement scores in reading compared to the other participants. Specifically, these two participants' most recent intellectual ability scores were within an average range, and they were the only participants who scored a level 2 in reading on the FCAT (see Table 1). For the remaining participants, their increase in mean 
scores, although considerable in some cases, would still result in the outcome of a failing grade in their U.S. history classes. Of these remaining participants, three had low average IQ scores and three had borderline low IQ scores (see Table 1). Although IQ scores present controversy, especially among learners with SLD from culturally and linguistically diverse (CLD) backgrounds (Taylor, 2009), this variable could be a consideration for educators when planning instruction as supplemental strategies could be necessary to help similar students, who might have lacked exposure to previous content, achieve a passing score in their courses. Furthermore, Participant 3, whose secondary exceptionality was Autism Spectrum Disorder (ASD) made the least learning gains under both conditions. Although he showed improvements over his pretest scores, these gains were very low and in some cases negligible. Perhaps this is due to the learning characteristics associated with students with ASD which include, but are not limited to, difficulty with comprehension of verbal and written language and difficulty understanding abstract concepts (Boucher, 2012; Schall \& McDonough, 2009).

Another possible reason for some participants' low scores may be that participants in this study were exposed to a given lesson once and then provided with one opportunity to study for their tests. The participants received instruction for 30 minutes on new content and then given 15 minutes to study that information. Perhaps if students were given more exposure (i.e., more time) and opportunities to practice their newly learned information, they would have performed better. Literature in the field of special education suggests that students with SLD and other disabilities benefit academically from multiple opportunities to respond and repeated practice (Barbetta et al., 1993; Haydon et al., 2013). Notwithstanding this established practice, two constraints of the 
current study were that a set curriculum with timeframes had to be followed and a block schedule, where participants attended their history class 2-3 days per week, was established in the school. Therefore, time spent on any one unit was limited and participants' opportunities to practice were affected.

All of the participants in the study were exposed to the same evidence-based teaching practices (i.e., direct and explicit instruction; Archer \& Hughes, 2011; Goeke, 2009; Hall, 2002) and a note taking system (i.e., interactive notebooks; Brower \& Lobdell, 1999; Endacott, 2007; Fisher, 2001; Mallozzi \& Heilbronner, 2013; Young, 2003). For some of the participants in this study, their academic weaknesses and lower level reading comprehension abilities may have been too substantial to overcome with note taking strategies and/or the use of instructional technology, and additional teaching procedures or content exposure might be necessary. Perhaps increasing these participants' exposure to ASR with corrective feedback may have improved their outcomes (Barbetta \& Heward, 1993).

This present study extends previous research in that it may be one of the first to compare the effects of mobile devices as an ASR system and studying from interactive notes on the acquisition of U.S. history content of secondary students with SLD. This is an important extension of previous research because trends in K-12 education indicate that greater emphasis is being placed on school districts to purchase and implement the use of the mobile devices. Overall, all of the participants in this study made learning gains using both interventions (studying with interactive notes and studying with Quizlet the iPad) with comparable achievement suggesting that each was a viable instructional option. Because the results of each intervention were comparable, student preference 
should be considered. That is, if iPads are available, then students who prefer them, should use them. Aside from iPad use, perhaps there are applications, other than Quizlet, that could be more effective. In this present study, the Quizlet App was used in the same manner during every session. It is possible that students may have gotten bored with the application. The use of a different application may have been more effective in producing greater learning gains from some of participants.

\section{Matching Versus Fill-in-the-Blank}

All of the participants in this study scored higher means on matching items versus fill-in-the-blank items during both conditions (see Table 2). In comparing the results of matching versus fill-in-the blank question items, scores for fill-in-the-blank items were consistently lower across all participants and conditions. This may be due to the fact that fill-in-the-blank items require the production of a response whereas matching items require the recognition of a response from a list of choices (Hinze \& Wiley, 2011; Larsen, Butler, \& Roediger, 2008). Hinze and Wiley (2011) suggest that fill-in-the-blank items are more difficult than matching due to the learner having to split his or her attention during the retrieval process between tested information and untested information. As such, fill-in-the-blank items place a greater demand on retrieval skills and working memory. This is a challenge for students with SLD because they are often characterized by weaknesses in working memory and difficulty trying to manipulate and manage information (Bulgren et al., 2007; Gersten \& Okolo, 2007). Therefore, these students may know the content but cannot retrieve that knowledge without a prompt or cue, such as a list of responses associated with the questions (Hinze \& Wiley, 2011). 
The interventions used in this study as post session reviews did not completely reflect the format of tests. The notes taken using the interactive notebook strategy did not match the style of questions on tests used in this study nor did studying using interactive notes require participants to generate responses. However, the format of the learn and match modes in the Quizlet App were more like the format of the test in that students had to generate responses during the learn mode (resembled fill-in-the-blank test items) and match terms and definitions during the match mode (resembled matching test items). For most of the participants, the similarities and differences in the interventions to the actual format of the test did not make a difference on their learning outcomes demonstrating that both interventions were effective.

\section{Rate of Correct Responses and Errors per Minute}

The second research question in this study was, "What is the effect of mobile technology when used as an end of session, independent review ASR system, on the rate at which students acquired U.S. history content? All seven participants demonstrated an increase in the rate of correct responses per minute. Moreover, all seven participants demonstrated a decrease in errors per minute under the iPad condition. These results indicate that students were developing fluency in their abilities to produce correct responses, although they did not achieve fluency during this study. Their decrease in their rate of errors per minute indicated that they were also becoming more accurate in their responses. These findings are consistent with the findings of Haydon et al. (2012) who reported that students increased their rate of correct responses after using a math-based application on an iPad. Overall, the results were positive and are consistent with the 
literature on ASR, which suggests that ASR increases content area fluency (Axtell, McCallum, Bell, \& Poncy, 2009; Cullen, Keesey, Alber-Morgan, \& Wheaton, 2013).

Although studying with Quizlet the iPad was an effective intervention in helping students develop accuracy in their responses, studying from their interactive notes was also an effective intervention. All seven participants demonstrated an increase in the rate of correct responses per minute and a decrease in errors per minute under the interactive notes condition. These findings may suggest that a post-session review, whether it is in the form of studying from a multimedia application on a mobile device or studying from handwritten notes, is effective in helping students develop fluency and accuracy.

Measuring the rate of correct responses and rate of errors is important when determining fluency because the two rates are independent measures of behavior, and therefore, should be measured concurrently to examine behavioral fluency (Greer, 2002). Fluency is also a measure of the rate of accuracy (Greer, 2002). In some instances, developing fluency may be a more sensitive measure of mastery than percent correct (Kubina \& Morrison, 2000). The speed of responses may indicate whether or not the student has developed control over the content being learned (Kubina \& Morrison). Furthermore, speed of accuracy may be an indicator of content mastery. For example, a participant who answered 8 out of 10 questions correctly in 5 minutes may demonstrate greater control over content knowledge compared to a participant who answered 8 out of 10 questions correctly in 15 minutes (Kubina \& Morrison).

\section{Social Validity}

Social validity is important in a research study in order to determine if the intervention had practical outcomes for key stakeholders (Wolf, 1978). On the social 
validity questionnaire, all seven participants responded that they felt studying using Quizlet on the iPad helped them learn U.S. history content. Furthermore, five of the participants expressed that they would use Quizlet on the iPad to study U.S. history in the future. Six of the participants responded that they preferred learning U.S. history via direct instruction, taking handwritten notes, and studying with Quizlet on the iPad versus learning U.S. history via direct instruction, taking handwritten notes, and studying from handwritten notes. Perhaps the novelty of the iPad is appealing to students, even to those whom did not reach mastery during the study. The use Quizlet on the iPad may be appealing to students because it is familiar to the interactive touch-based wireless devices (phones, tablets, gaming consoles, etc.) they are already exposed to outside of school. Conversely, the iPad may be appealing to some students because they may not have access to the aforementioned devices outside of school. Given that most of the participants indicated a preference for the iPad, perhaps they would have studied more if they were given an option regarding the type of post lesson review they wanted to use.

\section{Implications}

The results of this study have implications for history classrooms serving students with SLD. This study suggests that the use of a mobile, multimedia ASR system, such as the Quizlet App on the iPad, may help secondary students with SLD study U.S. history content and increase their scores on various assessments. Again, this study taught students historical facts, not historical analysis. Therefore, the results of the current study are limited to the teaching of historical facts. History teachers should consider implementing the use of mobile devices as an ASR review system into their classrooms to enhance content area learning gains and build fluency. However, teachers should be 
cautious in relying too heavily or solely on mobile devices as they are not the singular determining factor in student achievement. Although instructional technology did have a positive effect on learning gains, it is not a panacea for helping students with SLD overcome substantial deficits in academic abilities. Quizlet on the iPad was one application out of many learning applications that exist. There are other interactive, multimedia applications that may be more successful in helping students with SLD acquire content area skills. Further, when such applications are used, teachers should consider increasing the amount of time that students are exposed to the applications as repeated ASR and multiple opportunities to practice skills may help students achieve greater learning gains (Barbetta et al., 1993; Jerome \& Barbetta, 2005).

Regarding classroom instruction for students with SLD, teachers should continue to employ evidence-based instructional practices and consider using mobile devices as ASR systems to supplement those practices. With the growing trend of mobile devices in schools and the implementation of Bring Your Own Device (BYOD) programs, educational professionals should pair these devices with sound practices and use these devices as an extension of what students have already been taught in order to maximize their knowledge. Furthermore, teachers of students with disabilities should adopt universal instructional strategies that benefit a wide range of learners and allow for multiple means of representation, interaction, and expressions of learning.

For teachers of students with SLD in inclusive classrooms, technology may be a viable tool to accommodate the needs of learners who may require more individualized practice while simultaneously meeting the needs of other learners without learning disabilities (Akpan, Beard, McGahey, 2014). In essence, introducing mobile devices in 
content area classrooms may benefit all learners and provide teachers with an additional strategy to meet diverse needs and diverse learning styles. Learners with various levels of academic ability may use mobile devices to learn at their own pace while using the same classroom devices as their peers (Draper Rodriguez, Strnadova, \& Cummings, 2014). This may foster feelings of inclusion, motivation, increased student participation, and increased opportunities for success (Draper Rodriguez et al., 2014). Through the implementation of mobile devices, content area material can be more engaging, flexible, and accessible in a variety of formats for students with varying levels of academic abilities being served in K-12 classrooms. For example, in an iPad study conducted by Risconsente (2012), fifth-grade students increased their learning gains in math and reported that they enjoyed learning math more after the use of a math application on the iPad. In another iPad study, Harmon (2011) found that at-risk high school students who had access to iPads were more likely to produce longer essays than students who did not have access to iPads. In a study conducted by Demski (2011), teachers reported that English Language Learners (ELLs) who used the voice feature of a portable dictionary on a mobile device (i.e., iPod) to study English pronunciations were less shy about speaking English in front of their classmates. Teachers in that study also reported that the features of the mobile device allowed them to listen to recordings by their students and monitor their English language acquisition progress. These aforementioned studies demonstrate that mobile devices may: (a) have the capacity to engage diverse learners in a manner that they are comfortable with, (b) motivate students to focus on learning, (c) differentiate instruction and supplemental practice opportunities for students with diverse academic needs, and (d) allow teachers to monitor students' progress. 
Another recommendation from this study would be to implement a post session review directly after a lesson and right before a test. In this study, students with SLD showed learning gains when they studied from Quizlet on the iPad and when they studied using handwritten notes directly after a lesson and right before an assessment. Teachers of students who struggle with content area material should also consider introducing students to a note taking system so that students can learn how to organize new information and concepts in their notebooks (Boyle, 2012; Brower \& Lobdell, 1999; Endacott, 2007; Fisher, 2001; Mallozzi \& Heilbronner, 2013; Young, 2003).

Direct and explicit instruction was a constant during both interventions in this study. Teachers of students with SLD should include this practice in their repertoire of strategies to meet the range of abilities represented in their classrooms (Archer \& Hughes, 2011; Gersten et al., 2009a, 2009b). Direct and explicit instruction enriches the academic experience of students with SLD by providing them with corrective feedback and increased opportunities for active participation, among other features (Archer \& Hughes, 2011; Goeke, 2009).

\section{Limitations}

Although the results of this study are promising, there are limitations that must be considered. Given the precedent for educating students with SLD in inclusion classrooms, one major limitation in this study is that it took place in a self-contained classroom. Therefore, the results from the current study may not generalize to students with SLD in general education classroom settings. Another major limitation is that the Major Professor served as an independent observer for IOA data collection. This presents a potential for researcher bias. However, this concern might be mitigated because the 
tests were scored independently of the researcher, and given the nature of the types of questions on the tests (matching and fill-in-the-blank), there was little opportunity for observer drift.

There were several other limitations in this present study. Single subject designs, by nature, include small populations. As such, initial external validity is limited; however, this can be resolved through direct and systematic replication studies. Additionally, this present study was limited to students in Grade 8 studying U.S. history content who were identified as having SLD. The results of this study cannot be generalized, at this time, to students in other grades, with other disabilities, and learning other content areas. Furthermore, this study employed a specific application on a specific type of mobile device (Quizlet on the iPad) and a limited length of time spent using the application on the device (15 minutes per review session). Therefore, the results of this study cannot be generalized to other mobile devices, applications, and various lengths of time spent using other applications/devices. There may be other applications that offer more effective features than those found in Quizlet. Additionally, given more time, participants may have studied longer and made greater learning gains. A further limitation is that participants were exposed to each content lesson and Quizlet learning set once. Given this constraint, participants were not able to study or practice their newly learned content more than once.

Another limitation to this study was there was only one female participant and six male participants. Future studies could include more female participants. There was also a large spread in the academic abilities of the participants. Although all of the participants 
were struggling readers, some of the participants performed at a much lower achievement level than other participants.

The novelty of the iPad could have been a limitation, as well. The participants in this study only used iPads in their U.S. history class. These devices were not available to any of the participants in any of their other classes. In turn, this may have piqued their interests in using the iPads. Additionally, the matching and fill-in-the blank format may have been a limitation. Many of the participants struggled to complete the fill-in-theblank items and often left them blank, which in turn, resulted in those items being scored as errors. The participants of this study were characterized by their weaknesses in working memory during the retrieval process and this may have influenced their decisions to bypass answering the fill-in-the-blank items. Subsequently, this may have suppressed their overall scores.

Lastly, because the results of this study reflect performance outcomes with direct and explicit instruction as a constant during both intervention conditions, it is not possible to compare either condition to a direct and explicit instruction only condition. It is possible that direct and explicit instruction impacted the effectiveness of both interventions (studying from interactive notes and studying with Quizlet on the iPad).

\section{Suggestions for Future Research}

There are several recommendations for future research. In the current study, all of the participants were Hispanic middle school students with SLD. Future studies could include more culturally and linguistically diverse students in elementary or high school settings. This study also focused on one particular facet of social studies, U.S. history. Future research can focus on other topics such as civics, geography, or economics. 
Future research studies could focus on different applications on different mobile devices. This study used an app (Quizlet) designed for use on Apple's iOS operating system. Perhaps other studies could explore different interactive, multimedia applications designed for wireless devices running Android or Windows operating systems. Additionally, the current research involved participants using Quizlet on their own. Future researchers may want to examine the use of Quizlet used in a group format.

Different testing formats could also be explored in the future. Future studies could observe student outcomes on the use of all multiple choice questions, fill-in-in-the-blank items with a word bank, oral question-answer format, or a combination of formats. A behavioral observation component could also be added to future studies to observe students' behaviors and attitudes towards using mobile devices. A final suggestion would be to increase the length of time students spend studying during post lesson reviews.

\section{Summary}

The results of this study suggest that the use of mobile devices as an ASR system can have a degree of positive effect on the acquisition of U.S. history content by middle school students with SLD. In this study, students used the Quizet App on an iPad as an end of session review ASR system. For some participants, learning gains were substantial. For other participants, learning gains were low-to-moderate. The results of the study indicated that using a mobile device as an ASR system can help students increase their rate of correct responses per minute and decrease their errors per minute, thereby allowing them to increase fluency and accuracy. The results of this study also 
indicate that studying from interactive notes helps students with SLD make learning gains, increase their rate of correct responses, and decrease their rate of errors per minute.

This study supports the existing literature on ASR and expanded on the research by Jerome and Barbetta (2005). ASR, when paired with instructional technology, can increase learning gains in social studies for students with SLD. The results of this study also suggest that the integration of multimedia learning for students with SLD, in conjunction with note taking and direct and explicit instruction strategies, can lead to learning gains in U.S. history.

In this study, the effects of mobile devices as an end of session review ASR system were compared to the effects studying from handwritten notes written using the interactive notebook strategy as an end of session review. Comparative analysis suggested that both interventions (studying from interactive notes and studying with Quizlet on the iPad) had varying degrees of effectiveness in increasing the learning gains of students with SLD. In most cases, both interventions were equally effective.

Social validity results suggest that participants preferred learning U.S. history using Quizlet on the iPad paired with note taking and direct and explicit instruction. Participants also responded that studying on the iPad helped them learn history content and that they would use Quizlet on the iPad again in the future to study U.S. history content.

This study is important because it provides new insights on the use of emerging technologies being implemented in K-12 classrooms. It also provides information on the effectiveness of using interactive notebooks in social studies. Although emerging technologies are viable options for students in K-12 classrooms, their effectiveness may 
be comparable to other existing, evidence-based practices. With the push for implementation of mobile devices in K-12 classrooms, educational professionals should find uses of these devices that allow students to engage in multiple means of representation, engagement, and expression of content area materials. Teachers of students with SLD should consider implementing mobile devices as an ASR system to facilitate acquisition of content area knowledge. Teachers should use mobile devices as an ASR system to supplement evidence-based teaching practices, such as direct and explicit instruction, and not rely solely on technology to address the needs of struggling learners. The importance of mobile devices in K-12 education makes it an important topic of continuing research.

Recommendations for future research include: (a) include a more diverse population of students; (b) explore the use of other interactive applications on various mobile operating platforms; (c) focus on other social studies subjects such as civics, geography, or economics; (d) explore various testing formats such as oral questionanswer and multiple choice, and (e) increase the length of time students use to study during post lesson reviews. 


\section{REFERENCES}

AECT (2004). Definition of educational technology. Washington, DC: AECT.

Akpan, J., Beard, L. \& McGahey, J. (2014). Assistive Technology Enhances Academic Outcomes of all students. In M. Searson \& M. Ochoa (Eds.), Proceedings of Society for Information Technology \& Teacher Education International Conference 2014 (pp. 1796-1801). Chesapeake, VA: Association for the Advancement of Computing in Education (AACE).

Allsopp, D., Colucci, K., Doone, E., Perez, L., Bryant, J., \& Holhfeld, T. (2012). Interactive whiteboard technology for students with disabilities: A yearlong exploratory study. Journal of Special Education Technology, 27(4), 1-15.

Apple (2010). Apple press info. Retrieved from http://www.apple.com/pr/products/

Archer, A., \& Hughes, C. (2011). Explicit instruction: Effective and efficient teaching. New York, NY: Guilford Publications.

Axtell, P., McCallum, R., Bell, S., \& Poncy, B. (2009). Developing math automaticity using a class wide fluency building procedure for middle school students: A preliminary study. Psychology in the Schools, 46(6), 526-538.

Bain, R. (2005). "They thought the world was flat?" HPL principles in teaching high school history. In J. Bransford \& S. Donovan (Eds.), How students learn: History, math, and science in the classroom (pp. 179-214). Washington, DC: National Academies Press.

Bain, R. (2006). Rounding up unusual suspects: Facing the authority hidden in history textbooks and teachers. Teachers College Record, 108(10), 2080-2114.

Barbetta, P. M., \& Heron, T. E., \& Heward, W.L. (1993). Effects of active student response during error correction on the acquisition, maintenance, and generalization of sight words by students with developmental disabilities. Journal of Applied Behavior Analysis, 26(1), 111-119.

Barbetta, P. M., \& Heward, W. L. (1993). Effects of active student response during error correction on the acquisition, maintenance, and generalization of geography facts by elementary students with learning disabilities. Journal of Behavioral Education, 3(3), 217-233.

Barbetta, P. M., Heward, W. L., \& Bradley, D. M. C. (1993). Relative effects of wholeword and phonetic error correction on the acquisition and maintenance of sight words by students with developmental disabilities. Journal of Applied Behavior Analysis, 26, 99-110. 
Barbetta, P. M., Heward, W. L., Bradley, D. M. C., \& Miller, A. D. (1994). Effects of immediate and delayed error correction on the acquisition and maintenance of sight words by students with developmental disabilities. Journal of Applied Behavior Analysis, 27, 177-178.

Beck, I. L., McKeown, M., \& Gromoll, E. W. (1989). Learning from social studies text. Cognition and Instruction, 6, 99-153.

Becker, C. (1932). Everyman his own historian: Annual address of the President of the American Historical Association. American Historical Review, 37(2), 221-36.

Becker, W.C., \& Gersten, R. (1982). A follow-up of follow through: The later effects of The Direct Instruction Model on children in fifth and sixth grades. American Educational Research Journal, 19(1), 75-92.

Becker, W.C., Madsen, C.H., \& Arnold, C. (1967). The contingent use of teacher attention and praise in reducing classroom behavior problems. Journal of Special Education, 1(3), 287-307.

Berkeley, S. (2007). Reading comprehension instruction for students with learning disabilities. Advances in Learning and Behavioral Disabilities, 20, 79-99.

Berliner, D. C. (1980). Using research on teaching for improvement of classroom practice. Theory into Practice, 19, 302-308.

Berliner, D. C. (1990). What's all the fuss about instructional time? In M. Ben-Peretz \& R. Bromme (Eds.), The Nature of Time in Schools (pp. 3-35). New York, NY: Teachers College Press.

Berson, M. J. (1996). Effectiveness of computer technology in the social studies: A review of the literature. Journal Of Research On Computing In Education, 28(4), 486-499.

Berson, I. R., Berson, M. J., \& Manfra, M. (2012). Touch, type, and transform: iPads in the social studies classroom. Social Education, 76(2), 88-91.

Biggs, M., Homan, S., Dedrick, R., Minick, V., \& Rasinski, T. (2008). Using an interactive singing software program: A comparative study of struggling middle school readers. Reading Psychology, 29, 195-213.

Blankenship, T., Ayres, K. M. \& Langone, J. (2005). Effects of computer-based cognitive mapping on reading comprehension for students with emotional behavior disorders. Journal of Special Education Technology, 20, 15-24. 
Bloom, B. S. (1976). Human characteristics and school learning. New York, NY: McGraw-Hill.

Boon, R., Burke, M., Fore, C., \& Hagan-Burke, S. (2006). Improving student content knowledge in inclusive social studies classrooms using technology-based cognitive organizers: A systematic replication. Learning Disabilities: A Contemporary Journal, 4, 1-17.

Boon, R., Burke, M., Fore, C., \& Spencer, V. (2006). The impact of cognitive organizers and technology-based practices to promote student success in secondary social studies classrooms. The Journal of Special Education Technology, 21, 5-15.

Bouck, E.C. (2010). Technology and students with disabilities: Does it solve all problems? Currents Issues and Trends in Special Education: Research, Technology, and Teacher Preparation Advances in Special Education, 20, 91104.

Boucher, J. (2012). Research review: Structural language in Autistic Spectrum Disorder characteristics and causes. Journal of Child Psychology and Psychiatry, 53(3), 219-233.

Bouck, E. C., Okolo, C. M., Englert, C. S., \& Heutsche, A. (2008). Cognitive apprenticeship into the discipline: Helping students with disabilities think and act like historians. Learning Disabilities: A Contemporary Journal, 6(2), 21-40.

Boyle, J.R. (2012). Note-taking and secondary students with learning disabilities: Challenges and solutions. Learning Disabilities Research \& Practice, 27(2), 90101.

Bower, B., \& Lobdell, J. (1999). History alive! Engaging all learners in the diverse classroom. Rancho Cordova, CA: Teachers Curriculum Institute.

Bradley Commission on History in the Schools. (1988). Building a history curriculum: Guidelines for teaching history in schools. Westlake, OH: National Council for History Education.

Branson, M. (1998). The role of civic education: A position paper. Calabasas, CA: Center for Civic Education.

Bruner, J. (1960). The Process of Education. Cambridge, MA: The President and Fellows of Harvard College.

Bulgren, J.A., Deshler, D.D., \& Lenz, B.K. (2007). Engaging adolescents with LD in higher order thinking about history concepts using integrated content enhancement routines. Journal of Learning Disabilities, 40(2), 121-133. 
Burton, J. K., Moore, D. M. \& Magliaro, S. G. (2004). Behaviorism and instructional technology. In D. H. Jonassen (Ed.), Handbook of research on educational communications and technology (pp. 3-36). Mahwah, NJ: Erlbaum

Campigotto, R., McEwen,R., \& Demmans Epp, C.(2013). Especially social: Exploring the use of an iOS application in special needs classrooms. Computers \& Education, 60(1), 74-86.

Cantu, D. A., \& Warren, W. J. (2003). Teaching history in the digital classroom. New York, NY: ME Sharpe.

Carnine, D. W. (1976). Effects of two teacher-presentation rates on off-task behavior, answering correctly, and participation. Journal of Applied Behavior Analysis, 9, 199-206.

Chambers, B., Cheung, A., Madden, N., Slavin, R. E., \& Gifford, R. (2006). Achievement effects of embedded multimedia in a success for all reading program. Journal of Educational Psychology, 98(1), 232-237.

Chou, C.C., Block, L., \& Jesness, R. (2012). A case study of mobile learning pilot project in K-12 schools. Journal of Educational Technology Development and Exchange, 5(2), 11-26.

Conderman, G., Bresnahan, V., \& Hedin, L. (2011). Promoting active involvement in today's classrooms. Kappa Delta Pi Record, 47(4), 174-180.

Cooper, J. O., Heron, T. E., \& Heward, W. L. (2007). Applied behavior analysis (2nd ed.). Upper Saddle River, NJ: Pearson Education.

Cortiella, C. (2009). The state of learning disabilities. New York, NY: National Center For Learning Disabilities.

Cullen, J., Keesey, S., Alber-Morgan, S., \& Wheaton, J. (2013). The Effects of computerassisted instruction using Kurzweil 3000 on sight word acquisition for students with mild disabilities. Education and Treatment of Children, 36(2), 87-103.

Curtis, C.K. (1991). Social studies for students at-risk and with disabilities. In J.P. Shaver (Ed.), Handbook of research on social studies teaching and learning (pp. 157174). New York, NY: Macmillan.

Dallman-Jones, A. (1994). The expert educator: A reference manual of teaching strategies for quality education. Fond du Lac, WI: Three Blue Herons Publishing. 
Darling-Hammond, L. (2001). Inequality and access to knowledge. In J. A. Banks \& C. M. Banks (Eds.), Handbook of research on multicultural education (pp. 465483). San Francisco, CA: Jossey-Bass.

De La Paz, S. (2012). Effective instruction for history and the social studies: What works for students with learning disabilities. In B. Wong \& D. Butler (Eds.), Learning about learning disabilities (pp. 325-348). Oxford, UK: Elsevier.

Dede, C. (2005). Planning for neomillennial learning styles. Educause Quarterly, 28, 712.

Demski, J. (2011). ELL to go. T.H.E. Journal, 38(5), 28-32.

Dimino, J. A. (2007). Bridging the gap between research and practice. Journal of Learning Disabilities, 40(2), 183-189.

Draper, R. J., Broomhead, P. Jensen, A. P., Nokes, J. D. Siebert, D., (Eds.). (2010). (Re)imagining content-area literacy instruction. New York, NY: Teachers College Press.

Draper Rodriguez C., Strnadova I., Cumming T. (2014). Using iPads with students with disabilities: lessons learned from students, teachers, and parents. Intervention in School and Clinic, 49(4), 244-250.

Edyburn, D.L. (2013). Critical issues in advancing the special education technology evidence base. Exceptional Children, 80(1), 7-24.

Espin, C. A., Cevasco, J., van den Broek, P., Baker, S., \& Gersten, R. (2007). History as narrative: The nature and quality of historical understanding for students with LD. Journal Of Learning Disabilities, 40(2), 174-182.

Faggella-Luby, M. N., \& Deshler, D. D. (2008). Reading comprehension in adolescents with LD: What we know; What we need to learn. Learning Disabilities Research and Practice, 23, 70-78.

Ferretti, R. P., MacArthur, C. A., \& Okolo, C. M. (2001). Teaching for historical understanding in inclusive classrooms. Learning Disability Quarterly, 24, 59-71.

Ferretti, R.P., \& Okolo, C.M. (1997, April). Designing multimedia projects in the social studies: Effects on students' content knowledge and attitudes. Paper presented at the annual meeting of the American Educational Research Association, Chicago, IL.

Fisher, A. L. (2001). Implementing graphic organizer notebooks: The art and science of teaching content. Reading Teacher, 55(2), 116-120. 
Flanagan, D., Ortiz, S., Alfonso, V., \& Dynda, A. (2006). Integration of response to intervention and norm-referenced tests in learning disability identification: Learning from the Tower of Babel. Psychology in the Schools, 43(7), 807-82

Fletcher, J. M., Lyon, G. R., Fuchs, L. S., \& Barnes, M. A. (2007). Learning disabilities: From identification to intervention. New York: The Guilford Press.

Florida Department of Education. (2008). Next Generation Sunshine State Standards. Retrieved from http://www.fldoe.org/bii/curriculum/sss/

Ford, P. J. (2001). Paralysis lost: Impacts of virtual worlds on those with paralysis. Social Theory and Practice, 27(4), 661-680.

Frederick, R., Donnor, J., \& Haltley, L. (2009). Culturally responsive application of computer technologies in education. Educational Technology, 49(6), 9-13.

Friend, M. \& Bursuck, W. (2012). Including students with special needs: A practical guide for classroom teachers (4th ed.). Boston, MA: Allyn \& Bacon.

Fry, S. W. \& Gosky, R. (2007). Supporting social studies reading comprehension with an electronic pop-up dictionary. Journal of Research on Technology in Education, 40 (2), 127-139.

Futuresource. (2013). Technology in Education: Global Trends Universe Spend and Market Outlook. Retrieved from http://reports.futuresourceconsulting.com/ tabid/64/ItemId/ 123405/Default.aspx

Gagnon, P. (1989). Historical literacy: The case for history in American education. New York, NY: Macmillan.

Garcia, E. \& Friedman, A. (2011). “There's an App for that:” A study using Apple iPads in a United States History classroom. Studies in Teaching 2011 Research Digest: Action Research Projects Presented at Annual Research Forum, Wake Forest University, Winston-Salem, NC.

Gast, D. L. (2010). Single subject research methodology in behavioral sciences. D. L. Gast (Ed.), New York, NY: Routledge.

Gersten, R., Baker, S. K., Smith-Johnson, J., Dimino, J., \& Peterson, A. (2006). Eyes on the prize: Teaching complex historical content to middle school students with learning disabilities. Exceptional Children, 72(3), 264-280. 
Gersten, R., Beckmann, S., Clarke, B., Foegen, A., Marsh, L., Star, J. R., \& Witzel, B. (2009a). Assisting students struggling with mathematics: Response to intervention for elementary and middle schools. Washington, DC: U.S. Department of Education Institute of Educational Sciences.

Gersten, R., Compton, D., Connor, C. M., Dimino, J., Santoro, L., Linan-Thompson, S., \& Tilly, W. (2009b). Assisting students struggling with reading: Response to intervention and multi-tier intervention in primary grades. Washington, DC: U.S. Department of Education Institute of Educational Sciences.

Gersten, R., Fuchs, L., Williams, J., \& Baker, S. (2001). Teaching reading comprehension strategies to students with learning disabilities: A review of research. Review of Educational Research, 71(2), 279-320.

Gersten, R., \& Okolo, C. M. (2007). Teaching History-in All Its Splendid Messinessto Students with LD: Contemporary Research. Journal of Learning Disabilities, 40(2), 98-99.

Gillani, B. B. (2010). Inquiry-based training model and the design of e-learning environments. Issues in Informing Science \& Information Technology, 7, 1-9.

Glover, D., Miller, D., Averis, D. \& Door, V. (2007). The evolution of an effective pedagogy for teachers using the interactive whiteboard and modern languages: An empirical analysis from the secondary sector. Learning, Media and Technology, 32(1), 5-20.

Goeke, J. L. (2009). Explicit instruction: A framework for meaningful direct teaching. Upper Saddle River, NJ: Merrill.

Graham, S. (2008). Effective writing instruction for all students. Wisconsin Rapids, WI: Renaissance Learning.

Greenwood, C. R., Delquadri, J. D., \& Hall, R. V. (1984). Opportunity to respond and student academic achievement. In W. L. Heward, T. E. Heron, D. S. Hill, \& J. Trap-Porter (Eds.), Focus on behavior analysis in education (pp. 58-88). Columb us, $\mathrm{OH}$ : Merrill.

Gresham, F. M., Gansle, K. A., \& Noell, G. H. (1993). Treatment integrity in applied behavior analysis with children. Journal of Applied Behavior Analysis, 26(2), 257-263.

Greer, D. R. (2002). Designing Teaching Strategies: A behavior analysis systems approach. San Diego, California: Academic Press. 
Halaweh, M. (2013). Emerging technology: What is it? Journal of Technology Management \& Innovation, 3(8), 108-115.

Hall, T. (2002). Explicit instruction. Wakefield, MA: National Center on Accessing the General Curriculum. Retrieved from http://aim.cast.org/learn/historyarchive/ backgroundpapers/explicit_instruction

Harmon, J. (2011). Unlocking literacy with iPad. Through Students' Eyes Project, Euclid City Schools, Euclid, Ohio. Retrieved from http://www.throughstudentseyes.org/ iPads/Unlocking_Literacy_with_iPad/iPads.html

Hawkins, D. L. (1997). It's more than teaching history. The Social Studies, 88(3), 108112

Haydon, T., Conroy, M., Scott, T., Sindelar, P., Barber, B., \& Orlando, A. (2010). A comparison of three types of opportunities to respond on student academic and social behaviors. Journal of Emotional \& Behavioral Disorders, 18(1), 27-40.

Haydon, T., Hawkins, R., Denune, H., Kimener, L, McCoy, D. \& Basham, J. (2012). Comparison of iPads and worksheets on math skills of high school students with emotional disturbance. Behavioral Disorders, 37(4), 232-243.

Haydon, T., Marsicano, R., \& Scott, T. M. (2013). A comparison of choral and individual responding: A review of the literature. Preventing School Failure: Alternative Education for Children and Youth, 57(4), 181-188.

Heafner, T.L., \& Friedman, A.M. (2008). Wikis and constructivism in secondary social studies: Fostering a deeper understanding. Computers in the Schools, 25(3), 288302 .

Heffernan, N., Heffernan, C., Decoteau, M., \& Militello, M. (2012) Effective and meaningful use of educational technology: Three cases from the classroom. In C. Dede \& J. Richards (Eds.), Digital teaching platforms: Customizing classroom learning for each student (pp. 88-102). New York, NY: Teachers College Press.

Hernandez-Ramos, P. \& De La Paz, S. (2009). Learning history in middle school by designing multimedia in a project-based learning experience. Journal of Research on Technology in Education, 42(2), 151-173.

Heward, W. L. (2003). Exceptional Children: An Introduction to Special Education. Upper Saddle River, NJ: Prentice Hall.

Heward, W. L., Gardner III, R., Cavanaugh, R. A., Courson, F. H., Grossi, T. A., \& Barbetta, P. M. (1996). Everyone participates in this class. Teaching Exceptional Children, 28, 4-10. 
Higgins, S., Beauchamp, G., \& Miller, D. (2007). Reviewing the literature on interactive whiteboards. Learning, Media, \& Technology, 32(3), 213-225.

Higgins, K., \& Boone, R. (1990). Hypertext computer study guides and the social studies achievement of students with learning disabilities, remedial students, and regular education students. Journal of Learning Disabilities, 23, 529-540.

Higgins, K., \& Boone, R. (1992). Hypermedia computer study guides for social studies: Adapting a Canadian history text. Social Education, 56(3), 168-173.

Higgins, K., Boone, R., \& Lovitt, T. C. (1996). Hypertext support for remedial students And students with learning disabilities. Journal of Learning Disabilities, 29, 402412 .

Higgins, S., Falzon, C., Hall, I., Moseley, D., Smith, F., Smith, H., et al. (2005).

Embedding ICT in the literacy and numeracy strategies: Final report. Newcastle, England: Newcastle University.

Higher Education Opportunity Act of 2008 (Public Law 110-315). Retrieved from http://www2.ed.gov/policy/ highered/leg/hea08/index.html

Hitchcock, C. G., Meyer, A., Rose, D. \& Jackson, R. (2002). Access, participation, and progress in the general curriculum: A universal design for learning. Retrieved from http://www.cast.org/ncac/techbrief

Hughes, M.T. \& Parker-Katz, M. (2013). Integrating comprehension strategies into social studies instruction. The Social Studies, 104, 93-104

Hutchinson, A., Beschorner, B., \& Schmidt-Crawford, D. (2012). Exploring the use of iPad for literacy learning. The Reading Teacher, 66 (1), 15-23.

Individuals with Disabilities Education Act (IDEA). (2004). Identification of specific learning disabilities. Retrieved from http://idea.ed.gov/explore/view/ $\mathrm{p} / \% 2 \mathrm{Croot} \% 2 \mathrm{Cdynamic} \%$ 2CTopicalBrief $\% 2 \mathrm{C} 23 \% 2 \mathrm{C}$

Izzo, M. V., Yurick, A., Nagaraja, H. N., \& Novak, J.A. (2010). Effects of a 21st-Century curriculum on students' information technology and transition skills. Career Development for Exceptional Individuals, 33(2), 95-105.

Jarvenpaa, S. \& Lang, K. (2005). Managing the paradoxes of mobile technology. InformationSystems Management Journal, 22(4) 7-23. 
Javeri, M. (2007). Technology Integration: Best Practices, Concerns and Barriers in Urban Schools. In G. Richards (Ed.), Proceedings of World Conference on ELearning in Corporate, Government, Healthcare, and Higher Education 2007 (pp. 6059-6064). Chesapeake, VA: AACE.

Jerome, A., \& Barbetta, P.M. (2005). The effect of active student responding in computer-assisted instruction on social-studies learning by students with learning disabilities. Journal of Special Education Technology, 20(2), 13-23.

Johnson, A.P. (2010). Making connections in elementary and middle school social studies. Thousand Oaks, CA: Sage.

Jowett, E. L., Moore, D. W., \& Anderson, A. (2012). Using an iPad-based video modelling package to teach numeracy skills to a child with an autism spectrum disorder. Developmental Neurorehabilitation,15(4), 304-312.

Junglas, I. A., Johnson, N.A., Steel, D.J., Chon Abraham, D., \& MacLoughlin, P. (2007). Identity formation, learning styles and trust in virtual worlds. The DATA BASE for Advances in Information Systems, 38(4), 90-96.

Kazdin, A. E. (1982). Single-case research designs: Methods for clinical and applied settings. New York, NY: Oxford University Press.

Keskin, N.O. \& Metcalf, D. (2011). The current perspectives, theories and practices of mobile learning. The Turkish Online Journal of Educational Technology, 10(2), 202-208.

Kidd, T.T., \& Keengwe, J. (2010). Technology integration and urban schools: Implications for instructional practice. International Journal of Information and Communication Technology Evaluation, 6(3), 51-63.

Kincaid, J.P., Fishburne, R.P., Rogers, R.L., \& Chissom, B.S. (1975). Derivation of new readability formulas for Navy enlisted personnel. Research Branch Report 8-75. Chief of Naval Technical Training: Naval Air Station Memphis.

Kinder, D., \& Bursuck, B. (1992). An evaluation of history textbooks. Journal of Special Education, 25, 472-491.

Kinder, D., \& Carnine, D. (1991). Direct instruction: What it is and what it is becoming. Journal of Behavioral Education, 1(2), 193-213.

Kingsley, K.V. \& Boone, R. (2006). Effects of multimedia software on achievement of middle school students in an American history class. Journal of Research on Technology in Education, 41(2), 203-221. 
Kohut, A., Morin, R., \& Keeter, S. (2007). What Americans know: 1989-2007, Public knowledge of current affairs little changed by news and information revolutions. The Pew Research Center for the People \& the Press, 2.

Kubina, R. \& Morrison, R. (2000). Fluency in education. Behavior and Social Issues, 10, 83-99

Kuhn, M.R. \& Stahl, S. (2003). Fluency: A review of developmental and remedial practices. The Journal of Educational Psychology, 95, 3-21.

Lamella, L., \& Tincani, M. (2012). Brief wait time to increase response opportunity and correct responding of children with autism spectrum disorder who display challenging behavior. Journal of Developmental and Physical Disabilities, 24(6), 559-573.

Lerner, J. (2003). Learning disabilities: Theories, diagnosis, and teaching practices. Boston, MA: Houghton Mifflin.

Levine, D. P. (2007). The Birth of the citizenship schools: Entwining the struggles for literacy and freedom. History of Education Quarterly, 44(3), 388-414

Lewin, C., Somekh, B., \& Steadman, S. (2008). Embedding interactive whiteboards in teaching and learning: The process of change in pedagogic practice. Education \& Information Technologies, 13(4), 291-303.

Liang, T.H., Huang, Y.M., \& Tsai, C.C. (2012). An investigation of teaching and learning interaction factors for the use of the interactive whiteboard technology. Educational Technology \& Society, 15(4), 356-367.

Mallozzi, F. \& Heilbronner, N. (2013). The effects of using interactive student notebooks and specific written feedback on seventh grade students' science process skills. Electronic Journal of Science Education, 17(3), 1-24.

Mastropieri, M. A., \& Scruggs, T. E. (2010). The inclusive classroom: Strategies for effective Instruction (4th ed.). Upper Saddle River, NJ: Prentice Hall.

Mastropieri, M., Scruggs, T., \& Graetz, J. (2003). Reading comprehension instruction for secondary students: Challenges for struggling students and teachers. Learning DisabilityQuarterly, 26, 103-116.

Mastropieri, M. A., Scruggs, T. E., \& Whedon, C. (1997). Using mnemonic strategies to teach information about U.S. presidents: A classroom-based investigation. Learning Disability Quarterly, 20, 13-21. 
Marzano, R. J. (2004). Building background knowledge for academic achievement: Research on what works in schools. Alexandria, VA: ASCD.

Matson, J. \& Fodstad, J. (2010). Learning disabilities. In J. C. Thomas \& M. Hersen (Eds.), Handbook of Clinical Psychology Competencies (pp. 1301-1328). New York, NY: Springer Science \& Business Media.

Mayer, R. E. (1997). Multimedia learning: Are we asking the right questions? Educational Psychologist, 32, 1-19.

Mayer, R. E. (2001). Multimedia learning. Cambridge, England: Cambridge University Press.

Mayer, R. E.. (2005). Cambridge handbook of multimedia learning. New York, NY: Cambridge University Press.

Mayer, R. E. \& Moreno, R. (2002). Animation as an aid to multimedia learning. Educational Psychology Review, 14, 87-100.

MDCPS. (2013). Miami Dade County Public Schools assessment, research, and data analysis. Retrieved from http://oada.dadeschools.net/

Mechling, L. C., Gast, D. L., \& Krupa, K. (2007). Impact of smart board technology: An investigation of sight word reading and observational learning. Journal of Autism and Developmental Disorders, 37(10), 1869-1882.

Mercer, C.D., Campbell, K.U., Miller, M.D., Mercer, K.D., \& Lane, H.B. (2000). Effects of a reading fluency intervention for middle schoolers with specific learning disabilities. Learning Disabilities Research \& Practice, 15, 179-189.

Murray, O. T., \& Olcese, N. R. (2011). Teaching and learning with iPads, ready or not? TechTrends, 55(6), 42-48.

Nagy, W. E., Anderson, R. C., \& Herman, P. A. (1987). Learning word meaning from context during normal reading. American Educational Research Journal, 24(2), 237-270.

National Governors Association (NGA). (2010). NGA Center for Best Practices. Retrieved from http://www.nga.org/cms/center

National Center for Educational Statistics (NCES). (2010). U.S. Department of Education, Institute of Education Sciences, National Assessment of Educational Progress (NAEP), 1994, 2001, 2006 and 2010 U.S. History Assessments. 
National Center for Educational Statistics (NCES). (2012). U.S. Department of Education, Digest of Education Statistics. Retrieved from http://nces.ed.gov/programs/digest/d11/ch_2.asp

National Center for History in the Schools (NCHS). (1996). History Standards. Retrieved From http://www.nchs.ucla.edu/Standards/

National Council for the Social Studies (NCSS). (1992). Expectations of Excellence: Curriculum Standards for Social Studies. Retrieved from http://www.socialstudies.org/ standards/introduction

National Council for the Social Studies (NCSS). (2001). Creating Effective Citizens. Retrieved from http://www.socialstudies.org/toolkit

National Council for the Social Studies (NCSS). (2006). Technology Position Statement and Guidelines. Retrieved from http://www.socialstudies.org/positions/ technology

National Council for the Social Studies (NCSS). (2008). A Vision of Powerful Teaching and Learning in the Social Studies: Building Social Understanding and Civic Efficacy. Retrieved from http://www.socialstudies.org/positions/powerful

National Reading Panel. (2013). National Reading Panel: Overview. Retrieved from http://www.nichd.nih.gov/research/supported/Pages/nrp.aspx/nrpabout/about_nrp. htm

Neely, L., Rispoli, M., Camargo, S., Davis, H. and Boles, M. (2013). The effect of instructional use of an iPad on challenging behaviour and academic engagement for two students with autism. Research in Autism Spectrum Disorder, 7(4), 509516

Nokes, J. D. (2008). Aligning literacy practices in secondary history classes with research on learning. Middle Grade Research Journal, 3(3), 29-55

Nokes, J. D. (2011). Recognizing and addressing the barriers to adolescents' 'Reading Like Historians'. The History Teacher, 44(3), 379-404.

O'Reilly, T. (2005). What Is Web 2.0? Design patterns and business models for the next generation of software. Retrieved from http://www.oreillynet.com/pub/a/ oreilly/tim/news/2005/09/30/what-is-web-20.html

Ochoa-Becker, A. S. (2007). Democratic education for social studies: An issues-centered curriculum. Greenwich, CT: Information Age Publishing. 
Okolo, C. (2005). Interactive technologies and social studies instruction for students with mild disabilities. In D. L. Edyburn, K. Higgins, \& R. Boone (Eds.). Handbook of special education technology research and practice (pp. 623-641). Whitefish Bay, WI:Knowledge by Design Publications.

Okolo, C. M., Englert, C.S., Bouck, E.C., Heutsche, A. \& Wang, H. (2011). The Virtual History Museum: U.S. History in diverse eighth grade classrooms. Remedial and Special Education, 32(5), 417-428.

Okolo, C. M., Ferretti, R. P., \& MacArthur, C. A. (2007). Talking about history: Discussions in a middle school inclusive classroom. Journal of Learning Disabilities, 40(2), 154-165.

Parmar, R. S., Deluca, C. B., \& Janczak, T. M. (1994). Investigations into the relationship between science and language abilities of students with mild disabilities. Remedial and Special Education, 15, 117-126.

Passey, D. (2013). Titan Partnership - iPads Study: Final Report. Lancaster, England: Lancaster University.

Patton, J., Polloway, E., \& Cronin, M. (1987). Social studies instruction for handicapped students: A review of current practices. The Social Studies, 78, 131-135.

Paxton, R. (2002). The influence of author visibility on high school students solving a historical problem. Cognition and Instruction, 20(2), 197-248.

Paxton, R. (2003). Don't know much about history - never did. Phi Delta Kappan, 85(4), 264-273.

Pew Research Center. (2013a). 10 Things to know about how teens use technology. Pew Research Center's Internet \& American Life Project, July 2013. Retrieved from http://www.pewinternet.org/2013/07/10/10-things-to-know-about-how-teens-usetechnology/

Pew Research Center. (2013b). Tablet Ownership 2013. Pew Research Center's Internet \& American Life Project, June 2013. Retrieved from http://www.pewinternet.org/ 2013/06/10/tablet-ownership-2013/

Pilgrim, J., Bledsoe, C., \& Reily, S. (2012). New technologies in the classroom. Delta Kappa.Gamma Bulletin, 78(4), 16-22.

Plass, J. L., Heidig, S., Hayward, E. O., Homer, B. D., \& Um, E. (2014). Emotional design in multimedia learning: Effects of shape and color on affect and learning. Learning and Instruction, 29, 128-140. 
Plumert, J. M., Kearney, J.K., \& Cremer, J.F. (2004). Children's perception of gap affordances: Bicycling across traffic-filled intersections in an immersive virtual environment. Child Development, 75(4), 1243-1253.

Quizlet. (2013). How it works. Retrieved from http://quizlet.com/how-it-works

Rankhorn, B., England, G., Collins, S. M., Lockavitch, J. F., \& Algozzine, B. (1998). Effects of the failure free reading program on students with severe reading disabilities. Journal of Learning Disabilities, 31, 307-312.

Richards, S. B., Taylor, R. L., Ramasamy, R., \& Richards, R. Y. (1999). Single subject research: Applications in educational and clinical settings. San Diego, CA: Singular.

Risconscente, M. (2012). Mobile learning game improves $5^{\text {th }}$ graders' fractions knowledge and attitudes. Los Angeles, CA: GameDesk Institute.

Rose, S. A., \& Ferlund, P. M. (1997). Using technology for powerful social studies learning.Social Education, 61(3), 160-166.

Schall, C.M., \& McDonough, J.T. (2009). Autism spectrum disorders in adolescence and early adulthood: Characteristics and issues. Journal of Vocational Rehabilitation, $32,81-88$

Scheeler, M. C., Macluckie, M., \& Albright, K. (2010). Effects of immediate feedback delivered by peer tutors on the oral presentation skills of adolescents with learning disabilities. Remedial and Special Education, 31(2), 77-86.

Schenning, H., Knight, V., \& Spooner, F. (2013). Effects of structured inquiry and graphic organizers on social studies comprehension by students with autism spectrum disorders. Research in Autism Spectrum Disorders, 7(4)526-540. Schiefele, U., \& Krapp, A. (1996). Topics of interest and free recall of expository text. Learning and Individual Differences,8(2),141-160.

Schumaker, J. B., \& Deshler, D. D. (2003). Can students with LD become competent writers? Learning Disability Quarterly, 26(2), 129-141.

Scruggs, T.E., Mastropieri, M.A., \& Marshak, L. (2012). Peer-mediated instruction in inclusive secondary social studies learning: Direct and indirect learning effects. Learning Disabilities Research \& Practice, 27(1), 12-20

Scruggs, T.E., Mastropieri, M. A., \& Okolo, C. M. (2008). Science and social studies for students with disabilities. Focus on Exceptional Children, 41(2), 1-32. 
Shanahan, T. \& Shanahan, C. (2008). Teaching disciplinary literacy to adolescents: Rethinking content-area literacy. Harvard Educational Review, 78, 40-59.

Skinner, B.F. (1954). The science of learning and the art of teaching. Harvard Educational Review, 24(2), 86-97.

Skinner, B. F. (1958). Teaching machines. Science, 128(3330), 969-977.

SMART. (2010). The history of SMART. Retrieved from http://smarttech.com/us/ About+SMART/About+SMART/Innovation/Beginnings + of + an+industry

Smith, D. (2004). For whom the bell tolls: Imagining accidents and the development of crisis simulation in organizations. Simulation \& Gaming, 35(3), 347-362.

Smith, H., Higgins, S. Wall, K. \& Miller, J. (2005). Interactive whiteboards: Boon or bandwagon? A critical review of the literature. Journal of Computer Assisted Learning, 21(2) 91-101.

Smith, P.L., \& Ragan, T.J. (2005). Instructional Design (3rd ed) . New York: Merill

Smith, R. (2007). Being human: Historical knowledge and the creation of human nature. Manchester, England: Manchester University Press.

Smith, S.J. \& Okolo, C. (2010). Response to intervention and evidence-based practices: Where does technology fit? Learning Disability Quarterly, 33, 257-272.

Snow, C., Lawrence, J., \& White, C. (2009). Generating knowledge of academic language among urban middle school students. Journal of Research on Educational Effectiveness, 2, 325-344.

Software and Information Industry Association (SIIA). (2013). 2013 Results from the SIIA Vision K-20 Survey.

Sutherland, K. S., Alder, N., \& Gunter, P. L. (2003). The effect of increased rates of opportunities to respond on the classroom behavior of students with emotional/behavioral disorders. Journal of Emotional and Behavioral Disorders, $11,239-248$.

Swanson, H. L. (2011). The influence of working memory growth on reading and math performance in children with math and/or reading disabilities. In. P. Barrouillet, \& Gaillard, V. (Eds.), Cognitive mechanisms and constraints (pp. 203-230). London, England: Psychological Press. 
Tamim, R. F., Bernard, R. M., Borokhovski, E., Abrami, P. C., \& Schmid, R. F. (2011). What forty years of research says about the impact of technology on learning: A second-order meta-analysis and validation study. Review of Educational Research, 81, 4-28.

Taylor, R. L. (2009). Assessment of exceptional students: Educational and psychological procedures (8th ed.). Upper Saddle River, NJ: Pearson.

Taylor, R. L., Smiley, L.R., \& Richards, S.B. (2009). Exceptional students: Preparing teachers for the $21^{\text {st }}$ century. New York, NY: McGraw Hill

Tennyson, R. D. \& Schott, F. (1997). Instructional design theory research and models. In R. D. Tennyson, F. Schott, N. Seel, \& S. Dijkstra (Eds.). Instructional design: International perspective (pp. 395-412). Mahwah, NJ: Erlbaum.

Tomlinson, C. \& McTighe, J. (2006). Integrating differentiated instruction and understanding by design: Connecting content and kids. Alexandria, VA: ASCD

Townsend, D., Filippini, A., Collins, P., \& Biancarosa, G. (2012). Evidence for the importance of academic word knowledge for the academic achievement of diverse middle school students. The Elementary School Journal, 112(3), 497-518.

Van Scoter, J., \& Boss, S. (2002). Learners, language, and technology: Making connections that support literacy. Northwest Regional Educational Laboratory.

Vinovskis, M. A. (1999). History and educational policymaking. New Haven, CT: Yale University Press.

Wagner, M., Marder, C., Blackorby, J., Cameto, R., Newman, L., Levine, P., \& DaviesMercier, E., .. . Sumi, C. (2003). The achievements of youth with disabilities during secondary school. A report from the National Longitudinal Transition Study-2 (NLTS2). Menlo Park, CA: SRI International.

Wagner, M., Newman, L., Cameto, R., Garza, N., \& Levine, P. (2005). After high school: A first look at the post school experiences of youth with disabilities. A report from the National Longitudinal Transition Study-2 (NLTS2). Menlo Park, CA: SRI International.

Wesley, W. B. (1944). American history in schools and colleges. New York, NY: Macmillan.

West, R. P., \& Sloane, H. N. (1986). Teacher presentation rate and point delivery rate: Effects on classroom disruption, performance, accuracy, and response rate. BehaviorModification, 10(3), 267-286. 
Wolery, M., Gast, D. L., \& Hammond, D. (2010). Comparative intervention designs. In D.L. Gast (Ed.), Single subject research methodology in behavioral sciences (pp. 329-381). New York, NY: Routledge.

Wolf, M. M. (1978). Social validity: The case for subjective measurement or how applied behavior analysis is finding its heart. Journal of Applied Behavior Analysis, 11, 203-214.

Wyer, K. (2001). The great equalizer: Assistive technology launches a new era in inclusion. Teaching Tolerance, 19, 1-5.

Young, J. (2003). Science interactive notebooks in the classroom. Science Scope 26, 4446. 
APPENDIX A

INSTITUTIONAL REVIEW BOARD APPROVAL 


\section{MEMORANDUM}

To:

CC:

From:

Date:

Protocol Title:
Dr. Kyle Bennett

File

Donna J. Simonovitch, Coordinator, Research Integrity

May 2, 2014

\section{The Effect of Mobile Technology as an Active Student Response System on the Acquisition of U.S. History Content by Secondary Students with Specific Learning Disabilities}

The Florida Intemational University Office of Research Integity has reviewed your research study for the use of human subjects via the Exempt Review process.

$\begin{array}{lll}\text { IRB Protocol Exemption \#: } & \text { IRB-14-0082 } & \text { IRB Exemption Date: } \\ \text { TOPAZ Reference \#: } & 102316 & \end{array}$

As a requirement of $I R B$ Exemption you are required to:

1) Submit an Event Form and provide immediate notification of:

- Any additions or changes in the procedures involving human subjects.

- Every serious or unusual or unanticipated adverse event as well as problems with the rights or welfare of the human subjects.

2) Submit a Project Completion Report Form when the study is finished or discontinued.

Special N/A

Conditions:

For further information, you may visit the IRB website at http://research.fiu edu/irb. 
APPENDIX B

PARENTAL CONSENT FORM 


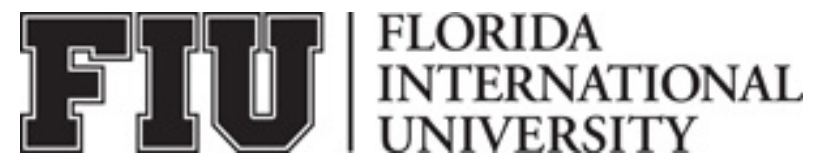

PARENTAL CONSENT TO PARTICIPATE IN A RESEARCH STUDY

The Effect of Mobile Technology as an Active Student Response System on the Acquisition of U.S. History Content by Secondary Students with Specific Learning Disabilities

You are being asked to give your permission for your child, to be in a research study. The investigator for this study is Ruba Monem, a doctoral candidate at Florida International University. The purpose of this study is to find out if using mobile devices, like iPads, can help students with specific learning disabilities or emotional behavioral disorders learn and remember U.S. History content.

If you agree to allow your child to participate in this study, he or she will be one of 10-12 students in this research study. Your child's participation will require about 60 minutes per U.S. History lesson, 3-4 days per week. The study will last approximately 8 to 10 weeks. If your child participates in this study, we will ask your child to do the following things:

1. Take a technology skills assessment to make sure he or she knows how to use an iPad,

2. Learn U.S. History content using the lecture method and note-taking,

3. Sometimes use an iPad application called Quizlet and other times use handwritten notes to study U.S. History content,

4. Take a pretest before each new unit (minimum of 10 pretests, there may more than 10),

5. Use the Quizlet application to complete fill-in and matching exercises related to what he or she studied,

6. Take a quiz after each study session (minimum of 20 quizzes, there may be more than 20), and

7. Answer a student questionnaire at the end of the study

There are minimal risks involved in this study. It is possible that your child might not learn the content using standard instruction paired with the Quizlet App or standard instruction paired with studying from his or her handwritten notes. There is no cost to you for your child's participation in the study. Your child may benefit from the study by learning that the Quizlet App or studying using handwritten notes helps him or her learn and remember U.S. History content.

Your child's participation in this study is voluntary. Your child is free to participate in the study or quit at any time during the study. You or your child may withdraw from this study at any time and no one will be upset with you or your child. There is no penalty if you or your child decide to withdraw from the study. If your child is withdrawn from the study, the information gathered about your child will not be used. 
The records of this study will be kept private and will be protected to the fullest extent provided by law. In any sort of report we might publish, we will not include any information that will make it possible to identify your child as a subject. Research records will be stored securely and only the researcher team will have access to the records. However, your child's records may be reviewed for audit purposes by authorized University or other agents who will be bound by the same provisions of confidentiality.

Any information obtained about your child from this study including answers to questionnaires or performance on a test, will be kept strictly confidential. Your child's real name will not be used. A code will be used so no one can link your child with his or her answers or other information.

If you have any questions about the purpose, procedures, or any other issues relating to this research study you may contact Ruba Monem at (removed for privacy). You may also contact Kyle Bennett at (removed for privacy). If you would like to talk with someone about your child's rights of being a subject in this research study or about ethical issues with this research study, you may contact the FIU Office of Research Integrity by phone at 305-3482494 or by email at ori@fiu.edu.

Thank you for your time, Ruba Monem

Florida International University

\section{PARTICIPANT AGREEMENT}

I have read the information in this consent form and agree to allow my child to participate in this study. I have had a chance to ask any questions I have about this study, and they have been answered for me. I understand that I will be given copy of this form for my records.

Signature of Parent/Guardian

Printed Name of Parent/ Guardian

Printed Name of Child Participant

Signature of Person Obtaining Consent
Date

Date 


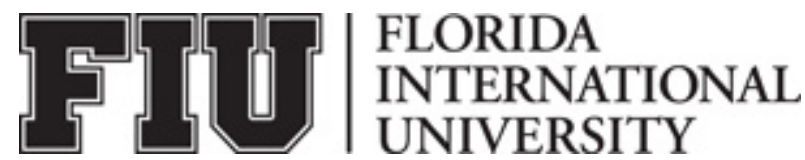

\section{CONSENTIMIENTO DEL PADRE O DE LA MADRE PARA PARTICIPAR EN UN ESTUDIO DE INVESTIGACIÓN}

El efecto de la tecnología móvil como Sistema de Respuesta Activa del Estudiante en la adquisición de datos sobre la Historia de Estados Unidos por estudiantes de secundaria con discapacidades específicas de aprendizaje

Por este medio se le pide permiso para que su hijo(a), , participe en un estudio de investigación. La investigadora de este estudio es Ruba Monem, candidata a doctorado en Florida International University. El propósito de este estudio es averiguar si el uso de dispositivos móviles, tales como iPads, puede ayudar a estudiantes con discapacidades específicas de aprendizaje o trastornos emocionales de la conducta a aprender y a recordar datos sobre la Historia de Estados Unidos.

Si usted acepta permitirle a su hijo(a) que participe en este estudio, su hijo(a) será uno de los 10 a 12 estudiantes que habrá en el mismo. La participación de su hijo(a) tomará alrededor de 60 minutos por cada lección de Historia de Estados Unidos 3 a 4 días a la semana. El estudio durará aproximadamente de 8 a 10 semanas. Si su hijo(a) participa en este estudio, le pediremos que haga lo siguiente:

1. Hacerle una evaluación de sus habilidades tecnológicas para asegurar que sabe usar una iPad:

2. Aprender datos sobre la Historia de Estados Unidos usando el método de asistencia a clases y toma de notas;

3. Usar en algunas ocasiones una aplicación para la iPad que se llama "Quizlet" y en otras usar notas escritas a mano para estudiar datos sobre la Historia de Estados Unidos;

4. Tomar una prueba previa antes de cada unidad (mínimo de 10 pruebas previas, puebe haber más de 10);

5. Usar la aplicación "Quizlet" para hacer los ejercicios de escribir o marcar las respuestas que correspondan a lo que ha estudiado;

6. Tomar un breve examen después de cada sesión de estudio (mínimo de 20 exámenes breves, puede haber más de 20); y

7. Responder a un cuestionario de preguntas para el estudiante al final del estudio.

Este estudio conlleva un riesgo mínimo. Es posible que su hijo(a) no aprenda los datos usando la instrucción estándar junto con la aplicación "Quizlet" o la instrucción estándar junto con estudiar usando sus notas escritas a mano. La participación de su hijo(a) no le va a costar nada a usted. Es posible que su hijo(a) se beneficie del estudio al aprender que la aplicación "Quizlet" o que el estudiar usando notas escritas a mano le puede ayudar a aprender y a recordar datos sobre la historia de Estados Unidos.

La participación de su hijo(a) en este estudio es voluntaria y tendrá plena libertad para participar en el estudio así como para dejar el mismo en cualquier momento. Tanto usted como su hijo(a) se podrán retirar de este estudio en cualquier momento y nadie se va a enojar con usted ni con su hijo(a) por eso. La decisión suya o de su hijo(a) de retirarse del estudio no conlleva sanción alguna. Si su hijo(a) se retira del estudio, la información que se haya recopilado acerca de su hijo(a) no se va a utilizar. 
Los expedientes de este estudio se mantendrán en privado y se protegerán al máximo que lo permita la ley. En cualquier tipo de informe que publiquemos, no pondremos información alguna que haga posible identificar a su hijo(a) como uno de los sujetos del estudio. Los expedientes de las investigaciones se guardan en un lugar seguro y solamente el equipo de investigadores podrá tener acceso a los mismos. Sin embargo, los expedientes de su hijo(a) también podrán ser revisados para fines de auditorías por agentes autorizados de la Universidad u otros agentes que estarán obligados por las mismas estipulaciones de confidencialidad.

Toda la información que se obtenga acerca de su hijo(a) en este estudio, incluyendo las respuestas a los cuestionarios y el desempeño en las pruebas y exámenes, se mantendrá en estricta confidencialidad. No se usará el nombre verdadero de su hijo(a) sino una clave para que nadie pueda vincular a su hijo(a) con las respuestas que dio ni con ninguna otra información.

Si tiene alguna pregunta acerca del propósito, de los procedimientos o cualquier otro asunto relacionado con este estudio de investigación, se puede comunicar con Ruba Monem llamando al (removed for privacy). También puede comunicarse con Kyle Bennett llamando al (removed for privacy). Si desea consultar a alguien acerca de los derechos que tiene su hijo(a) como sujeto de este estudio de investigación o acerca de asuntos éticos relacionados con el estudio, se puede comunicar con la Oficina de FIU para la Integridad de las Investigaciones 1lamando al 305-3482494 o por correo electrónico a ori@fiu.edu.

Gracias por su tiempo,

Ruba Monem

Florida International University

\section{ACUERDO DEL PARTICIPANTE}

He leído la información que aparece en este formulario de consentimiento y acepto permitir que mi hijo(a) participe en este estudio. He tenido la oportunidad de hacer las preguntas que haya tenido acerca del estudio, a las cuales se les ha dado respuesta. Entiendo que se me dará una copia de este formulario para guardarla como constancia.

Firma del padre, madre o tutor

Nombre en letra de molde del padre, madre o tutor

Nombre en letra de molde del participante infantil

Firma de la persona que obtiene el consentimiento
Fecha

Fecha 
APPENDIX C

PARTICIPANT ASSENT FORM 


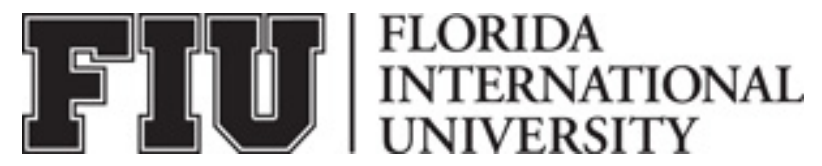

\section{CHILD ASSENT TO PARTICIPATE IN A RESEARCH STUDY}

Title: The Effect of Mobile Technology as an Active Student Response System on the Acquisition of U.S. History Content of Secondary Students with Specific Learning Disabilities

We would like for you to be in a research study we are doing. A research study is a way to learn information about something. We would like to find out more about using mobile devices, like iPads, in the classroom to help students with specific learning disabilities or emotional behavioral disorders learn and remember U.S. History information.

If you agree to participate in this study, you will be one of 10-12 students in this research study. Your participation will require about 60 minutes per U.S. History lesson, 3-4 days per week. The study will last about 8-10 weeks.

If you participate in this study, we will ask you to do the following things:

1. Take a technology skills assessment to make sure you know how to use an iPad,

2. Learn U.S. History content using the lecture method and note-taking,

3. Sometimes use an iPad application called Quizlet and other times use handwritten notes to study U.S.

History information,

4. Take a pretest before each new unit (minimum of 10 pretests, there may be more than 10 ), 5. Use the Quizlet application to complete fill-in and matching exercises related to what you studied,

6. Take a quiz after each study session (minimum of 20 quizzes, there may be more than 20), and

7. Answer a questionnaire at the end of the study

There are little known risks to you for being in this study. You may find out that using Quizlet on the iPad or studying your handwritten notes does not help you learn U.S. History information.

This study may help you learn that the Quizlet App on the iPad or using your handwritten notes helps you learn and remember more U.S. History information.

You will not need to pay for anything to participate in this study.

The records of this study will be kept private and will be protected by the researchers. Your real name will not be used on any information that we will collect for the study. In any kind of report we might publish, we will not use your real name.

You do not have to be in this study if you don't want to and you can quit the study at any time. No one will get mad at you if you decide you don't want to participate and there is no penalty if you decide to quit during the study. If you decide to quit during the study, your information will not be used.

If you have any questions about the research study you may contact Ruba Monem at (removed for privacy). You may also contact Kyle Bennett at (removed for privacy). If you would like to talk 
with someone about your rights of being a participant in this research study, you may contact the FIU Office of Research Integrity by phone at 305-348-2494 or by email at ori@fiu.edu.

\section{PARTICIPANT AGREEMENT}

This research study has been explained to me and I agree to be in this study.

Signature of Child Participant

Date

Printed Name of Child Participant

Signature of Person Obtaining Consent

Date 


\section{APPENDIX D}

TECHNOLOGY SKILLS ASSESSMENT FORM 


\section{iPad Technology Skills Assessment}

Participant:

Date:

A plus sign $(+)$ denotes tasks performed accurately by the student.

A minus sign (-) denotes tasks performed incorrectly or no response by the student.

\begin{tabular}{|l|l|c|}
\hline 1. & Student can attach headphones to the iPad. & $+\quad-$ \\
\hline 2. & Student can set up and adjust the iPad stand. & $+\quad-$ \\
\hline 3. & $\begin{array}{l}\text { Student can use the wake mode. } \\
\text { 4. }\end{array}$ & $\begin{array}{l}\text { Student can turn the iPad to change orientation from portrait to } \\
\text { landscape. }\end{array}$ \\
\hline 5. & $\begin{array}{l}\text { Student can use one finger to scroll up and down, left and right } \\
\text { through information. }\end{array}$ & + \\
\hline 6. & $\begin{array}{l}\text { Student can adjust the volume using the buttons on the side of the } \\
\text { iPad. }\end{array}$ & + \\
\hline 7. & $\begin{array}{l}\text { Student can single tap to access or launch applications. } \\
\text { the side of the iPad. }\end{array}$ & + \\
\hline
\end{tabular}




\section{APPENDIX E}

\section{INTEROBSERVER AGREEMENT FORM}




\section{Inter-Observer Agreement (IOA) Form}

Participant:

Pretest or Test \#: Session Date:

Directions: This form compares the data collected by the researcher with the data collected by the second observer.

\section{Number of Correct Responses}

Rater 1:

Rater 2:

\section{Rate of Correct Responses}

\# rate correct agreed:

\# rate correct disagreed:

\section{Rate of Incorrect Responses}

\# rate incorrect agreed:

\# rate incorrect disagreed:

\section{Total}

Number of Agreements

Number of Disagreements

IOA Formula

Total \# of Agreements $\div$ Total \# of Disagreements and Agreements $\times 100=$ $\%$ IOA 


\section{APPENDIX F}

TREATMENT FIDELITY FORM 


\section{Treatment Fidelity Form}

Completed by:

Date:

\begin{tabular}{|l|l|cc|}
\hline \multicolumn{2}{|l|}{$\begin{array}{l}\text { Condition A } \\
\text { Content Instruction and Independent Review Using Notes }\end{array}$} & Implemented \\
\hline 1 & Turn on projector. Launch PowerPoint lesson. & + & - \\
\hline 2 & $\begin{array}{l}\text { Tell students it is time to start the lesson and to take out their } \\
\text { notebooks. }\end{array}$ & + & - \\
\hline 3 & Set timer for 30 minutes. & + & - \\
\hline 4 & Lecture with PowerPoint while students take notes for 30 minutes. & + & - \\
\hline 5 & $\begin{array}{l}\text { When time is up, turn off projector and tell students to clear their } \\
\text { desks except for their hand written notes. }\end{array}$ & + & - \\
\hline 6 & $\begin{array}{l}\text { Tell students they have 15 minutes to study their notes before they } \\
\text { take a test. Set timer for 15 minutes. }\end{array}$ & + & - \\
\hline 7 & $\begin{array}{l}\text { When time up, tell students to put their notes away. } \\
\text { Tell students it is time to take a test. } \\
\text { Tell students they have 15 minutes to complete the test. } \\
\text { Tell students they should turn in their tests as soon as they are done. }\end{array}$ & & - \\
\hline 8 & Distribute tests to students. & + & - \\
\hline 9 & Set timer for 15 minutes. & + & - \\
\hline 10 & Write test start time on each student's test. & + & - \\
\hline 11 & $\begin{array}{l}\text { Write test finish time when each student hands in his/her completed } \\
\text { test. }\end{array}$ & + & - \\
\hline & & & \\
\hline
\end{tabular}

\begin{tabular}{|l|l|cc|}
\hline \multicolumn{2}{|l|}{\begin{tabular}{l}
\multicolumn{1}{|c|}{ Condition B } \\
Content Instruction and Independent Review Using Quizlet
\end{tabular}} & Implemented \\
\hline 1 & The iPads prepared prior to lesson: Guided access enabled & + & - \\
\hline 2 & Turn on projector. Launch PowerPoint lesson. & + & - \\
\hline 3 & $\begin{array}{l}\text { Tell students it is time to start the lesson and to take out their } \\
\text { notebooks. }\end{array}$ & + & - \\
\hline 4 & Set timer for 30 minutes. & + & - \\
\hline 5 & $\begin{array}{l}\text { Lecture with PowerPoint plus while students take notes for 30 } \\
\text { minutes. }\end{array}$ & + & - \\
\hline 6 & $\begin{array}{l}\text { When time is up, turn off projector and tell students to clear their } \\
\text { desks. }\end{array}$ & + & - \\
\hline 7 & $\begin{array}{l}\text { Tell students they will have 15 minutes to use the iPad: } \\
\text { Explain to students that they will use the cards mode for 5 minutes, } \\
\text { the learn mode for 5 minutes, and the scatter mode for 5 minutes. } \\
\text { Tell students they will be timed in each mode. }\end{array}$ & & \\
\hline 8 & Distribute iPads to students. & + & - \\
\hline 9 & $\begin{array}{l}\text { Set timer for 5 minutes, tell students to start cards mode. When time } \\
\text { is up, tell students to stop and go to learn mode. }\end{array}$ & + & - \\
\hline 10 & Set timer for 5 minutes, tell students to start learn mode. When time is & + & - \\
\hline
\end{tabular}




\begin{tabular}{|c|l|cc|}
\hline & up, tell students to stop and go to scatter mode. & & \\
\hline 11 & $\begin{array}{l}\text { Set timer for } 5 \text { minutes, tell students to start scatter mode. When time } \\
\text { is up, tell students to stop and power off the iPad screen. }\end{array}$ & + & - \\
\hline 12 & Collect iPads. & + & - \\
\hline 13 & $\begin{array}{l}\text { Tell students it is time to take a test. } \\
\text { Tell students they have } 15 \text { minutes to complete the test. } \\
\text { Tell students they should turn in their test as soon as they are done. }\end{array}$ & + & - \\
\hline 14 & Distribute tests to students. & + & - \\
\hline 15 & Set timer for 15 minutes. & + & - \\
\hline 16 & Write test start time on each student's test. & + & - \\
\hline 17 & $\begin{array}{l}\text { Write test finish time when each student hands in his or her } \\
\text { completed test. }\end{array}$ & + & - \\
\hline
\end{tabular}

\begin{tabular}{|l|l|cc|c|}
\hline \multicolumn{1}{|c|}{ Pretest Probes } & Implemented & NA \\
\hline 1 & Tell students to clear their desks except for a pen or pencil & + & - & \\
\hline 2 & Distribute tests to students & + & - & \\
\hline 3 & Set timer for 45 minutes & + & - & \\
\hline 4 & Tell students they have 45 minutes to complete the test & + & - & \\
\hline 5 & Start timer and tell students to begin & + & - & \\
\hline 6 & Write test start time on each student's test & + & - & \\
\hline 7 & $\begin{array}{l}\text { Write test finish time when each student hands in his/her } \\
\text { completed test }\end{array}$ & + & - & \\
\hline 8 & $\begin{array}{l}\text { After 45 minutes, tell students that time is up and collect } \\
\text { tests, record finish time }\end{array}$ & + & - & \\
\hline
\end{tabular}


APPENDIX G

DATA COLLECTION FORM: NUMBER OF CORRECT RESPONSES 


\section{Data Collection Form}

\section{Number of Correct Responses}

Observer

Participant

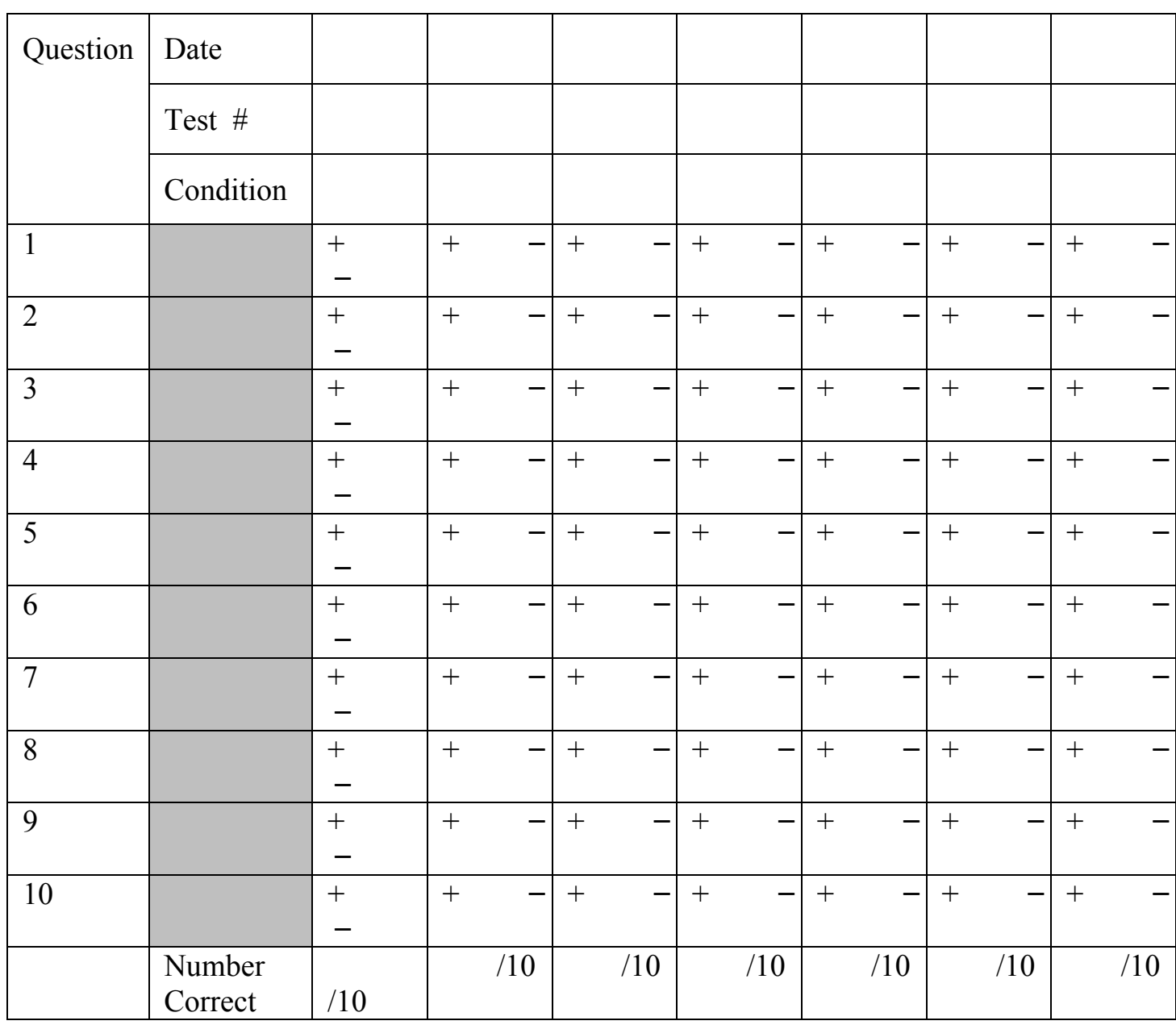

Score Guide

+ Correct Response

- Incorrect or No Response

Special Notes: 


\section{Data Collection Form}

\section{Pretest Number of Correct Responses}

Observer

Participant

\begin{tabular}{|c|c|c|c|c|c|c|c|c|c|c|c|c|c|c|c|}
\hline \multirow[t]{2}{*}{ Question } & Date & & & & & & & & & & & & & & \\
\hline & Pretest \# & \multicolumn{2}{|c|}{1} & \multicolumn{2}{|c|}{2} & \multicolumn{2}{|c|}{3} & \multicolumn{2}{|c|}{4} & \multicolumn{2}{|c|}{5} & \multicolumn{2}{|c|}{6} & \multicolumn{2}{|c|}{7} \\
\hline 1 & & + & - & + & - & + & - & + & - & + & - & + & - & + & - \\
\hline 2 & & + & - & + & - & + & - & + & - & + & - & + & - & + & - \\
\hline 3 & & + & - & + & - & + & - & + & - & + & - & + & - & + & - \\
\hline 4 & & + & - & + & - & + & - & + & - & + & - & + & - & + & - \\
\hline 5 & & + & - & + & - & + & - & + & - & + & - & + & - & + & - \\
\hline 6 & & + & - & + & - & + & - & + & - & + & - & + & - & + & - \\
\hline 7 & & + & - & + & - & + & - & + & - & + & - & + & - & + & - \\
\hline 8 & & + & - & + & - & + & - & + & - & + & - & + & - & + & - \\
\hline 9 & & + & - & + & - & + & - & + & - & + & - & + & - & + & - \\
\hline 10 & & + & - & + & - & + & - & + & - & + & - & + & - & + & - \\
\hline 11 & & + & - & + & - & + & - & + & - & + & - & + & - & + & - \\
\hline 12 & & + & - & + & - & + & - & + & - & + & - & + & - & + & - \\
\hline 13 & & + & - & + & - & + & - & + & - & + & - & + & - & + & - \\
\hline 14 & & + & - & + & - & + & - & + & - & + & - & + & - & + & - \\
\hline 15 & & + & - & + & - & + & - & + & - & + & - & + & - & + & - \\
\hline 16 & & + & - & + & - & + & - & + & - & + & - & + & - & + & - \\
\hline 17 & & + & - & + & - & + & - & + & - & + & - & + & - & + & - \\
\hline 18 & & + & - & + & - & + & - & + & - & + & - & + & - & + & - \\
\hline 19 & & + & - & + & - & + & - & + & - & + & - & + & - & + & - \\
\hline 20 & & + & - & + & - & + & - & + & - & + & - & + & - & + & - \\
\hline 21 & & + & - & + & - & + & - & + & - & + & - & + & - & + & - \\
\hline 22 & & + & - & + & - & + & - & + & - & + & - & + & - & + & - \\
\hline 23 & & + & - & + & - & + & - & + & - & + & - & + & - & + & - \\
\hline 24 & & + & - & + & - & + & - & + & - & + & - & + & - & + & - \\
\hline 25 & & + & - & + & - & + & - & + & - & + & - & + & - & + & - \\
\hline 26 & & + & - & + & - & + & - & + & - & + & - & + & - & + & - \\
\hline 27 & & + & - & + & - & + & - & + & - & + & - & + & - & + & - \\
\hline 28 & & + & - & + & - & + & - & + & - & + & - & + & - & + & - \\
\hline 29 & & + & - & + & - & + & - & + & - & + & - & + & - & + & - \\
\hline 30 & $\begin{array}{l}\text { Number } \\
\text { Correct }\end{array}$ & + & - & + & - & + & - & + & - & + & - & + & - & + & - \\
\hline
\end{tabular}

Score Guide:

+ Correct Response

- Incorrect or No Response

Special Notes: 
APPENDIX H

DATA COLLECTION FORM: RATE OF CORRECT

AND INCORRECT RESPONSES 


\section{Data Collection Form}

\section{Rate of Correct Responses and Incorrect Responses}

Observer:

Participant:

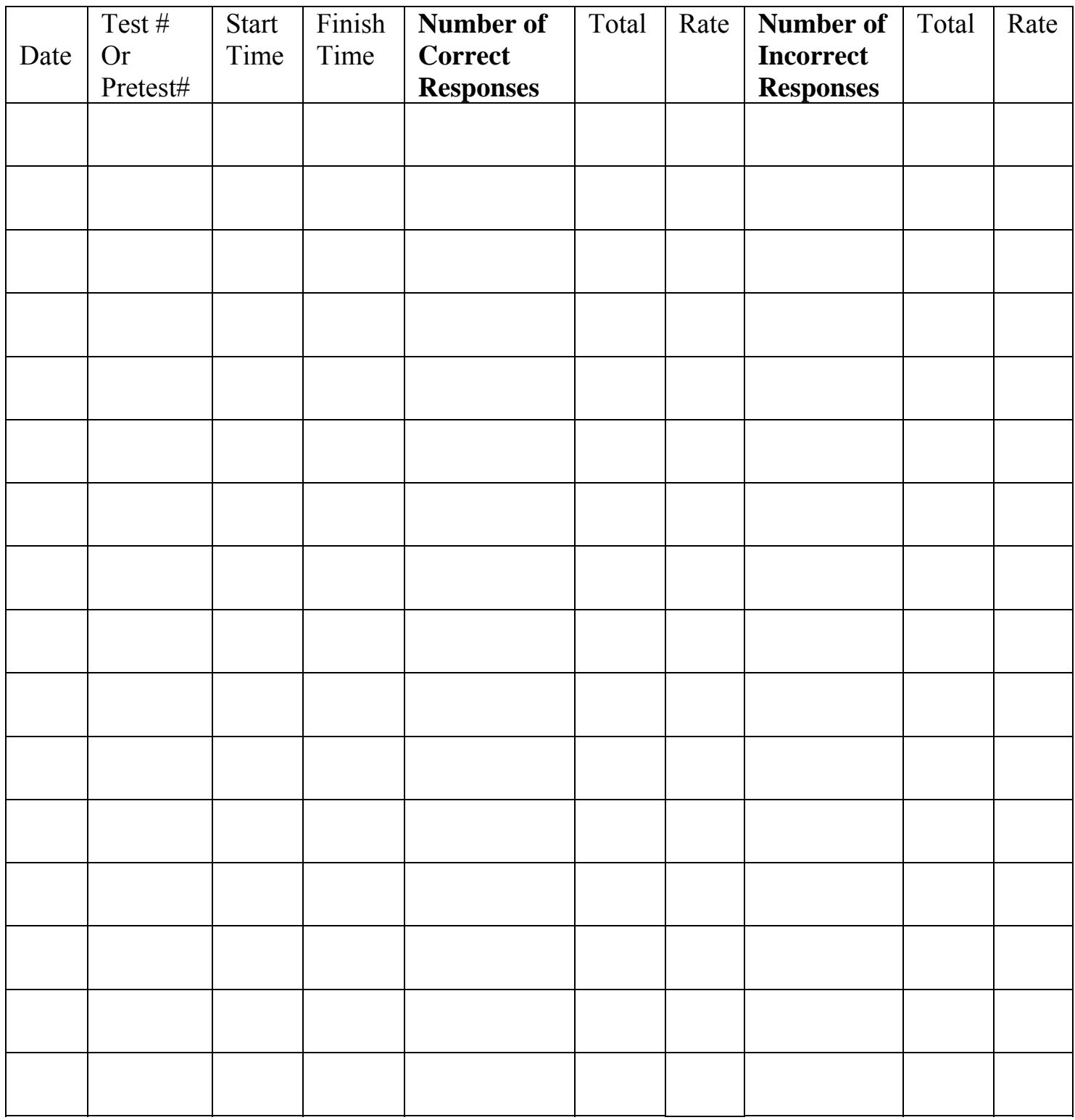

Formula for Rate $=$ number of responses divided by length of time (minutes) Special Notes 
APPENDIX I

EXAMPLE OF U.S. HISTORY PRETEST 
Participant

Date

Start Time

Finish Time

\section{Pretest}

\section{Unit 4: Building the English Colonies}

Directions: Write the letter of the definition next to the correct vocabulary word.

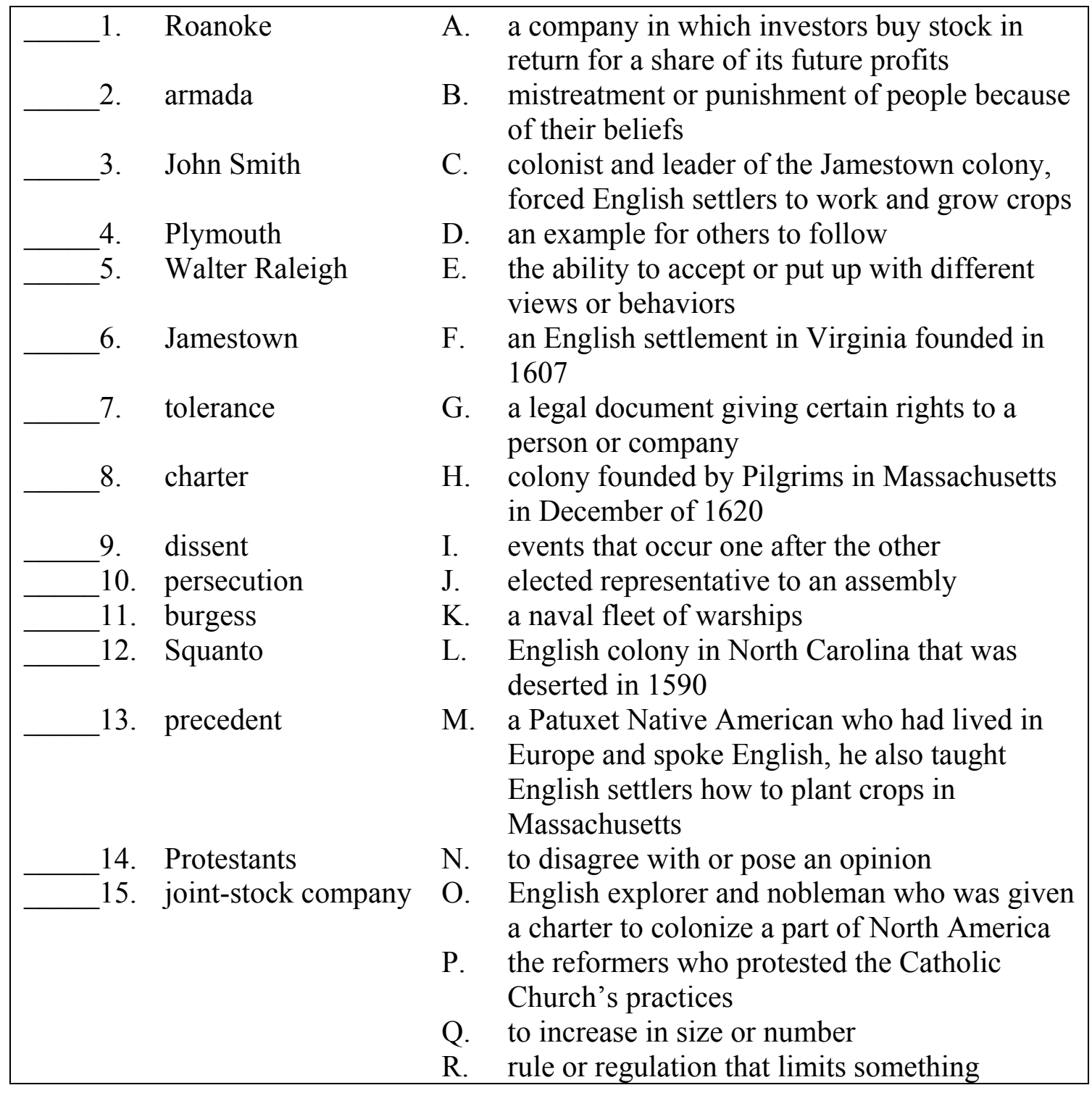




\section{Directions: Read each statement. Fill in the blank with the correct word or words to complete each statement.}

16. The first English child born in the American colonies was

17. In 1517, a German monk named Martin Luther launched the Reformation.

18. Protestants who wanted to leave the Church of England and found their own churches were called

19. The Jamestown colonists called the winter of 1609-1610 the time.

20. Followers of the Church of England who wanted to reform or purify the Church were known as

21. In 1534, King Henry VIII established the Church of England, or Church.

22. King Philip II, a Catholic, did not consider Queen Elizabeth a rightful ruler because she was a

23. The Mayflower___ was a legal contract signed by male passengers aboard the Mayflower stating that their settlement would have fair laws to protect the general good.

24. colonist John Rolfe in 1613 .

was a Powhatan Native who married Jamestown

25. The was an English document which stated that the King could not raise taxes without consulting the Great Council of nobles and church leaders.

26. The leader of the Plymouth Colony in 1620 was

27. John White was delayed in bringing supplies and more settlers to Roanoke because of a war with

28. In a government, voters elect representatives to make laws for them.

29. The House of in Virginia was an assembly where representatives and other members of the governor made laws.

30. was an Englishman who introduced tobacco seeds to the Virginia colony in 1609. 
APPENDIX J

NEXT GENERATION SUNSHINE STATE STANDARDS FOR SOCIAL STUDIES 


\section{Next Generation Sunshine State Standards}

\section{Social Studies Grade 8 American History}

Standard 3: Demonstrate an understanding of the causes, course, and consequences of the American Revolution and the founding principles of our nation. (SS.8.A.3)

- Benchmark: 1. Explain the consequences of the French and Indian War in British policies for the American colonies from 1763 - 1774. (SS.8.A.3.1)

- Benchmark: 2. Explain American colonial reaction to British policy from 1763 - 1774. (SS.8.A.3.2)

- Benchmark: 3. Recognize the contributions of the Founding Fathers (John Adams, Sam Adams, Benjamin Franklin, John Hancock, Alexander Hamilton, Thomas Jefferson, James Madison, George Mason, George Washington) during American Revolutionary efforts. (SS.8.A.3.3)

- Benchmark: 4. Examine the contributions of influential groups to both the American and British war efforts during the American Revolutionary War and their effects on the outcome of the war. (SS.8.A.3.4)

- Benchmark: 5. Describe the influence of individuals on social and political developments during the Revolutionary era. (SS.8.A.3.5)

- Benchmark: 6. Examine the causes, course, and consequences of the American Revolution. (SS.8.A.3.6)

- Benchmark: 7. Examine the structure, content, and consequences of the Declaration of Independence. (SS.8.A.3.7)

- Benchmark: 8. Examine individuals and groups that affected political and social motivations during the American Revolution. (SS.8.A.3.8)

- Benchmark: 9. Evaluate the structure, strengths, and weaknesses of the Articles of Confederation and its aspects that led to the Constitutional Convention. (SS.8.A.3.9)

- Benchmark: 10. Examine the course and consequences of the Constitutional Convention (New Jersey Plan, Virginia Plan, Great Compromise, Three-Fifths Compromise, compromises regarding taxation and slave trade, Electoral College, state vs. federal power, empowering a president). (SS.8.A.3.10)

- Benchmark: 11. Analyze support and opposition (Federalists, Federalist Papers, Anti-Federalists, Bill of Rights) to ratification of the U.S. Constitution. (SS.8.A.3.11)

- Benchmark: 12. Examine the influences of George Washington's presidency in the formation of the new nation. (SS.8.A.3.12)

- Benchmark: 13. Explain major domestic and international economic, military, political, and sociocultural events of John Adams's presidency. (SS.8.A.3.13)

- Benchmark: 14. Explain major domestic and international economic, military, political, and sociocultural events of Thomas Jefferson's presidency. (SS.8.A.3.14)

- Benchmark: 15. Examine this time period (1763-1815) from the perspective of historically underrepresented groups (children, indentured servants, Native Americans, slaves, women, working class). (SS.8.A.3.15)

Standard 4: Demonstrate an understanding of the domestic and international causes, course, and consequences of westward expansion. (SS.8.A.4)

- Benchmark: 1. Examine the causes, course, and consequences of United States westward expansion and its growing diplomatic assertiveness (War of 1812, Convention of 1818, Adams-Onis Treaty, Missouri Compromise, Monroe Doctrine, Trail of Tears, Texas annexation, Manifest Destiny, Oregon Territory, Mexican American War/Mexican Cession, California Gold Rush, Compromise of 1850, Kansas Nebraska Act, Gadsden Purchase). (SS.8.A.4.1)

- Benchmark: 2. Describe the debate surrounding the spread of slavery into western territories and Florida. (SS.8.A.4.2) 
APPENDIX K

EXAMPLE OF U.S. HISTORY TEST 
Participant

Date

Start Time

Finish Time

Test A

\section{Unit 4: Building the English Colonies}

Directions: Write the letter of the definition next to the correct vocabulary word.

\begin{tabular}{|c|c|c|c|}
\hline 1. & Roanoke & A. & a naval fleet of warships \\
\hline 2. & armada & B. & $\begin{array}{l}\text { mistreatment or punishment of people because of } \\
\text { their beliefs }\end{array}$ \\
\hline 3. & Walter Raleigh & C. & events that occur one after the other \\
\hline-4. & tolerance & D. & $\begin{array}{l}\text { English explorer and nobleman who was given a } \\
\text { charter to colonize a part of North America }\end{array}$ \\
\hline \multirow[t]{3}{*}{5 . } & persecution & E. & $\begin{array}{l}\text { the ability to accept or put up with different views } \\
\text { or behaviors }\end{array}$ \\
\hline & & F. & $\begin{array}{l}\text { English colony in North Carolina that was } \\
\text { deserted in } 1590\end{array}$ \\
\hline & & G. & $\begin{array}{l}\text { a legal document giving certain rights to a person } \\
\text { or company }\end{array}$ \\
\hline
\end{tabular}

Directions: Read each statement. Fill in the blank with the correct word or words to complete each statement.

6. The first English child born in the American colonies was

7. In 1517, a German monk named Martin Luther launched the Reformation.

8. Followers of the Church of England who wanted to reform or purify the Church were known as

9. In 1534, King Henry VIII established the Church of England, or Church

10. John White was delayed in bringing supplies and more settlers to Roanoke because of a war with 


\section{APPENDIX L}

SOCIAL VALIDITY MEASURE 


\section{Student Questionnaire}

Name:

Date:

1. How did you feel about using Quizlet on the iPad to study U.S. History?

2. Do you think using Quizet on the iPad helped you learn history?

3. What did you like the best about using Quizlet on the iPad?

4. What did you like the least about using Quizlet on iPad?

5. Do you think you would use Quizlet on an iPad to help you study U.S. History in the future?

6. Do you prefer learning U.S. History with lecture and note-taking only or with Quizlet, lecture, and note-taking? 
VITA

\section{RUBA MONEM}

2015

Doctor of Education

Florida International University

Miami, Florida

2009

Master of Science in Education

Florida International University

Miami, Florida

2005

Bachelor of Science in Education

Miami Dade College

Miami, Florida

\section{PUBLICATIONS AND PRESENTATIONS}

Monem, R. (2010). Metacognitive functions, interest, and student engagement in the writing process: A review of the literature. In M. S. Plakhotnik, S. M. Nielsen, \& D. M. Pane (Eds.), Proceedings of the Ninth Annual College of Education \& GSN Research Conference. Miami: Florida International University.

Monem, R. (2010). Think before you speak: Increasing a student's appropriate verbal responses during classroom instruction. In M. S. Plakhotnik, S. M. Nielsen, \& D. M. Pane (Eds.), Proceedings of the Ninth Annual College of Education \& GSN Research Conference. Miami: Florida International University.

Monem, R. (2012). Inequities in urban education. In J. Wynne, L. Delpit, \& R. Miles (Eds.). Confessions of a White educator: Stories in search of social justice and diversity $(\mathrm{xx}-\mathrm{xx})$. Dubuque, IA: Kendall Hunt Publishing.

Monem, R. (in press). Metacognitive function and self-scaffolding in MMORPGs. The Qualitative Report.

Monem, R. \& Gil, V. (2012, October). Using iPad virtual applications to support content area skills. Poster presented at the $66^{\text {th }}$ Annual Florida Council for Exceptional Children Conference. Jupiter, Florida.

Weinstein, M., \& Monem, R. (2011, October). Virtual environments for teen safety education: The development of Bumbles Café. Paper presented at the 139th Annual Meeting of The American Public Health Association. Washington, District of Columbia. 